Civilian Radioactive Waste Management System Management \& Operating Contractor

\title{
Summary Report of Laboratory Critical Experiment Analyses Performed for the Disposal Criticality Analysis Methodology
}

B00000000-01717-5705-00076 REV 02

September 1999

Prepared for:

U. S. Department of Energy

Yucca Mountain Site Characterization Project Office

P.O. Box 30307

Las Vegas, Nevada 89036-0307

Prepared by:

Civilian Radioactive Waste Management System

Management \& Operating Contractor

1261 Town Center Drive

Las Vegas, Nevada 89144

Under Contract Number

DE-AC08-91RW00134 


\title{
Civilian Radioactive Waste Management System Management \& Operating Contractor
}

\section{Summary Report of Laboratory Critical Experiment Analyses Performed for the Disposal Criticality Analysis Methodology}

\author{
B00000000-01717-5705-00076 REV 02
}

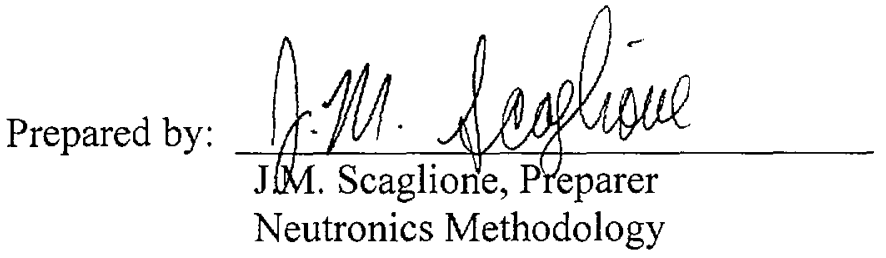

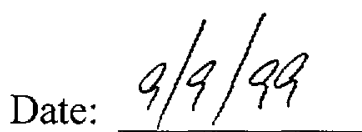

Checked By:

Date: $9 / q / 9 q$

Approved by:

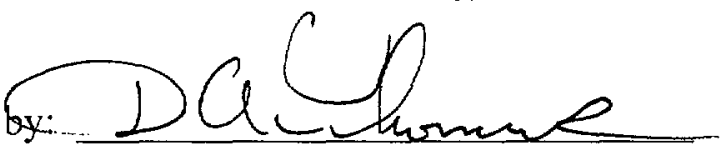

D.A. Thomas, Supervisor

Neutronics Methodology

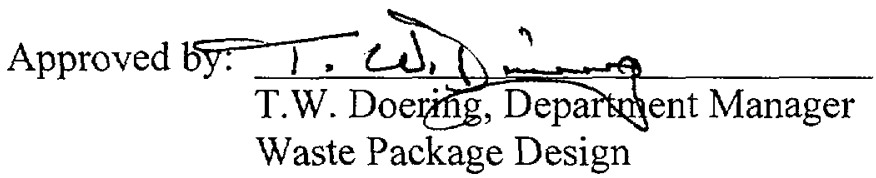

Date: $09 / 09 / 1999$

Date: 9.9 .1999 


\section{HISTORY OF CHANGE PAGE}

Initial Issuance, REV 00

September 4, 1997

Revised, REV 01

July 16,1998

Replaced all of Section 2.2

Added Section 3.2.6

Replaced all of Section 4

Deleted the HXST and HXT calculations due to redundancy

Revised, REV 02

September 1999

Complete revision to include calculations performed with

latest version of MCNP code (MCNP4B2), to evaluate

results produced with use of different cross-section libraries,

and to evaluate the results from additional cases 


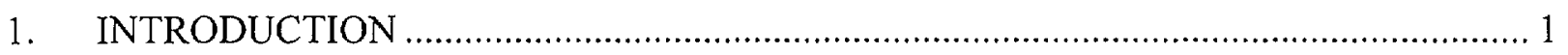

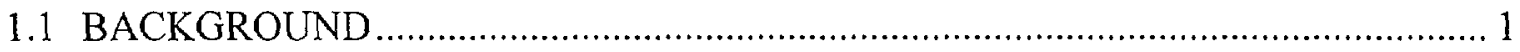

1.2 OBJECTIVE

1.3 SCOPE

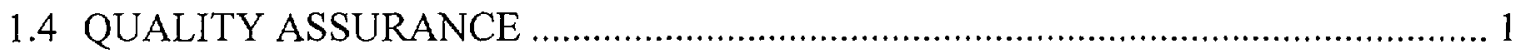

1.5 USE OF COMPUTER SOFTWARE …………………..................................... 2

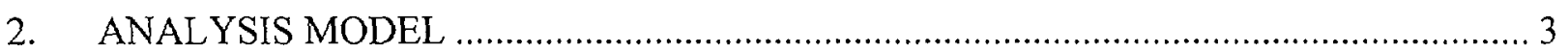

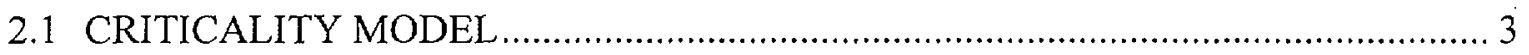

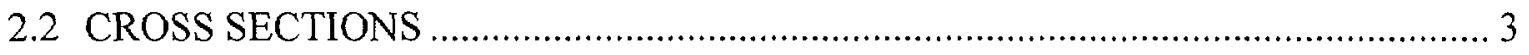

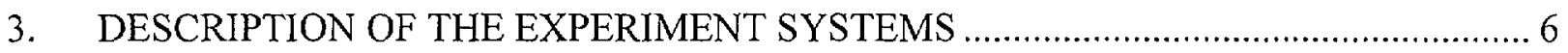

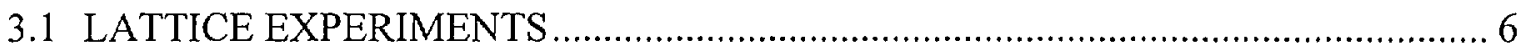

3.1.1 Critical Configurations of Subcritical Clusters of $2.35 \mathrm{wt} \%$ Enriched $\mathrm{UO}_{2}$ Rods

in Water with Fixed Neutron Absorber Plates ............................................................. 6

3.1.2 Water-Reflected Fuel Rod Clusters in Square Pitched Arrays.............................. 7

3.1.3 LEU Systems Typical of N-Reactor Fuel in the K Basin.................................... 8

3.1.4 Critical Configurations with Subcritical Clusters of $4.31 \mathrm{wt} \%$ Enriched $\mathrm{UO}_{2}$

Rods in Water with Reflecting Walls ...................................................................... 8

3.1.5 Critical Configurations with $4.31 \mathrm{wt} \%{ }^{235} \mathrm{U}$ Enriched $\mathrm{UO}_{2}$ Rods in Highly

Borated Water Lattices ........................................................................................ 9

3.1.6 Critical Configurations with Neutron Flux Traps ............................................. 9

3.1.7 Electric Power Research Institute 2.35 wt\% Enriched Light Water Reactor Fuel

Critical Configurations .......................................................................................

3.1.8 Water-Moderated, Lead-Reflected Uranium Dioxide Rod Array ....................... 9

3.1.9 Laboratory Critical Experiments from the Urania-Gadolinia: Nuclear Model

Development and Critical Experiment Benchmark Report.......................................... 10

3.1.10 Saxton $\mathrm{UO}_{2}$ and $\mathrm{PuO}_{2}-\mathrm{UO}_{2}$ Critical Configurations .................................... 10

3.1.11 Critical Configurations Simulating Light Water Reactor Fuel in Close

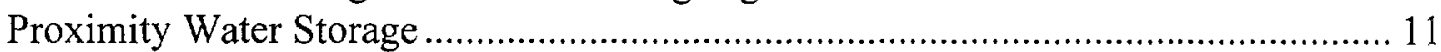

3.1.12 Electric Power Research Institute Mixed Oxide Critical Configurations ........ 12

3.1.13 Critical Triangular Lattice of MOX \& UO $\mathrm{U}_{2}$ Fuel Rods.................................. 12

3.1.14 TRIGA (Training, Research, Isotopes, General Atomics) Fuel Rod

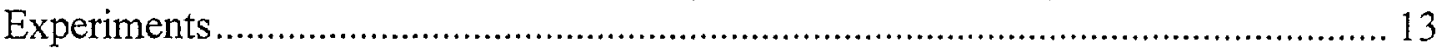

3.1.15 SPERT-D Fuel Experiments ............................................................... 13

3.1.16 Water-Moderated Hexagonally Pitched Lattices of Highly Enriched Fuel Rods

of Cross-Shaped Cross Section ............................................................................... 14

3.1.17 Critical Experiments of EBOR Fuel Pins in Water ......................................... 16

3.1.18 Intermediate Heterogeneous Assembly with Highly Enriched Uranium Dioxide

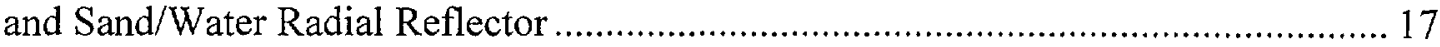

3.1.19 FFTF Fuel Pin Array Experiments.......................................................... 18

3.1.20 High Enriched Uranium Metal Fast (HMF) Systems..................................... 19

3.1.21 Plutonium Fast Metal (PMF) Systems …………....................................... 20

3.1.22 Intermediate Enriçhed Uranium Metal Fast (IMF) Systems ............................. 20 
3.2 HOMOGENEOUS SOLUTION EXPERIMENTS............................................... 24

3.2.1 Mixed Plutonium and Natural Uranium Nitrate Solutions ............................. 24

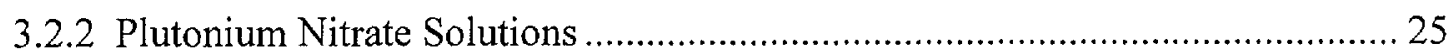

3.2.3 Highly Enriched Uranium Nitrate Solutions ............................................ 26

3.2.4 Intermediate-Enrichment Uranium Solutions .......................................... 28

3.2.5 Intermediate-Enriched Uranium Nitrate Solutions...................................... 28

3.2.6 Intermediate-Enriched Uranyl Sulfate Solutions ................................... 28

3.2.7 Low-Enrichment Uranium Solutions ............................................................ 29

3.2.8 Low Enriched Uranyl Flouride Solutions .................................................. 29

3.2.9 ${ }^{233}$ U Fuel Homogeneous Criticals .......................................................... 30

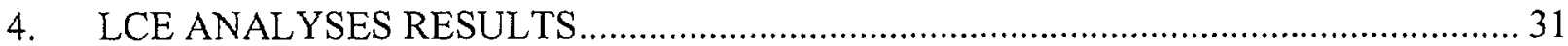

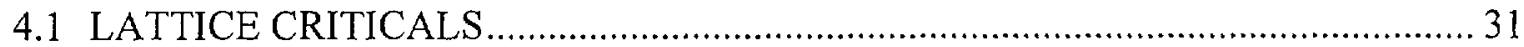

4.2 HOMOGENEOUS CRITICALS …........................................................... 43

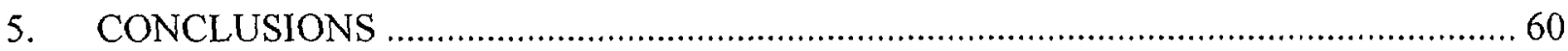

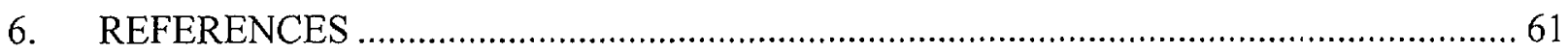


3.1-1. Cross Section of the Critical Assembly Representation Through the Core Center............ 18

4.1-1. Mixed Oxide Fuel Pin Lattice Critical Experiments (Thermal) ....................................... 32

4.1-2. Mixed Oxide Fuel Pin Lattice Critical Experiments (Intermediate) ................................. 33

4.1-3. High Enriched Uranium Oxide Fuel Pin Lattice Critical Experiments (Thermal) ............. 34

4.1-4. High Enriched Uranium Oxide Fuel Pin Lattice Critical Experiments (Intermediate) ...... 35

4.1-5. High Enriched Uranium Oxide Fuel Plate Lattice Critical Experiments (Thermal) .......... 36

4.1-6. High Enriched Uranium Oxide Single-Zone Cruciform Rod Lattice Critical Experiments

(Thermal)

4.1-7. High Enriched Uranium Oxide Dual-Zone Cruciform Rod Lattice Critical Experiments

(Thermal)

4.1-8. Intermediate Enriched Uranium Oxide Fuel Pin Lattice Critical Experiments (Thermal). 39

4.1-9. Low Enriched Uranium Oxide Fuel Pin Lattice Critical Experiments (Thermal) ............. 40

4.1-10. Low Enriched Uranium Oxide Fuel Pin Lattice Critical Experiments (Intermediate) .... 42

4.2-1. Homogeneous Critical Experiments Using Mixed Plutonium and Natural Uranium Nitrate

Solutions (Thermal) ................................................................................................ 45

4.2-2. Homogeneous Critical Experiments Using Plutonium Nitrate Solutions (Thermal) ......... 47

4.2-3. Plutonium Metal Critical Experiments (Fast) ............................................................... 48

4.2-4. Homogenous Critical Experiments Using High Enriched Uranium Nitrate Solutions

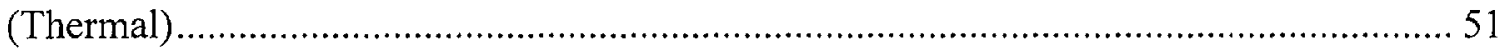

4.2-5. High Enriched Uranium Metal Critical Experiments (Fast)............................................ 52

4.2-6. Homogenous Critical Experiments Using Intermediate Enriched Uranium Fuel (Thermal)

4.2-7. Homogenous Critical Experiments Using Intermediate Enriched Uranium Fuel

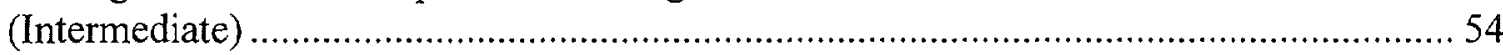

4.2-8. Intermediate Enriched Uranium Metal Critical Experiments (Fast) ................................ 55

4.2-9. Homogenous Critical Experiments Using Low Enriched Uranium Nitrate Solutions (Thermal) :............................................................................................................ 56

4.2-10. Homogenous Critical Experiments Using Low Enriched Uranium Solutions

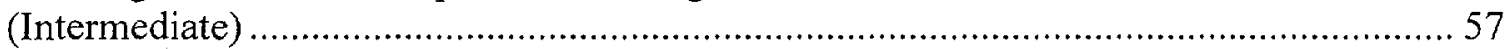

4.2-11. Homogenous Critical Experiments Using Uranium-233 Fuel (Thermal) ........................58

4.2-12. Homogenous Critical Experiments Using Uranium-233 Fuel (Fast) ............................... 59 
2.2-1. MCNP Cross Section Libraries Used in the LCE Reactivity Calculations ......................... 3

3-1. TBV References and Associated Tracking Numbers ........................................................... 6

3.1-1. Differences in Absorber Plates used for Clusters of $2.35 \mathrm{wt} \% \mathrm{UO}_{2}$ Fuel Rods................. 7

3.1-2. Water-Reflected Fuel Rod Cluster Critical Experiments ………………………………..... 7

3.1-3. MKIA Fuel Assembly Experiments ………………............................................... 8

3.1-4. Differences in Experimental Configurations for Clusters of $2.35 \mathrm{wt} \% \mathrm{UO}_{2}$ Fuel Rods ..... 8

3.1-5. Urania-Gadolinia Critical Experiment Descriptions ................................................... 10

3.1-6. Saxton Single-Region Critical Configuration Parameters................................................ 11

3.1-7. Saxton Multi-Region Critical Configuration Parameters ................................................. 11

3.1-8. Close Proximity Critical Benchmark Characterization Parameters ................................. 12

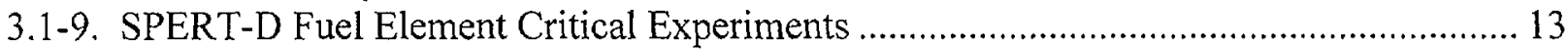

3.1-10. Benchmarks for HCT-003 Class of Experiments ...................................................... 15

3.1-11. Benchmarks for HCT-004 Class of Experiments ..................................................... 15

3.1-12. Benchmarks for HCT-006 Class of Experiments ...................................................... 15

3.1-13. Benchmarks for HCT-007 Class of Experiments ....................................................... 16

3.1-14. Benchmarks for HCT-008 Class of Experiments ........................................................... 16

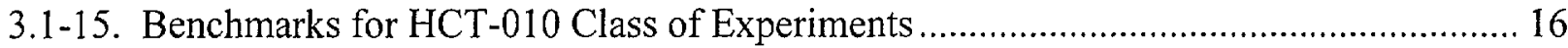

3.1-16. Benchmarks for HCI-002 Class of Experiments ........................................................ 17

3.1-17. FFTF Bierman Array Critical Experiments ............................................................ 19

3.1-18. HMF Russian Criticality Safety Benchmark Experiments ........................................... 19

3.1-19. PMF Russian Criticality Safety Benchmark Experiments ……………………............. 20

3.1-20. IMF Experimental Description ................................................................................. 21

3.1-21. Dimensions and Mass Characteristics of the IMF-003 Critical Assembly ……............. 21

3.1-22. Dimensions and Mass Characteristics of the IMF-004 Critical Assembly .................... 22

3.1-23. Dimension and Mass Characteristics of the IMF-005 Critical Assembly ………............ 22

3.1-24. Dimensions and Mass Characteristics of the IMF-006 Critical Assembly ..................... 23

3.1-25. Dimensions and Mass Characteristics of the IMF-008 Critical Assembly .................... 23

3.2-1. Benchmark Problem Summary for Configurations Incorporating Mixed Plutonium and Natural Uranium Nitrate Solutions ......................................................................... 24

3.2-2. Benchmark Problem Summary for Configurations Incorporating Plutonium Nitrate

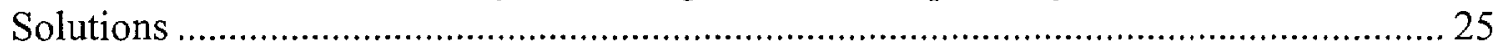

3.2-3. Benchmark Problem Summary for Configurations Incorporating Highly Enriched

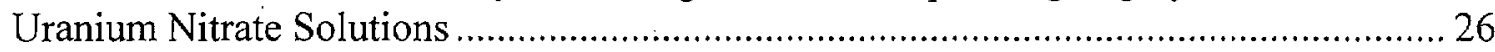

3.2-4. Benchmark Problem Summary for Configurations Incorporating Low-Enrichment

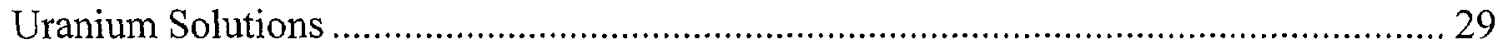

4.1-1. Mixed Oxide Fuel Pin Lattice Critical Experiments (Thermal) ......................................... 32

4.1-2. Mixed Oxide Fuel Pin Lattice Critical Experiments (Intermediate) ................................. 33

4.1-3. High Enriched Uranium Oxide Fuel Pin Lattice Critical Experiments (Thermal) ............. 34

4.1-4. High Enriched Uranium Oxide Fuel Pin Lattice Critical Experiments (Intermediate) ..... 35

4.1-5. High Enriched Uranium Oxide Fuel Plate Lattice Critical Experiments (Thermal) ......... 36

4.1-6. High Enriched Uranium Oxide Single-Zone Cruciform Rod Lattice Critical Experiments

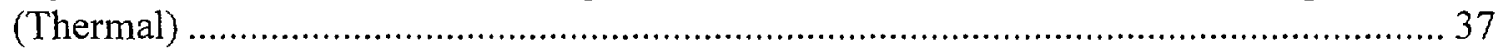

4.1-7. High Enriched Uranium Oxide Dual-Zone Cruciform Rod Lattice Critical Experiments

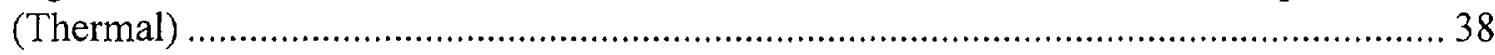


4.1-8. Intermediate Enriched Uranium Oxide Fuel Pin Lattice Critical Experiments (Thermal) 39

4.1-9. Low Enriched Uranium Oxide Fuel Pin Lattice Critical Experiments (Thermal) ............ 40

4.1-10. Low Enriched Uranium Oxide Fuel Pin Lattice Critical Experiments (Intermediate) .... 41

4.2-1. Homogeneous Critical Experiments Using Mixed Plutonium and Natural Uranium Nitrate Solutions (Thermal) ............................................................................................ 44

4.2-2. Homogeneous Critical Experiments Using Plutonium Nitrate Solutions (Thermal) ........ 46

4.2-3. Plutonium Metal Critical Experiments (Fast) ............................................................... 48

4.2-4. Homogenous Critical Experiments Using High Enriched Uranium Nitrate Solutions

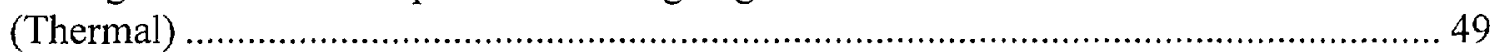

4.2-5. High Enriched Uranium Metal Critical Experiments (Fast)........................................... 52

4.2-6. Homogenous Critical Experiments Using Intermediate Enriched Uranium Fuel (Thermal)

4.2-7. Homogenous Critical Experiments Using Intermediate Enriched Uranium Fuel

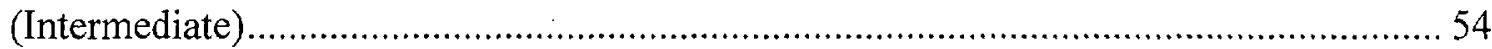

4.2-8. Intermediate Enriched Uranium Metal Critical Experiments (Fast) ................................ 55

4.2-9. Homogenous Critical Experiments Using Low Enriched Uranium Nitrate Solutions

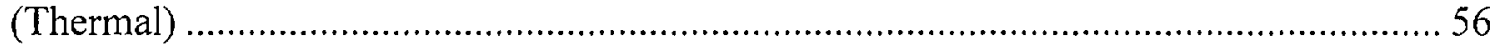

4.2-10. Homogenous Critical Experiments Using Low Enriched Uranium Solutions (Intermediate) ....................................................................................................... 57

4.2-11. Homogenous Critical Experiments Using Uranium-233 Fuel (Thermal) ………….........58

4.2-12. Homogenous Critical Experiments Using Uranium-233 Fuel (Fast) ............................... 59

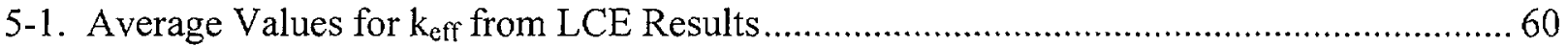




\section{INTRODUCTION}

This report, Summary Report of Laboratory Critical Experiment Analyses Performed for the Disposal Criticality Analysis Methodology, contains a summary of the laboratory critical experiment (LCE) analyses used to support the validation of the disposal criticality analysis methodology.

\subsection{BACKGROUND}

The United States Department of Energy (DOE) Office of Civilian Radioactive Waste Management (OCRWM) is developing a methodology for criticality analysis to support disposal of commercial spent nuclear fuel in a geologic repository. A supplement to the Disposal Criticality Analysis Methodology Topical Report is scheduled to be submitted to the United States Nuclear Regulatory Commission (NRC) for formal review later in 1999. This technical report is one of a series of reports that provides a summary of the results of the analyses that support the development of the disposal criticality analysis methodology.

\subsection{OBJECTIVE}

The objective of this report is to present a summary of the LCE analyses' results. These results demonstrate the ability of MCNP to accurately predict the critical multiplication factor $\left(\mathrm{k}_{\mathrm{eff}}\right)$ for fuel with different configurations. Results from the LCE evaluations will support the development and validation of the criticality models used in the disposal criticality analysis methodology. These models and their validation have been discussed in the Disposal Criticality Analysis Methodology Topical Report (CRWMS M\&O 1998a).

\subsection{SCOPE}

The scope of this Summary Report includes the LCE analytical results for the following types of critical experiments:

- Lattice Criticals

- Homogeneous Mixture Criticals

- Fast Metal Fuel Criticals.

Additional types of critical experiments may be added in future revisions to this report.

\subsection{QUALITY ASSURANCE}

The Quality Assurance (QA) program applies to the development of this report. The data provided in this report will indirectly be used to develop the methodology for evaluating the Monitored Geologic Repository (MGR) waste package and engineered barrier segment. The QAP-2-3 (Classification of Permanent Items) evaluation entitled Classification of the Preliminary MGDS Repository Design (p. IV-11, CRWMS M\&O 1999a) has identified the waste package as an MGR item important to radiological safety and waste isolation. The Waste Package Operations responsible manager has evaluated the technical document development activity in accordance with QAP-2-0, Conduct of Activities. The QAP-2-0 activity evaluation, Neutronics Methodology (CRWMS M\&O 1999e), has determined that the preparation and 
review of this technical document is subject to Quality Assurance Requirements and Description (DOE OCRWM 1998) requirements. As specified in NLP-3-18, Documentation of QA Controls on Drawings, Specifications, Design Analyses, and Technical Documents, this activity is subject to QA controls.

\subsection{USE OF COMPUTER SOFTWARE}

As discussed in CRWMS M\&O (1999b), CRWMS M\&O (1999c), and CRWMS M\&O (1999d), the MCNP code was used to calculate the eigenvalue for the LCE configurations. The software specifications are as follows:

Program Name: MCNP

Version/Revision Number: Version 4B2LV

CSCI Number: 30033 V4B2LV

Computer Type: HP 9000 Series Workstations

Computer Processing Unit Number: (Bloom) 700887

The input and output files for the various MCNP calculations are documented throughout CRWMS M\&O (1999b), CRWMS M\&O (1999c), and CRWMS M\&O (1999d), such that an independent repetition of the software use may be performed. The MCNP software used was: (a) appropriate for the application of eigenvalue calculations, (b) used only within the range of validation as documented throughout Briesmeister (1997) and CRWMS M\&O (1998b), and (c) obtained from the Software Configuration Manager in accordance with appropriate procedures.

Title: Excel

Version/Revision Number: Microsoft $®$ Excel 97

The Excel spreadsheet program was used for simple graphical displays of the results as presented in Section 4 of this report. 


\section{ANALYSIS MODEL}

This section provides a description of the configurations used to generate the supporting analytic results reported in this document.

\subsection{CRITICALITY MODEL}

The criticality models used to calculate the reactivity of the various experiments are discussed in CRWMS M\&O (1999b), CRWMS M\&O (1999c), and CRWMS M\&O (1999d). The tool used to assess the reactivity of each of the experiments is MCNP 4B (Briesmeister 1997 and CRWMS M\&O 1998b), which is an implementation of the Monte Carlo method. The computer inputs for the LCE calculations are provided in Attachments I, III, and V of CRWMS M\&O (1999b), CRWMS M\&O (1999c), and CRWMS M\&O (1999d).

\subsection{CROSS SECTIONS}

Table 2.2-1 lists all of the MCNP cross section library identifiers (ZAIDs) used in the LCE reactivity calculations documented in CRWMS M\&O (1999b), CRWMS M\&O (1999c), and CRWMS M\&O (1999d). The MCNP ZAID is used to identify a cross section library. The ZAID consists of a four- or five-digit element and isotope identifier followed by a cross section library suffix. The first one or two digits in the ZAID refer to the atomic number of the corresponding element. The three digits preceding the decimal always refer to the isotopic mass number. The suffix identifies the library. Details are in Appendix G of Briesmeister (1997).

Each of the critical experiments were run with three sets of cross-section libraries - ENDF/B-V, ENDF/B-VI, and a hybrid set that is a combination of the two referred to as the WPO Selected set which comes from CRWMS M\&O (1998c). The WPO Selected set uses isotopic crosssection data that is from ENDF/B-VI in place of elemental cross-sections that came from ENDF/B-V for certain elements. A complete listing is provided in CRWMS M\&O (1998c).

Table 2.2-1. MCNP Cross Section Libraries Used in the LCE Reactivity Calculations

\begin{tabular}{|c|c|c|c|c|}
\hline Element/lsotope & $\begin{array}{l}\text { MCNP } \\
\text { ZAID }\end{array}$ & Temperature (K) & Library name & Data source \\
\hline $\mathrm{H}-1$ & $1001.50 \mathrm{c}$ & 294.0 & rmccs & ENDF/B-V.O \\
\hline $\mathrm{H}-1$ & $1001.60 \mathrm{c}$ & 294.0 & endf 60 & ENDF/B-VI.1 \\
\hline $\mathrm{H}-2$ & $1002.55 \mathrm{c}$ & 294.0 & rmccs & LANL/T-2 \\
\hline $\mathrm{H}-2$ & $1002.60 \mathrm{c}$ & 294.0 & endf60 & ENDF/B-VI.0 \\
\hline Li-6 & $3006.50 \mathrm{c}$ & 294.0 & rmccs & ENDF/B-V.D \\
\hline Li-6 & $3006.60 \mathrm{c}$ & 294.0 & endf60 & ENDF/B-VI.1 \\
\hline $\mathrm{Li}-7$ & $3007.55 c$ & 294.0 & rmces & ENDF/B-V.2 \\
\hline $\mathrm{Li}-7$ & $3007.60 \mathrm{c}$ & 294.0 & endf 60 & ENDF/B-VI.O \\
\hline $\mathrm{Be}-9$ & $4009.50 \mathrm{c}$ & 294.0 & rmccs & ENDF/B-V.O \\
\hline $\mathrm{Be}-9$ & $4009.60 c$ & 294.0 & endf60 & ENDF/B-VI.O \\
\hline B-10 & $5010.50 \mathrm{c}$ & 294.0 & rmccs & ENDF/B-V.O \\
\hline B-10 & $5010.60 c$ & 294.0 & endf60 & ENDF/B-VI.1 \\
\hline $\mathrm{B}-11$ & $5011.56 \mathrm{c}$ & 294.0 & newxs & LANL $\pi-2$ \\
\hline $\mathrm{B}-11$ & $5011.60 c$ & 294.0 & endf60 & ENDF/B-VI.0 \\
\hline C-nat & $6000.50 c$ & 294.0 & rmccs & ENDF/B-V.O \\
\hline C-nat & $6000.60 \mathrm{c}$ & 294.0 & endf60 & ENDF/B-VI.1 \\
\hline $\mathrm{C}-12$ & $6012.50 c$ & 294.0 & rmccs & ENDF/B-V.O \\
\hline
\end{tabular}


Table 2.2-1. MCNP Cross Section Libraries Used in the LCE Reactivity Calculations

\begin{tabular}{|c|c|c|c|c|}
\hline Element/lsotope & $\begin{array}{l}\text { MCNP } \\
\text { ZAID }\end{array}$ & Temperature (K) & Library name & Data source \\
\hline $\mathrm{N}-14$ & $7014.50 \mathrm{c}$ & 294.0 & rmccs & ENDF/B-V.O \\
\hline $\mathrm{N}-14$ & $7014.60 \mathrm{c}$ & 294.0 & endf60 & LANL $\pi-2$ \\
\hline $\mathrm{N}-15$ & $7015.55 c$ & 294.0 & rmccsa & LANL/T-2 \\
\hline $\mathrm{N}-15$ & $7015.60 \mathrm{c}$ & 294.0 & endf60 & ENDF/B-VI.O \\
\hline $0-16$ & $8016.50 \mathrm{c}$ & 294.0 & rmccs & ENDF/B-V.O \\
\hline $0-16$ & $8016.60 c$ & 294.0 & endf 60 & ENDF/B-VI.O \\
\hline $0-17$ & $8017.60 \mathrm{c}$ & 294.0 & endf60 & ENDF/B-VI.O \\
\hline F-19 & $9019.50 c$ & 294.0 & endf5p & ENDF/B-V.O \\
\hline F-19 & $9019.60 \mathrm{c}$ & 294.0 & endf 60 & ENDF/B-VI.0 \\
\hline $\mathrm{Na}-23$ & $11023.50 \mathrm{c}$ & 294.0 & endf5p & ENDF/B-V.O \\
\hline $\mathrm{Na}-23$ & $11023.60 \mathrm{c}$ & 294.0 & endf 60 & ENDF/B-VI.1 \\
\hline Mg-nat & $12000.50 \mathrm{c}$ & 294.0 & endf5u & ENDF/B-V.O \\
\hline Mg-nat & $12000.60 \mathrm{c}$ & 294.0 & endf60 & ENDF/B-VI.0 \\
\hline Al-27 & $13027.50 \mathrm{c}$ & 294.0 & rmccs & ENDF/B-V.O \\
\hline $\mathrm{Al}-27$ & $13027.60 \mathrm{c}$ & 294.0 & endf60 & ENDF/B-VI.0 \\
\hline Si-nat & $14000.50 c$ & 294.0 & endf5p & ENDF/B-V.O \\
\hline Si-nat & $14000.60 \mathrm{c}$ & 294.0 & endf60 & ENDF/B-VI.0 \\
\hline$P-31$ & $15031.50 \mathrm{c}$ & 294.0 & endf5u & ENDF/B-V.O \\
\hline P-31 & $15031.60 \mathrm{c}$ & 294.0 & endf60 & ENDF/B-VI.0 \\
\hline S-32 & $16032.50 \mathrm{c}$ & 294.0 & endf5u & ENDF/B-V.0 \\
\hline S-32 & $16032.60 \mathrm{c}$ & 294.0 & endf60 & ENDF/B-VI.O \\
\hline Cl-nat & $17000.50 \mathrm{c}$ & 294.0 & endf5p & ENDF/B-V.O \\
\hline Cl-nat & $17000.60 \mathrm{c}$ & 294.0 & endf 60 & ENDF/B-VI.O \\
\hline K-nat & $19000.50 c$ & 294.0 & endf5u & ENDF/B-V.O \\
\hline K-nat & $19000.60 \mathrm{c}$ & 294.0 & endf60 & ENDF/B-VI.O \\
\hline Ca-nat & $20000.50 \mathrm{c}$ & 294.0 & endf5u & ENDF/B-V.0 \\
\hline Ca-nat & $20000.60 \mathrm{c}$ & 294.0 & endf60 & ENDF/B-VI.0 \\
\hline Ti-nat & $22000.50 c$ & 294.0 & endf5u & ENDF/B-V.O \\
\hline Ti-nat & $22000.60 \mathrm{c}$ & 294.0 & endf60 & ENDF/B-VI.0 \\
\hline V-nat & $23000.50 c$ & 294.0 & endf5u & ENDF/B-V.0 \\
\hline$V$-nat & $23000.60 c$ & 294.0 & endf60 & ENDF/B-VI.O \\
\hline Cr-nat & $24000.50 \mathrm{c}$ & 294.0 & rmccs & ENDF/B-V.O \\
\hline $\mathrm{Cr}-50$ & $24050.60 c$ & 294.0 & endf60 & ENDF/B-VI.1 \\
\hline $\mathrm{Cr}-52$ & $24052.60 \mathrm{c}$ & 294.0 & endf 60 & ENDF/B-VI.1 \\
\hline $\mathrm{Cr}-53$ & $24053.60 c$ & 294.0 & endf 60 & ENDF/B-VI.1 \\
\hline Cr-54 & $24054.60 c$ & 294.0 & endf60 & ENDF/B-VI.1 \\
\hline $\mathrm{Mn}-55$ & $25055.50 \mathrm{c}$ & 294.0 & endf5u & ENDF/B-V.O \\
\hline Mn-55 & $25055.60 c$ & 294.0 & endf60 & ENDF/B-VI.O \\
\hline Fe-nat & $26000.55 c$ & 294.0 & rmccs & LANL $\pi-2$ \\
\hline $\mathrm{Fe}-54$ & $26054.60 \mathrm{c}$ & 294.0 & endf 60 & ENDF/B-VI.1 \\
\hline $\mathrm{Fe}-56$ & $26056.60 \mathrm{c}$ & 294.0 & endf 60 & ENDF/B-VI.1 \\
\hline $\mathrm{Fe}-57$ & $26057.60 \mathrm{c}$ & 294.0 & endf60 & ENDF/B-VI.1 \\
\hline $\mathrm{Fe}-58$ & $26058.60 \mathrm{c}$ & 294.0 & endf60 & ENDF/B-VI.1 \\
\hline Ni-nat & $28000.50 \mathrm{c}$ & 294.0 & rmccs & ENDF/B-V.O \\
\hline $\mathrm{Ni}-58$ & $28058.60 \mathrm{c}$ & 294.0 & endf 60 & ENDF/B-VI.1 \\
\hline $\mathrm{Ni}-60$ & $28060.60 \mathrm{c}$ & 294.0 & endf 60 & ENDF/B-VI.1 \\
\hline $\mathrm{Ni}-61$ & $28061.60 \mathrm{c}$ & 294.0 & endf 60 & ENDF/B-VI.1 \\
\hline $\mathrm{Ni}-62$ & $28062.60 \mathrm{c}$ & 294.0 & endf60 & ENDF/B-VI.1 \\
\hline $\mathrm{Ni}-64$ & $28064.60 \mathrm{c}$ & 294.0 & endf 60 & ENDF/B-VI.1 \\
\hline Cu-nat & $29000.50 \mathrm{c}$ & 294.0 & rmces & ENDF/B-V.O \\
\hline $\mathrm{Cu}-63$ & $29063.60 \mathrm{c}$ & 294.0 & endf60 & ENDF/B-VI.2 \\
\hline $\mathrm{Cu}-65$ & $29065.60 \mathrm{C}$ & 294.0 & endf60 & ENDF/B-VI.2 \\
\hline Ga-nat & $31000.50 \mathrm{c}$ & 294.0 & rmces & ENDF/B-V.0 \\
\hline Ga-nat & $31000.60 c$ & 294.0 & endf60 & ENDF/B-V1.0 \\
\hline Zr-nat & $40000.56 \mathrm{c}$ & 294.0 & misc $5 \times s$ & ENDF/B-V: XTM \\
\hline Zr-nat & $40000.60 \mathrm{c}$ & 294.0 & endf60 & ENDF/B-VI.1 \\
\hline
\end{tabular}


Table 2.2-1. MCNP Cross Section Libraries Used in the LCE Reactivity Calculations

\begin{tabular}{|c|c|c|c|c|}
\hline Element/Isotope & $\begin{array}{c}\text { MCNP } \\
\text { ZAID }\end{array}$ & Temperature $(\mathrm{K})$ & Library name & Data source \\
\hline $\mathrm{Nb}-93$ & $41093.50 \mathrm{c}$ & 294.0 & endf5p & ENDF/B-V.O \\
\hline $\mathrm{Nb}-93$ & $41093.60 c$ & 294.0 & endf 60 & ENDF/B-VI.1 \\
\hline Mo-nat & $42000.50 c$ & 294.0 & endf5u & ENDF/B-V.0 \\
\hline Mo-nat & $42000.60 c$ & 294.0 & endf 60 & ENDF/B-VI.O \\
\hline Cd-nat & $48000.50 c$ & 294.0 & endf5u & ENDF/B-V.O \\
\hline $\mathrm{Ba}-138$ & $56138.50 c$ & 294.0 & rmccs & ENDF/B-V.O \\
\hline $\mathrm{Ba}-138$ & $56138.60 \mathrm{c}$ & 294.0 & endf60 & ENDF/B-VI.0 \\
\hline $\mathrm{Gd}-152$ & $64152.50 \mathrm{c}$ & 294.0 & endf5u & ENDF/B-V.O \\
\hline Gd-152 & $64152.60 \mathrm{c}$ & 294.0 & endf60 & ENDF/B-VI.0 \\
\hline Gd-154 & $64154.50 \mathrm{c}$ & 294.0 & endf5u & ENDF/B-V.O \\
\hline Gd-154 & $64154.60 c$ & 294.0 & endf60 & ENDF/B-VI.0 \\
\hline $\mathrm{Gd}-155$ & $64155.50 \mathrm{c}$ & 294.0 & endf5u & ENDF/B-V.O \\
\hline $\mathrm{Gd}-155$ & $64155.60 c$ & 294.0 & endf60 & ENDF/B-VI.O \\
\hline $\mathrm{Gd}-156$ & $64156.50 \mathrm{c}$ & 294.0 & endf5u & ENDF/B-V.O \\
\hline Gd-156 & $64156.60 c$ & 294.0 & endf 60 & ENDF/B-VI.0 \\
\hline Gd-157 & $64157.50 \mathrm{c}$ & 294.0 & endf5u & ENDF/B-V.O \\
\hline Gd-157 & $64157.60 c$ & 294.0 & endf 60 & ENDF/B-VI.0 \\
\hline Gd-158 & $64158.50 c$ & 294.0 & endf5u & ENDF/B-V.0 \\
\hline Gd-158 & $64158.60 c$ & 294.0 & endf60 & ENDF/B-VI.O \\
\hline Gd-160 & $64160.50 c$ & 294.0 & endf5u & ENDF/B-V.O \\
\hline Gd-160 & $64160.60 \mathrm{c}$ & 294.0 & endf 60 & ENDF/B-VI.O \\
\hline W-nat & $74000.55 c$ & 294.0 & rmces & ENDF/B-V.2 \\
\hline$W-182$ & $74182.60 \mathrm{c}$ & 294.0 & endf 60 & ENDF/B-VI.O \\
\hline W-183 & $74183.60 \mathrm{c}$ & 294.0 & endf 60 & ENDF/B-VI.O \\
\hline$W-184$ & $74184.60 \mathrm{c}$ & 294.0 & endf60 & ENDF/B-VI.0 \\
\hline W-186 & $74186.60 \mathrm{c}$ & 294.0 & endf 60 & ENDF/B-VI.0 \\
\hline U-233 & $92233.50 \mathrm{c}$ & 294.0 & rmccs & ENDF/B-V.O \\
\hline U-233 & $92233.60 \mathrm{c}$ & 294.0 & endf60 & ENDF/B-VI.O \\
\hline U-234 & $92234.50 \mathrm{c}$ & 294.0 & endf5p & ENDF/B-V.O \\
\hline U-234 & $92234.60 \mathrm{c}$ & 294.0 & endf 60 & ENDF/B-VI.O \\
\hline U-235 & $92235.50 \mathrm{c}$ & 294.0 & rmccs & ENDF/B-V.O \\
\hline U-235 & $92235.60 \mathrm{c}$ & 294.0 & endf 60 & ENDF/B-VI.2 \\
\hline U-236 & $92236.50 \mathrm{c}$ & 294.0 & endf5p & ENDF/B-V.0 \\
\hline U-236 & $92236.60 \mathrm{c}$ & 294.0 & endf 60 & ENDF/B-VI.O \\
\hline U-238 & $92238.50 c$ & 294.0 & rmccs & ENDF/B-V.O \\
\hline U-238 & $92238.60 \mathrm{c}$ & 294.0 & endf60 & ENDF/B-VI.2 \\
\hline Pu-238 & $94238.50 \mathrm{c}$ & 294.0 & endf5p & ENDF/B-V.0 \\
\hline $\mathrm{Pu}-238$ & $94238.60 \mathrm{c}$ & 294.0 & endf60 & ENDF/B-VI.0 \\
\hline Pu-239 & $94239.55 c$ & 294.0 & rmces & ENDF/B-V.2 \\
\hline Pu-239 & $94239.60 c$ & 294.0 & endf60 & ENDF/B-VI.2 \\
\hline $\mathrm{Pu}-240$ & $94240.50 \mathrm{c}$ & 294.0 & rmccs & ENDF/B-V.O \\
\hline Pu-240 & $94240.60 c$ & 294.0 & endf60 & ENDF/B-VI.2 \\
\hline $\mathrm{Pu}-241$ & $94241.50 \mathrm{c}$ & 294.0 & endf5p & ENDF/B-V.O \\
\hline Pu-241 & $94241.60 c$ & 294.0 & endf 60 & ENDF/B-VI.1 \\
\hline $\mathrm{Pu}-242$ & $94242.50 \mathrm{c}$ & 294.0 & endf5p & ENDF/B-V.O \\
\hline Pu-242 & $94242.60 c$ & 294.0 & endf 60 & ENDF/B-VI.O \\
\hline Am-241 & $95241.50 \mathrm{c}$ & 294.0 & endf5u & ENDF/B-V.O \\
\hline Am-241 & $95241.60 \mathrm{c}$ & 294.0 & endf60 & LANL $/ T-2$ \\
\hline
\end{tabular}

pp. 6 through 9 of CRWMS M\&O 1999b

NOTE: ${ }^{\text {nat }}=$ natural element composition 


\section{DESCRIPTION OF THE EXPERIMENT SYSTEMS}

The represented experiments are described in Baldwin et al. (1979) through Wittekind (1992). The data from OECD-NEA (1998) is from a standard handbook, is generally accepted by the scientific and engineering community, and used in a number of license applications and validation reports through out the nuclear industry. The data in this reference is therefore considered "Accepted Data". Throughout the rest of this section, information from the references specified in Table 3-1 should be considered to be verified (TBV) in that they are not considered accepted data sources per the retroactive procedural requirement of AP-SIII.2Q initiated by the July 27, 1999 issuance of the DOE Letter, "Accepted Data Call", from R.E. Spence to J.L. Younker (DOE 1999).

Table 3-1. TBV References and Associated Tracking Numbers

\begin{tabular}{|c|c|}
\hline Reference & TBV Tracking Number \\
\hline Baldwin et al. 1979 & TBV-1357 \\
\hline Newman 1984 & TBV-1358 \\
\hline Taylor 1965 & TBV-1359 \\
\hline Wittekind 1992 & TBV-1360 \\
\hline Bierman 1990 & TBV-1361 \\
\hline Bierman et al. 1977 & TBV-1362 \\
\hline Bierman et al. 1981 & TBV-1363 \\
\hline Bierman and Clayton 1981 & TBV-1364 \\
\hline Durst et al. 1982 & TBV-1365 \\
\hline Bierman et al. 1984 & TBV-1366 \\
\hline Brown et al. 1965 & TBV-1367 \\
\hline DeHardt and Bowman 1995 & TBV-1368 \\
\hline Mele et al. 1994 & TBV-1369 \\
\hline Miyoshi et al. 1997 & TBV-1370 \\
\hline Bierman et al. 1979 & TBV-1371 \\
\hline
\end{tabular}

It should be noted that some of the experiments were not true critical configurations, but were subcritical approaches extrapolated to critical. The number of digits in the values cited herein may be the results of a calculation or may reflect the input from another source; consequently, the number of digits should not be interpreted as an indication of accuracy. In the following sections, intermediate-enriched uranium (IEU) is defined as having a ${ }^{235} \mathrm{U}$ concentration greater than $10 \mathrm{wt} \%$ but less than $80 \mathrm{wt} \%$. Low-enriched uranium (LEU) and high-enriched uranium (HEU) are outside this range.

\subsection{LATTICE EXPERIMENTS}

The fresh fuel LCEs presented in this section represent moderated lattice configurations containing fissile oxide fuel. Each of the LCE configurations described in this section have been analyzed with the MCNP code system using the cross section library previously described (Section 2.2). An experiment identifier for each configuration is provided for subsequent reference when the results are reported.

\subsubsection{Critical Configurations of Subcritical Clusters of $2.35 \mathrm{wt} \%$ Enriched $\mathrm{UO}_{2}$ Rods in Water with Fixed Neutron Absorber Plates}

Experiments with subcritical clusters of low-enrichment $\mathrm{UO}_{2}$ fuel rods were performed at the Pacific Northwest Laboratory and documented by Bierman et al. (1977). The four experiments 
modeled with MCNP consisted of three rectangular arrays of aluminum-clad fuel rods. The fuel rods comprising the arrays had a uniform enrichment of $2.35 \mathrm{wt} \%{ }^{235} \mathrm{U}$. The three arrays of fuel were arranged in a row and, in three of the experiments, sheets of neutron poison were interposed between adjacent arrays. The structure of the experimental assembly was provided by aluminum structural members on the margins of the fuel arrays. Axial support for the fuel rods was provided by an acrylic base plate. The lateral alignment of the fuel rods was provided by another acrylic plate. The experimental apparatus was closely reflected by full-density water.

The pertinent differences among these four experiments are shown in Table 3.1-1. These critical experiments help demonstrate the ability of MCNP to accurately predict the critical multiplication factor for configurations containing light-water reactor fuel separated by absorber plates.

Table 3.1-1. Differences in Absorber Plates used for Clusters of 2.35 $w t \% \mathrm{UO}_{2}$ Fuel Rods

\begin{tabular}{|c|c|}
\hline Experiment identifier & Interposed plate $^{\text {exp1 }}$ \\
\hline $\operatorname{exp2}$ & none \\
\hline $\operatorname{exp3}$ & Boral $^{\mathrm{TM}}$ \\
\hline $\operatorname{exp4}$ & Type 6061 Aluminum $^{\text {Type 304 Stainless Steel }}$ \\
\hline
\end{tabular}

\subsubsection{Water-Reflected Fuel Rod Clusters in Square Pitched Arrays}

A series of critical experiments with clusters of aluminum clad $\mathrm{UO}_{2}$ fuel rods in a large waterfilled tank was performed over a period of several years at the Critical Mass Laboratory at Pacific Northwest Laboratories (PNL). Eight cases were analyzed under this category that correspond to water-reflected clusters at $2.032 \mathrm{~cm}$ square pitch with no absorber plates, reflecting walls, dissolved poison, or gadolinium impurity. Table 3.1-2 provides a brief description of the experiments. Each of the experiments used $2.35 \mathrm{wt} \%{ }^{235} \mathrm{U}$ enriched $\mathrm{UO}_{2}$ fuel with an average loading of $17.08 \mathrm{~g}$ of ${ }^{235} \mathrm{U}$ per rod (OECD-NEA 1998, p. 7 LCT-001).

Table 3.1-2. Water-Reflected Fuel Rod Cluster Critical Experiments

\begin{tabular}{|l|l|c|}
\hline $\begin{array}{l}\text { Experiment } \\
\text { identifier }\end{array}$ & $\begin{array}{l}\text { Description (p. 10, OECD-NEA 1998, LCT-001) } \\
\text { number of rods }{ }^{1}(X \times \mathrm{Y}), \text { number of clusters, cluster separation }\end{array}$ & $\mathrm{H} / \mathrm{X} \mathrm{ratio}^{2}$ \\
\hline Case 1 & $20 \times 18.08,1$ cluster & 459 \\
\hline Case 2 & $20 \times 17,3$ clusters, $11.92 \pm 0.04 \mathrm{~cm}$ separation & 487 \\
\hline Case $3^{3}$ & $20 \times 16,3$ clusters, $8.41 \pm 0.05 \mathrm{~cm}$ separation & 469 \\
\hline Case 4 & $20 \times 16$ (center), $22 \times 16$ (two outer), 3 clusters, $10.05 \pm 0.05 \mathrm{~cm}$ separation & 474 \\
\hline Case 5 & $20 \times 15,3$ clusters, $6.39 \pm 0.05 \mathrm{~cm}$ separation & 459 \\
\hline Case 6 & $20 \times 15$ (center), $24 \times 15$ (two outer), 3 clusters, $8.01 \pm 0.06 \mathrm{~cm}$ separation & 462 \\
\hline Case 7 & $20 \times 14,3$ clusters, $4.46 \pm 0.10 \mathrm{~cm}$ separation & 449 \\
\hline Case $8^{4}$ & $19 \times 6,3$ clusters, $7.57 \pm 0.04 \mathrm{~cm}$ separation & 467 \\
\hline
\end{tabular}

NOTES: ${ }^{1}$ For three-cluster configurations, the first dimension is along the direction of the cluster placement. The second dimension is the width of facing sides, as shown in Figure 5 of OECD-NEA 1998, on p. 11 LCT001 . 
${ }^{2}$ The H/X ratio is the ratio of hydrogen to fissile material per unit cell. These values are from p. 9 of CRWMS M\&O 1999c.

${ }^{3}$ The cluster separation referenced was $8.41 \mathrm{~cm}$, but footnote (d) on p. 10 LCT-001 of OECD-NEA 1998, states that the cluster separation should be $0.762 \mathrm{~cm}$ less. Thus, $7.648 \mathrm{~cm}$ was represented in the MCNP case for the cluster separation.

${ }^{4}$ The cluster separation referenced was $7.57 \mathrm{~cm}$, but footnote (d) on p. 10 LCT-001 of OECD-NEA 1998, states that the cluster separation should be $0.762 \mathrm{~cm}$ less. Thus, $6.808 \mathrm{~cm}$ was represented in the MCNP case for the cluster separation.

\subsubsection{LEU Systems Typical of N-Reactor Fuel in the K Basin}

Three cases which analyzed a lattice of actual N-Reactor MKIA fuel elements were performed. The MKIA cases analyzed 101.2 fuel elements, 67.4 fuel elements, and 90.3 fuel elements with corresponding pitches of $7.112 \mathrm{~cm}, 7.874 \mathrm{~cm}$, and $8.636 \mathrm{~cm}$, respectively (p. 52, Wittekind 1992). The MKIA experiments were performed for three different lattice pitches resulting in three experimental values to achieve a $\mathrm{k}_{\mathrm{eff}}$ of unity. The lattice pitches and corresponding critical number of fuel elements are listed in Table 3.1-3. It should be noted that the MKIA experiments used $26.2 \mathrm{in}$. $(66.548 \mathrm{~cm})$ long fuel elements stacked two high for a $52.4 \mathrm{in}$. $(133.096 \mathrm{~cm})$ fuel column per lattice (p. 5, Brown et al. 1965) with 121 filled fuel lattices (p. 52, Wittekind 1992).

Table 3.1-3. MKIA Fuel Assembly Experiments

\begin{tabular}{|c|c|c|c|}
\hline $\begin{array}{c}\text { Experiment } \\
\text { identifier }\end{array}$ & Lattice pitch & $\begin{array}{c}\text { Critical number of fuel elements } \\
\text { experimentally determined }\end{array}$ & $\mathrm{H} / \mathrm{X}$ ratio \\
\hline SUBC2P8H & $7.112 \mathrm{~cm}$ & 101.2 & 994 \\
\hline SUBC3P1H & $7.874 \mathrm{~cm}$ & 67.4 & 1414 \\
\hline SUBC3P4H & $8.636 \mathrm{~cm}$ & 90.3 & 1876 \\
\hline
\end{tabular}

NOTE: ${ }^{1}$ Values are from $\mathrm{p} .11$ of CRWMS M\&O $1999 \mathrm{c}$

\subsubsection{Critical Configurations with Subcritical Clusters of 4.31 wt $\%$ Enriched $\mathrm{UO}_{2}$ Rods in Water with Reflecting Walls}

These three experiments were also performed at the PNL and were documented in Bierman et al. (1981) and Bierman and Clayton (1981). In these experiments three similar fuel assemblies were laterally surrounded by reflectors of different compositions. The fuel lattices in each critical experiment contained $4.31 \mathrm{wt} \%{ }^{235} \mathrm{U}$ enriched $\mathrm{UO}_{2}$ fuel rods on a square pitch of $1.892 \mathrm{~cm}$. The distinguishing characteristics of each experiment are given in Table 3.1-4. These critical experiments demonstrate the ability of MCNP to accurately predict the critical multiplication factor for configurations with different shielding materials used for reflectors.

Table 3.1-4. Differences in Experimental Configurations for Clusters of $2.35 \mathrm{wt} \% \mathrm{UO}_{2}$ Fuel Rods

\begin{tabular}{|c|c|c|}
\hline Experiment identifier & Reference & Reflector \\
\hline $\operatorname{exp5}$ & Bierman et al. 1981 & uranium \\
\hline $\operatorname{exp6}$ & Bierman et al. 1981 & lead \\
\hline $\operatorname{exp7}$ & Bierman and Clayton 1981 & stainless steel \\
\hline
\end{tabular}




\subsubsection{Critical Configurations with $4.31 \mathrm{wt} \%{ }^{235} \mathrm{U}$ Enriched $\mathrm{UO}_{2}$ Rods in Highly Borated Water Lattices}

This set of four experiments was performed at the PNL and documented by Durst et al. (1982). These experiments used $4.31 \mathrm{wt} \%{ }^{235} \mathrm{U}$ uniformly enriched $\mathrm{UO}_{2}$ fuel rods arranged in squarepitch, water-moderated lattices of different size with various amounts of boric acid in the moderator. The fuel rods were clad with aluminum and were loaded into polypropylene lattice templates fastened inside a plexiglass tank. The plexiglass tank was surrounded on all four sides by an unborated water reflector and was positioned on top of a plexiglass slab. The borated water was restricted to the water volume inside the plexiglass tank.

Rectangular critical arrays were constructed by sequentially filling rows of the lattice template starting at the plexiglass tank wall. The water level in the tank was held constant by removing an appropriate volume of water as each fuel rod was loaded. These experiments were denoted as "exp8" through "exp11."

\subsubsection{Critical Configurations with Neutron Flux Traps}

Pacific Northwest Laboratories performed experiments studying the effect of neutron flux traps on criticality. These experiments were documented by Bierman (1990) and served as the source for two configurations modeled with MCNP. These two critical experiments were each composed of four fuel rod arrays arranged in a square and separated by a neutron flux trap region. Each fuel lattice in a given configuration was nearly equal in size. Two polypropylene lattice templates were used to position the fuel rods. The fuel rods were composed of aluminumclad $4.31 \mathrm{wt} \%{ }^{235} \mathrm{U}$ enriched $\mathrm{UO}_{2}$ fuel. The neutron flux traps were created by positioning two plates of Boral ${ }^{\mathrm{TM}}$ between interacting faces of each fuel lattice. The experimental configurations were moderated and closely reflected by full-density water. These experiments are denoted as "exp12" and "exp13."

\subsubsection{Electric Power Research Institute 2.35 wt\% Enriched Light Water Reactor Fuel Critical Configurations}

Criticality experiments were sponsored by Electric Power Research Institute (EPRI) for light water reactor fuel configurations. These were documented by EPRI and subsequently described by Dehart and Bowman (1995). Two critical experiment configurations composed of watermoderated lattices of $2.35 \mathrm{wt} \%$ enriched $\mathrm{UO}_{2}$ fuel rods were modeled with MCNP. The fuel rods were supported in a core structure composed of "eggcrate" type lattice plates with an upper lead shield. The configuration was closely reflected by full-density water laterally and below the fuel. These experiments were designated as "exp14" and "exp15."

\subsubsection{Water-Moderated, Lead-Reflected Uranium Dioxide Rod Array}

OECD-NEA (1998) LEU-COMP-THERM-027 documents a series of four experiments involving lead-reflected, water-moderated arrays of low-enriched $\mathrm{UO}_{2}$ fuel rods. The experiments were subcritical approaches extrapolated to critical; the multiplication factor reached was very close to 1.000 (within $0.1 \%$ ). The experiments were tests of the lead reflector effect. Only the first case was evaluated in CRWMS M\&O (1999d). This case consisted of a 14 x 14 array of $4.74 \mathrm{wt} \%$ enriched $\mathrm{UO}_{2}$ fuel rods reflected on four sides by $30-\mathrm{cm}$-thick lead 
reflectors with no water gap between the array and the lead reflectors. This experiment was denoted as lct27-1.

\subsubsection{Laboratory Critical Experiments from the Urania-Gadolinia: Nuclear Model Development and Critical Experiment Benchmark Report}

A number of critical experiments were performed by Babcock and Wilcox for urania fuel incorporating gadolinia as an integral burnable absorber. These experiments were documented in Newman (1984). The configurations modeled with MCNP included critical configurations containing arrangements of $2.46 \mathrm{wt} \%{ }^{235} \mathrm{U}$ enriched $\mathrm{UO}_{2}$ fuel rods, $4.02 \mathrm{wt} \%{ }^{235} \mathrm{U}$ enriched $\mathrm{UO}_{2}$ fuel rods, combination $4 \mathrm{wt} \% \mathrm{Gd}_{2} \mathrm{O}_{3}$ and $96 \mathrm{wt} \%$ (1.944 wt $\%{ }^{235} \mathrm{U}$ enriched) $\mathrm{UO}_{2}$ fuel rods, $\mathrm{Ag}$ In-Cd absorber rods, and $\mathrm{B}_{4} \mathrm{C}$ absorber rods. The fuel rods were supported by a top and bottom aluminum "eggcrate" type grid plate. The fuel rods rested on an aluminum base plate. The central $45 \times 45$ array of rod lattice cells was separated into nine $15 \times 15$ arrays of rod lattice cells. These arrays were intended to simulate pressurized water reactor fuel assembly lattices.

Descriptions of the experimental configurations are shown in Table 3.1-5.

Table 3.1-5. Urania-Gadolinia Critical Experiment Descriptions

\begin{tabular}{|c|c|c|c|c|c|c|c|}
\hline $\begin{array}{l}\text { Exp. } \\
I^{\mathrm{a}}\end{array}$ & $\begin{array}{c}\text { Number } \\
\text { of } 2.46 \\
\text { wt } \% \\
{ }^{235} \mathrm{U} \text { fuel } \\
\text { rods }\end{array}$ & $\begin{array}{c}\text { Number } \\
\text { of } 4.02 \\
\text { wt } \% \\
{ }^{235} \mathrm{U} \text { fuel } \\
\text { rods }\end{array}$ & $\begin{array}{l}\text { Number } \\
\text { of } \mathrm{Gd}_{2} \mathrm{O}_{3} \\
\text { fuel rods }\end{array}$ & $\begin{array}{c}\text { Number } \\
\text { of } B_{4} C \\
\text { rods }\end{array}$ & $\begin{array}{l}\text { Number } \\
\text { of } \\
\text { Ag-In-Cd } \\
\text { rods }\end{array}$ & $\begin{array}{l}\text { Number } \\
\text { of } \\
\text { void rods }\end{array}$ & $\begin{array}{c}\text { Number } \\
\text { of water } \\
\text { holes }\end{array}$ \\
\hline ugd1 & 4808 & 0 & 0 & 0 & 0 & 0 & 153 \\
\hline ugd2 & 4808 & 0 & 0 & 0 & 16 & 0 & 137 \\
\hline ugd3 & 4788 & 0 & 20 & 0 & 0 & 0 & 153 \\
\hline ugd4 & 4788 & 0 & 20 & 0 & 16 & 0 & 137 \\
\hline ugd5 & 4780 & 0 & 28 & 0 & 0 & 0 & 153 \\
\hline ugd6 & 4780 & 0 & 28 & 0 & 16 & 0 & 137 \\
\hline ugd 7 & 4780 & 0 & $\begin{array}{c}28 \\
\text { (Annular) }\end{array}$ & 0 & 0 & 0 & 153 \\
\hline ugd8 & 4772 & 0 & 36 & 0 & 0 & 0 & 153 \\
\hline ugd9 & 4772 & 0 & 36 & 0 & 16 & 0 & 137 \\
\hline ugd10 & 4772 & 0 & 36 & 0 & 0 & 16 & 137 \\
\hline ugd12 & 3920 & 888 & 0 & 0 & 0 & 0 & 153 \\
\hline ugd13 & 3920 & 888 & 0 & 16 & 0 & 0 & 137 \\
\hline ugd14 & 3920 & 860 & 28 & 0 & 0 & 0 & 153 \\
\hline ugd15 & 3920 & 860 & 28 & 16 & 0 & 0 & 137 \\
\hline ugd16 & 3920 & 852 & 36 & 0 & 0 & 0 & 153 \\
\hline ugd17 & 3920 & 852 & 36 & 16 & 0 & 0 & 137 \\
\hline ugd18 & 3676 & 944 & 0 & 0 & 0 & 0 & 180 \\
\hline ugd19 & 3676 & 928 & 16 & 0 & 0 & 0 & 180 \\
\hline ugd20 & 3676 & 912 & 32 & 0 & 0 & 0 & 180 \\
\hline
\end{tabular}

NOTE: ${ }^{\mathrm{I}} \mathrm{ID}=$ Identifier

\subsubsection{Saxton $\mathrm{UO}_{2}$ and $\mathrm{PuO}_{2}-\mathrm{UO}_{2}$ Critical Configurations}

Single- and multi-region uranium and plutonium oxide fueled cores, water moderated, clean, and borated, have been used in a series of critical experiments at the Westinghouse Reactor Evaluation Center in support of the Saxton Plutonium Program. In this series of experiments, 
criticality was achieved entirely by varying the water level inside the core tank. The fuel used in the experiments were $\mathrm{UO}_{2}$ fuel with $5.74 \mathrm{wt} \%{ }^{235} \mathrm{U}$ enrichment, and mixed oxide (MOX) fuel containing $6.6 \mathrm{wt} \% \mathrm{PuO}_{2}$ and natural enriched $\mathrm{UO}_{2}$ (p. A-1, Taylor 1965). This work was documented by Taylor (1965) and subsequently described by DeHart and Bowman (1995). This section includes eight single-region configurations and six multi-region configurations. The fuel rods were loaded into a single rectangular array for each critical experiment. The fuel rods were supported by three aluminum grid plates with holes for rod emplacement. The fuel rod type, pitch, array size, moderator height, and boron concentration were adjusted in each LCE. Table 3.1-6 presents a description of the various single-region experiments and Table 3.1-7 presents a description of the multi-region experiments.

Table 3.1-6. Saxton Single-Region Critical Configuration Parameters

\begin{tabular}{|c|c|c|c|c|}
\hline $\begin{array}{c}\text { Experiment } \\
\text { identifier }\end{array}$ & Fuel & Pitch $(\mathbf{c m})$ & $\begin{array}{c}\text { Core } \\
\text { configuration }\end{array}$ & $\begin{array}{c}\text { Critical water } \\
\text { height (cm) }\end{array}$ \\
\hline $\mathrm{ssr} 83$ & $\mathrm{UO}_{2}$ & 1.3208 & 449 cylindrical & 95.25 \\
\hline $\mathrm{ssr} 48$ & $\mathrm{UO}_{2}$ & 1.4224 & $19 \times 19$ square & 83.71 \\
\hline $\mathrm{ssr} 70$ & $\mathrm{MOX}$ & 1.3208 & $22 \times 23$ square & 84.56 \\
\hline $\mathrm{ssr} 57$ & $\mathrm{MOX}$ & 1.4224 & $19 \times 19$ square & 82.46 \\
\hline $\mathrm{ssr66}$ & $\mathrm{MOX}$ & 1.4224 & $21 \times 21$ square & 89.70 \\
\hline $\mathrm{ssr} 53$ & $\mathrm{MOX}$ & 1.8669 & $13 \times 13$ square & 70.11 \\
\hline $\mathrm{ssr} 74$ & $\mathrm{MOX}$ & 2.0117 & $12 \times 12$ square & 78.43 \\
\hline
\end{tabular}

Table 3.1-7. Saxton Multi-Region Critical Configuration Parameters

\begin{tabular}{|c|c|c|}
\hline $\begin{array}{c}\text { Experiment } \\
\text { identifier }\end{array}$ & Core configuration & $\begin{array}{c}\text { Critical water } \\
\text { height (cm) }\end{array}$ \\
\hline smr1 & $19 \times 19$ square: $11 \times 11$ MOX center region; $\mathrm{UO}_{2}$ outer region & 91.07 \\
\hline smr9 & $\begin{array}{c}19 \times 19 \text { square: } 11 \times 11 \mathrm{MOX} \text { center region; } \mathrm{UO}_{2} \text { outer region; } \mathrm{Al} \\
\text { plate at the fuel interface }\end{array}$ & 92.07 \\
\hline smr5 & $27 \times 27$ square: $19 \times 19 \cup_{2}$ center region; MOX outer region & 86.70 \\
\hline smr11 & $\begin{array}{c}27 \times 27 \text { square: } 19 \times 19 \mathrm{MOX} \text { center region; } \mathrm{UO}_{2} \text { outer region; water } \\
\text { slot at the region boundary }\end{array}$ & 99.80 \\
\hline smr12 & $\begin{array}{c}27 \times 27 \text { square: } 19 \times 19 \mathrm{MOX} \text { center region; } \mathrm{UO}_{2} \text { outer region; } \mathrm{Al} \\
\text { slab at the interface }\end{array}$ & 106.35 \\
\hline smr8 & $\begin{array}{c}27 \times 27 \text { square: } 19 \times 19 \mathrm{MOX} \text { center region; } \mathrm{UO}_{2} \text { outer region; } \mathrm{L} \\
\text { shaped } \mathrm{UO}_{2} \text { insert in } \mathrm{MOX} \text { region }\end{array}$ & 92.19 \\
\hline
\end{tabular}

\subsubsection{Critical Configurations Simulating Light Water Reactor Fuel in Close Proximity Water Storage}

Babcock and Wilcox performed experiments simulating neutron multiplication in pool storage racks. These were documented in Baldwin et al. (1979). Twenty such critical configurations, each containing a $3 \times 3$ array of $14 \times 14$ fuel rod assemblies, were modeled with MCNP. Two different methods were utilized to support the fuel assemblies in the critical experiment core. The first support method used top and bottom grid plates to hold the fuel rods in place. The second support method used a bottom grid plate and vertical alignment system consisting of locating bars and fastening plates. The gaps between assemblies contained a number $\mathrm{B}_{4} \mathrm{C}$ rods and water, stainless steel sheets and water, borated aluminum sheets and water, or only water. 
The critical experiment arrays were assembled in an aluminum core tank. The fuel rods were composed of $2.46 \mathrm{wt} \%{ }^{235} \mathrm{U}$ enriched $\mathrm{UO}_{2}$ clad in Type 6061 aluminum. The $\mathrm{B}_{4} \mathrm{C}$ rods were aluminum tubes filled with $\mathrm{B}_{4} \mathrm{C}$ powder. Six sets of borated aluminum sheets were used in the critical experiments. The soluble boron concentration and moderator heights were adjusted to obtain a critical configuration.

The key parameters which distinguish the twenty critical configurations are shown in Table 3.18.

Table 3.1-8. Close Proximity Critical Benchmark Characterization Parameters

\begin{tabular}{|c|c|c|c|}
\hline Experiment identifier & $\begin{array}{l}\text { Assembly spacing, } \\
\text { rod pitch }\end{array}$ & Number of $B_{4} C$ rods & $\begin{array}{l}\text { Metal between unit } \\
\text { assemblies }\end{array}$ \\
\hline core2 & 0 & 0 & $n / a^{2}$ \\
\hline core3 & 1 & 0 & n/a \\
\hline core4 & 1 & 84 & $n / a$ \\
\hline core5 & 2 & 64 & $n / a$ \\
\hline core6 & 2 & 64 & $n / a$ \\
\hline core7 & 3 & 34 & $n / a$ \\
\hline core 8 & 3 & 34 & $n / a$ \\
\hline core9 & 4 & 0 & $n / a$ \\
\hline core10 & 3 & $n / a$ & none \\
\hline core11 & 1 & $n / a$ & $S^{3}$ \\
\hline core12 & 2 & $n / a$ & SS \\
\hline core13 & 1 & $n / a$ & $\mathrm{~B} / \mathrm{Al}$ set 5 \\
\hline core14 & 1 & $n / a$ & $\mathrm{~B} / \mathrm{Al}$ set 4 \\
\hline core15 & 1 & n/a & B/Al set 3 \\
\hline core16 & 2 & $n / a$ & B/AI set 3 \\
\hline core17 & 1 & $n / a$ & B/Al set 2 \\
\hline core18 & 2 & $n / a$ & B/AI set 2 \\
\hline core19 & 1 & $n / a$ & $\mathrm{~B} / \mathrm{Al}$ set 1 \\
\hline core 20 & 2 & $n / a$ & $\mathrm{~B} / \mathrm{Al}$ set 1 \\
\hline core21 & 3 & $n / a$ & B/Al set 1 \\
\hline
\end{tabular}

NOTES: ' number of rod pitches

${ }^{2} \mathrm{n} / \mathrm{a}=$ not applicable

${ }^{3} \mathrm{SS}=$ stainless steel

\subsubsection{Electric Power Research Institute Mixed Oxide Critical Configurations}

DeHart and Bowman (1995) describe criticality tests with mixed oxide fuel performed for the Electric Power Research Institute. Six critical experiment configurations composed of unborated and borated water moderated lattices of $2 \mathrm{wt} \% \mathrm{PuO}_{2}\left(8 \mathrm{wt} \%{ }^{240} \mathrm{Pu}\right) / 98 \mathrm{wt} \% \mathrm{UO}_{2}$ (natural) fuel rods were modeled with MCNP. The fuel rods were clad with aluminum and were supported in a core structure composed of "eggcrate" type lattice plates with an upper lead shield. The configurations were closely reflected with full-density water laterally and below the core. These experiments are denoted as "exp22" through "exp27."

\subsubsection{Critical Triangular Lattice of $\mathrm{MOX} \& \mathrm{UO}_{2}$ Fuel Rods}

Bierman et al. (1984) documented critical experiments performed at PNL incorporating both urania and mixed-oxide (MOX) fuel rods in a triangular lattice. One such experiment, designated "exp34", contained a triangular lattice of uniformly distributed $\mathrm{PuO}_{2}-\mathrm{UO}_{2}$ and $\mathrm{UO}_{2}$ 
fuel rods. The fuel rods were placed in a uniform distribution with a $\mathrm{Pu} /{ }^{235} \mathrm{U}$ ratio approximating that of a 20,000 MWd/MTU burnup. Each $\mathrm{PuO}_{2}-\mathrm{UO}_{2}$ fuel rod was surrounded by six $\mathrm{UO}_{2}$ fuel rods with a triangular lattice pitch. The fuel rods were supported by three polypropylene lattice plates.

\subsubsection{TRIGA (Training, Research, Isotopes, General Atomics) Fuel Rod Experiments}

These benchmark experiments documented in Mele et al. (1994) used fresh stainless steel clad TRIGA fuel rods in a TRIGA Mark II reactor. The configuration was a cylindrical water filled reactor with an annular graphite reflector. The fuel elements were arranged in six concentric rings, and were made up of $20 \mathrm{wt} \%{ }^{235} \mathrm{U}$ mixed with zirconium hydride. The fuel had a 1.65 hydrogen-zirconium atom ratio. Two experiments of this type were evaluated and are identified as "tri17" and "tri18".

\subsubsection{SPERT-D Fuel Experiments}

Twenty-three critical experiments involving lattices of SPERT-D fuel elements were performed at Oak Ridge National Laboratories (ORNL). The fuel elements consisted of plates of uraniumaluminum alloy. Each fuel element contained approximately 300 grams (p. 1, OECD-NEA 1998, HEU-MET-THERM-006 [HMT-006]) of ${ }^{235} \mathrm{U}$ in 22 aluminum clad fuel plates. The average enrichment was $93.17 \mathrm{wt} \%{ }^{235} \mathrm{U}$ (p. 10, OECD-NEA 1998). Table 3.1-9 provides a listing of the various SPERT-D cases and the experiment identifiers. The reflector and moderator for cases 1 through 18 was demineralized water, and an aqueous solution of uranyl nitrate $\mathrm{U}(92.6) \mathrm{O}_{2}\left(\mathrm{NO}_{3}\right)_{2}$ in cases 19 through 23 (p. 10, OECD-NEA 1998, HMT-006).

Table 3.1-9. SPERT-D Fuel Element Critical Experiments

\begin{tabular}{|c|c|c|}
\hline $\begin{array}{c}\text { Experiment } \\
\text { identifier }\end{array}$ & Global description & $\begin{array}{c}\text { Reflector above fuel } \\
\text { (cm) (p. 23, OECD-NEA } \\
\text { 1998, HMT-006) }\end{array}$ \\
\hline spert1 & $4 \times 3.77$ lattice $, 4.63 \mathrm{~kg} \mathrm{U} U^{235}, 0.0$ in. spacing & 9.825 \\
\hline spert2 & $4 \times 3.16$ lattice, $3.87 \mathrm{~kg} \mathrm{U}^{235}, 0.25$ in. spacing & 12.8982 \\
\hline spert3 & 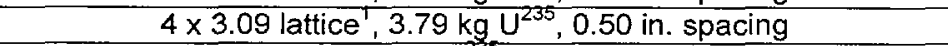 & 9.8401 \\
\hline spert4 & circular, $3.48 \mathrm{~kg} \mathrm{U}^{235}, 0.50$ in. spacing & 7.3136 \\
\hline spert5 & $4 \times 3.16$ lattice $, 3.87 \mathrm{~kg} \mathrm{U}^{235}, 0.75$ in. spacing & 17.21 \\
\hline spert6 & $4 \times 3.70$ lattice $, 4.54 \mathrm{~kg} \mathrm{U}^{235}, 1.00$ in. spacing & 13.853 \\
\hline spert7 & $5 \times 4.03$ lattice $, 6.16 \mathrm{~kg} \mathrm{U}^{235}, 1.25$ in. spacing & 13.0186 \\
\hline spert8 & $6 \times 5.34$ lattice $, 9.82 \mathrm{~kg} \mathrm{U}^{235}, 1.50$ in. spacing & 11.3984 \\
\hline spert9 & $7 \times 6.68$ lattice $, 6.16 \mathrm{~kg} \mathrm{U}^{235}, 1.60$ in. spacing & 12.0359 \\
\hline spert10 & $4 \times 3.2 \times 3$ lattice $, 11.78 \mathrm{~kg} \mathrm{U}^{235}, 0.0 \mathrm{in}$. spacing & 9.4309 \\
\hline spert11 & $3 \times 3.36 \times 3$ lattice $, 9.28 \mathrm{~kg} \mathrm{U}^{235}, 0.50$ in. spacing & 12.0994 \\
\hline spert12 & $4 \times 4 \times 3$ lattice $, 14.71 \mathrm{~kg} \mathrm{U}^{235}, 1.25$ in. spacing & 8.0 \\
\hline spert13 & slab $16 \times 2.32,11.37 \mathrm{~kg} \mathrm{U}^{235}, 1.25$ in. spacing & 11.6162 \\
\hline spert14 & slab $16 \times 3,14.71 \mathrm{~kg} \mathrm{U} U^{235}, 0.50$ in $/ 2.19$ in. spacing & 7.5728 \\
\hline spert15 & slab $16 \times 4,19.62 \mathrm{~kg} \mathrm{U}{ }^{235}, 0.50 \mathrm{in} . / 2.56 \mathrm{in}$. spacing & 10.75 \\
\hline spert16 & 2 slabs $16 \times 2,19.62 \mathrm{~kg} \mathrm{U}{ }^{235}, 0.50$ in. $/ 0.50$ in. $/ 6.37$ in. spacing & 12.7351 \\
\hline spert17 & slab $4 \times 5.0^{1}$ w/ Cd, $6.19 \mathrm{~kg} \mathrm{U}^{235}, 0.0$ in. $/ 0.75$ in. spacing & 10.7471 \\
\hline spert18 & slab $4 \times 7.04^{1} \mathrm{w} / \mathrm{Cd}, 8.64 \mathrm{~kg} \mathrm{U}{ }^{235}, 0.0$ in. $/ 0.75 \mathrm{in}$. spacing & 13.8573 \\
\hline spert19 & $\begin{array}{c}\text { U Nitrate }\left(3.99 \mathrm{~g} \mathrm{U}^{235} / \text { liter }\right) \& 3 \times 3.09,2.86 \mathrm{~kg} \mathrm{U}^{235}, 0.5 \mathrm{in} \text {. spacing, } \\
0.0 \mathrm{~g} \mathrm{~B} / \text { liter }\end{array}$ & 6.8208 \\
\hline spert20 & 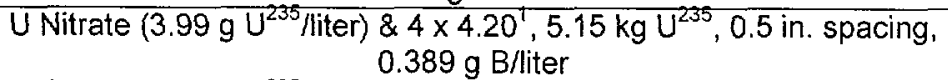 & 8.3311 \\
\hline spert21 & $\begin{aligned} \text { UNitrate }\left(3.99 \mathrm{~g} \mathrm{U}^{235} / \text { liter }\right) & \& 5 \times 4.41^{1}, 6.76 \mathrm{~kg} \mathrm{U}^{235}, 0.5 \mathrm{in} \text { spacing, } \\
& 0.579 \mathrm{~g} \mathrm{~B} / \text { liter }\end{aligned}$ & 4.6946 \\
\hline
\end{tabular}


Table 3.1-9. SPERT-D Fuel Element Critical Experiments

\begin{tabular}{|c|c|c|}
\hline $\begin{array}{l}\text { Experiment } \\
\text { identifier }\end{array}$ & Global description & $\begin{array}{c}\text { Reflector above fuel } \\
\text { (cm) (p. 23, OECD-NEA } \\
\text { 1998, HMT-006) }\end{array}$ \\
\hline spert22 & $\begin{array}{c}\text { U Nitrate }\left(3.99 \mathrm{~g} \mathrm{U}^{235} / \text { liter) } \& 6 \times 4.966^{\prime}, 8.90 \mathrm{~kg} \mathrm{U}^{235}, 0.5 \text { in. spacing, }\right. \\
0.773 \mathrm{~g} \mathrm{~B} / \text { liter }\end{array}$ & 5.5725 \\
\hline spert23 & $\begin{array}{c}\text { U Nitrate }\left(3.99 \mathrm{~g} \mathrm{U}^{235} / \text { liter) } \& 6 \times 5.55^{1}, 10.15 \mathrm{~kg} \mathrm{U}^{235}, 0.5 \text { in. spacing, }\right. \\
0.871 \mathrm{~g} \mathrm{B/liter}\end{array}$ & 7.7118 \\
\hline
\end{tabular}

NOTE: ' Dimensions of lattice (number of elements)

\subsubsection{Water-Moderated Hexagonally Pitched Lattices of Highly Enriched Fuel Rods of Cross-Shaped Cross Section}

A series of critical experiments with water moderated hexagonally pitched lattices of highly enriched fuel rods of cross-shaped cross section was performed over several years in the Russian Research Center (RRC) "Kurchatov Institute". Each of the experiments used $\mathrm{UO}_{2}$ plus copper fuel, and were taken from the benchmark compilation OECD-NEA (1998), Vol. II. These experiments were categorized under the HEU-Comp-Therm (HCT) class of experiments in the reference. The 28 experiments analyzed under this category consist of the following:

1) Fifteen critical two-zone lattice experiments corresponding to different combinations of inner and peripheral zones of cross-shaped fuel rods at two pitches. Descriptions for these experimental configurations and their experiment identifiers are presented in Table 3.1-10.

2) Four critical configurations of hexagonal lattices of fuel rods with $\mathrm{Gd}$ or $\mathrm{Sm}$ rods. These experiments consisted of double lattices of fuel rods and absorber rods containing $\mathrm{Gd}$ or Sm. Descriptions of these experimental configurations and their experiment identifiers are presented in Table 3.1-11.

3) One critical configuration of hexagonal pitched clusters of lattices of fuel rods with $\mathrm{Cu}$ rods. The configuration was arranged with a $5.2-\mathrm{mm}$ pitch and a total of 2257 fuel rods. In the reference, two cases were evaluated: one considered the fuel rod as a cylinder in a simplified model, and the other represented the fuel rod in a detailed cross-shaped model; only the detailed case is represented in this report.

4) Three critical configurations with uniform hexagonal lattices with pitch values of 5.6, 10.0, and $21.13 \mathrm{~mm}$. Descriptions for these experimental configurations and their experiment identifiers are presented in Table 3.1-12.

5) Three critical configurations with double hexagonal lattices of fuel rods and zirconium hydride rods. Descriptions for these experimental configurations and their experiment identifiers are presented in Table 3.1-13. In the reference, two sets of cases were evaluated: one considered the fuel rod as a cylinder in a simplified model, and the other represented a detailed cross-shaped fuel rod model; only the detailed cases are represented in this report.

6) Two critical configurations with double hexagonal lattices of fuel rods and boron carbide rods. Descriptions for these experimental configurations and their experiment identifiers are presented in Table 3.1-14. 
Table 3.1-10. Benchmarks for HCT-003 Class of Experiments

\begin{tabular}{|c|c|}
\hline $\begin{array}{l}\text { Experiment } \\
\text { identifier }\end{array}$ & Configuration description \\
\hline hct3-1 & $\begin{array}{l}\text { Center zone: } 12.2 \mathrm{~mm} \text { pitch, } 19 \text { rods } \\
\text { Outer zone: } 6.1 \mathrm{~mm} \text { pitch, } 1390 \text { rods }\end{array}$ \\
\hline hct3-2 & $\begin{array}{l}\text { Center zone: } 12.2 \mathrm{~mm} \text { pitch, } 61 \text { rods } \\
\text { Outer zone: } 6.1 \mathrm{~mm} \text { pitch, } 1182 \text { rods }\end{array}$ \\
\hline het3-3 & $\begin{array}{c}\text { Center zone: } 12.2 \mathrm{~mm} \text { pitch, } 121 \text { rods } \\
\text { Outer zone: } 6.1 \mathrm{~mm} \text { pitch, } 897 \text { rods }\end{array}$ \\
\hline hct3-4 & $\begin{array}{l}\text { Center zone: } 12.2 \mathrm{~mm} \text { pitch, } 199 \text { rods } \\
\text { Outer zone: } 6.1 \mathrm{~mm} \text { pitch, } 577 \text { rods }\end{array}$ \\
\hline hct3-5 & $\begin{array}{c}\text { Center zone: } 12.2 \mathrm{~mm} \text { pitch, } 271 \text { rods } \\
\text { Outer zone: } 6.1 \mathrm{~mm} \text { pitch, } 325 \text { rods }\end{array}$ \\
\hline hat3-6 & $\begin{array}{l}\text { Center zone: } 6.1 \mathrm{~mm} \text { pitch, } 1099 \text { rods } \\
\text { Outer zone: } 12.2 \mathrm{~mm} \text { pitch, } 167 \text { rods }\end{array}$ \\
\hline het3-7 & $\begin{array}{l}\text { Center zone: } 6.1 \mathrm{~mm} \text { pitch, } 793 \text { rods } \\
\text { Outer zone: } 12.2 \mathrm{~mm} \text { pitch, } 250 \text { rods }\end{array}$ \\
\hline het3-8 & $\begin{array}{l}\text { Center zone: } 6.1 \mathrm{~mm} \text { pitch, } 757 \text { rods } \\
\text { Outer zone: } 12.2 \mathrm{~mm} \text { pitch, } 249 \text { rods }\end{array}$ \\
\hline $\operatorname{hct} 3-9$ & $\begin{array}{l}\text { Center zone: } 6.1 \mathrm{~mm} \text { pitch, } 445 \text { rods } \\
\text { Outer zone: } 12.2 \mathrm{~mm} \text { pitch, } 319 \text { rods }\end{array}$ \\
\hline het310 & $\begin{array}{l}\text { Center zone: } 6.1 \mathrm{~mm} \text { pitch, } 217 \text { rods } \\
\text { Outer zone: } 12.2 \mathrm{~mm} \text { pitch, } 372 \text { rods }\end{array}$ \\
\hline het311 & $\begin{array}{l}\text { Center zone: } 6.1 \mathrm{~mm} \text { pitch, } 85 \text { rods } \\
\text { Outer zone: } 12.2 \mathrm{~mm} \text { pitch, } 415 \text { rods }\end{array}$ \\
\hline hct312 & $\begin{array}{c}\text { Center zone: } 18.3 \mathrm{~mm} \text { pitch, } 121 \text { rods } \\
\text { Outer zone: } 6.1 \mathrm{~mm} \text { pitch, } 985 \text { rods }\end{array}$ \\
\hline $\operatorname{hct} 313$ & $\begin{array}{c}\text { Center zone: } 18.3 \mathrm{~mm} \text { pitch, } 301 \text { rods } \\
\text { Outer zone: } 6.1 \mathrm{~mm} \text { pitch, } 426 \text { rods }\end{array}$ \\
\hline het314 & $\begin{array}{l}\text { Center zone: } 6.1 \mathrm{~mm} \text { pitch, } 763 \text { rods } \\
\text { Outer zone: } 18.3 \mathrm{~mm} \text { pitch, } 186 \text { rods }\end{array}$ \\
\hline het315 & $\begin{array}{l}\text { Center zone: } 6.1 \mathrm{~mm} \text { pitch, } 337 \text { rods } \\
\text { Outer zone: } 18.3 \mathrm{~mm} \text { pitch, } 325 \text { rods }\end{array}$ \\
\hline
\end{tabular}

Table 3.1-11. Benchmarks for HCT-004 Class of Experiments

\begin{tabular}{|c|c|}
\hline $\begin{array}{c}\text { Experiment } \\
\text { identifier }\end{array}$ & Configuration description \\
\hline hct4-1 & $106 \mathrm{Gd}$ rods on $27.54 \mathrm{~mm}$ pitch, 2760 fuel rods \\
\hline hct4-2 & $55 \mathrm{Gd}$ rods on $36.72 \mathrm{~mm}$ pitch, 2520 fuel rods \\
\hline hct4-3 & $121 \mathrm{Sm}$ rods on $27.54 \mathrm{~mm}$ pitch, 3198 fuel rods \\
\hline hct4-4 & $58 \mathrm{Gd}$ rods on $36.72 \mathrm{~mm}$ pitch, 2727 fuel rods \\
\hline
\end{tabular}

Table 3.1-12. Benchmarks for HCT-006 Class of Experiments

\begin{tabular}{|c|c|}
\hline $\begin{array}{c}\text { Experiment } \\
\text { identifier }\end{array}$ & Configuration description \\
\hline hct6-t1 & 1819 fuel rods on a $5.6 \mathrm{~mm}$ pitch \\
\hline hct6-t2 & 457 fuel rods on a $10.0 \mathrm{~mm}$ pitch \\
\hline hct6-t3 & 554 fuel rods on a $21.13 \mathrm{~mm}$ pitch \\
\hline
\end{tabular}


Table 3.1-13. Benchmarks for HCT-007 Class of Experiments

\begin{tabular}{|c|c|}
\hline $\begin{array}{c}\text { Experiment } \\
\text { identifier }\end{array}$ & Configuration description \\
\hline hct7-4 & $523 \mathrm{Zr}$ rods on $10.5655 \mathrm{~mm}$ pitch, 1064 fuel rods \\
\hline hct7-5 & $121 \mathrm{Zr}$ rods on $21.1310 \mathrm{~mm}$ pitch, 1400 fuel rods \\
\hline hct7-6 & $31 \mathrm{Zr}$ rods on $42.2620 \mathrm{~mm}$ pitch, 1484 fuel rods \\
\hline
\end{tabular}

Table 3.1-14. Benchmarks for HCT-008 Class of Experiments

\begin{tabular}{|c|c|}
\hline $\begin{array}{c}\text { Experiment } \\
\text { identifier }\end{array}$ & Configuration description \\
\hline hct8-1 & $217 \mathrm{~B}_{4} \mathrm{C}$ rods $(1.0 \mathrm{~g} \mathrm{~B} / \mathrm{rod})$ on $21.2 \mathrm{~mm}$ pitch, 3460 fuel rods \\
\hline hct8-2 & $169 \mathrm{~B}_{4} \mathrm{C}$ rods $(3.5 \mathrm{~g}$ B/rod $)$ on $26.5 \mathrm{~mm}$ pitch, 4130 fuel rods \\
\hline
\end{tabular}

\subsubsection{Critical Experiments of EBOR Fuel Pins in Water}

Twenty-one critical experiments involving lattices of EBOR (Experimental Beryllium Oxide Reactor) fuel pins were performed in 1967 at ORNL. The fuel pins consisted of compressed ceramic pellets contained in Hastelloy X-280 tubes. The pellets were a homogeneous mixture of $\mathrm{U}(62.4) \mathrm{O}_{2}$ and $\mathrm{BeO}$. Two sets of experiments were conducted. The first set of experiments (total of 15 experiments) consisted of EBOR fuel pins arranged in various lattice configurations moderated and reflected by water (p. 8, OECD-NEA 1998, HEU-COMP-THERM-010 [HCT010]). The second set (6 experiments) consisted of EBOR fuel pins arranged in various lattice configurations with boron and/or with uranyl nitrate in the water (p. 14, OECD-NEA 1998, HCT-010). Experimental configuration descriptions and identifiers are presented in Table 3.115.

Table 3.1-15. Benchmarks for HCT-010 Class of Experiments

\begin{tabular}{|c|c|c|c|c|}
\hline $\begin{array}{l}\text { Experiment } \\
\text { identifier }\end{array}$ & $\begin{array}{c}\text { Surface } \\
\text { separation } \\
\text { (cm) }\end{array}$ & $\begin{array}{c}\text { Critical } \\
\text { number of } \\
\text { pins }\end{array}$ & $\begin{array}{l}\text { Critical height of } \\
\text { solution above } \\
\text { the fuel in the fuel } \\
\text { tank (cm) }\end{array}$ & Solution inside the core \\
\hline hct101 & 0.290 & 222 & 15.2000 & Water \\
\hline hct102 & 0.290 & 223 & -50.3000 & Water \\
\hline hct103 & 0.536 & $13 \overline{8}$ & 30.8000 & Water \\
\hline hct104 & 0.790 & 102 & -21.3000 & Water \\
\hline hct105 & 1.046 & 85 & 15.2000 & Water \\
\hline het106 & 1.046 & 86 & -60.8000 & Water \\
\hline hct107 & 1.323 & 78 & 15.2000 & Water \\
\hline hct108 & 1.323 & 79 & -39.0000 & Water \\
\hline hat109 & 1.300 & 77 & -3.90000 & Water \\
\hline hct110 & 1.554 & 75 & 15.2000 & Water \\
\hline hot111 & 1.554 & 76 & -61.3000 & Water \\
\hline hct112 & 1.826 & 77 & -43.2000 & Water \\
\hline hat113 & 2.042 & 83 & -34.1000 & Water \\
\hline hct114 & $\begin{array}{l}1.544 \\
1.585^{b} \\
\end{array}$ & 96 & -10.4000 & Water \\
\hline hot115 & 1.6477 & 75 & -12.2000 & Water \\
\hline hat116 & 1.5478 & 99 & 19.3675 & Water \\
\hline hot117 & 1.5478 & 114 & 19.3675 & Aqueous solution of boron \\
\hline het118 & 1.5478 & 113 & 19.3675 & Aqueous solution of boron \\
\hline het119 & 1.5478 & 133 & 19.3675 & Aqueous solution of boron \\
\hline
\end{tabular}


Table 3.1-15. Benchmarks for HCT-010 Class of Experiments

\begin{tabular}{|c|c|c|c|c|}
\hline $\begin{array}{c}\text { Experiment } \\
\text { identifier }\end{array}$ & $\begin{array}{c}\text { Surface } \\
\text { separation } \\
(\mathbf{c m})\end{array}$ & $\begin{array}{c}\text { Critical } \\
\text { number of } \\
\text { pins }\end{array}$ & $\begin{array}{c}\text { Critical height of } \\
\text { solution above } \\
\text { the fuel in the fuel } \\
\text { tank }(\mathbf{c m})^{\mathbf{a}}\end{array}$ & Solution inside the core \\
\hline hct120 & 1.5478 & 83 & 19.3675 & Aqueous solution of uranyl nitrate \\
\hline hct121 & 1.5478 & 133 & 19.3675 & $\begin{array}{c}\text { Aqueous solution of uranyl nitrate } \\
\text { and boron }\end{array}$ \\
\hline
\end{tabular}

NOTES: ${ }^{2}$ Negative water heights refer to distance below top of fuel.

${ }^{b}$ The average surface separation was $1.544 \mathrm{~cm}$ between pins in the 16-pin direction and $1.585 \mathrm{~cm}$ in the 6pin direction.

\subsubsection{Intermediate Heterogeneous Assembly with Highly Enriched Uranium Dioxide and Sand/Water Radial Reflector}

An experiment was performed at the RRC "Kurchatov Institute" to investigate accidental sand and water immersion criticality safety of the thermionic intermediate reactor-converter with highly enriched fuel (approximately $96 \%{ }^{235} \mathrm{U}$ ), zirconium hydride moderator, and end beryllium reflectors (p. 1, OECD-NEA 1998, HEU-COMP-INTER-002 HCI-002). Described in this category are five configurations of the critical assemblies simulating water ingress into different reactor cavities, as well as surrounding the reactor with sand and water. The experimental descriptions of each configuration are presented in Table 3.1-16. Figure 3.1-1 illustrates the thermionic intermediate reactor as simulated. In configurations 1 and 2, wet sand is the reflector material and the rotating drums are filled with wet sand. All cavities are filled with water. The number of drums and the position of the control drums vary. In configurations 3,4 , and 5 , the drum channels were removed, water is the radial reflector, and the number of drums and their positions vary.

Table 3.1-16. Benchmarks for $\mathrm{HCl}-002$ Class of Experiments

\begin{tabular}{|c|c|c|c|c|}
\hline \multirow[b]{2}{*}{$\begin{array}{l}\text { Experiment } \\
\text { identifier }\end{array}$} & \multicolumn{2}{|c|}{ Material } & \multicolumn{2}{|r|}{ Rotating drums } \\
\hline & $\begin{array}{c}\text { Radial } \\
\text { reflector }\end{array}$ & $\begin{array}{c}\text { Core } \\
\text { cavities }\end{array}$ & $\begin{array}{c}\text { Total } \\
\text { number }\end{array}$ & $\begin{array}{l}\text { Position in } \\
\text { assemblies }\end{array}$ \\
\hline hci2-1 & $\begin{array}{r}\mathrm{SiO}_{2} \\
+\mathrm{H}_{2} \mathrm{O} \\
\end{array}$ & $\mathrm{H}_{2} \mathrm{O}$ & 12 & $\begin{array}{c}C D-5, \varphi=36^{\circ} \\
\mathrm{CD}-1 \uparrow, \mathrm{CD}-3 \downarrow, \mathrm{CD}-6 \downarrow, \text { the other } \mathrm{CD} \text { and all SD } \uparrow\end{array}$ \\
\hline hci2-2 & $\begin{array}{r}\mathrm{SiO}_{2} \\
+\mathrm{H}_{2} \mathrm{O}\end{array}$ & $\mathrm{H}_{2} \mathrm{O}$ & 11 & $\begin{array}{c}\mathrm{CD}-5, \varphi=121^{\circ} \\
\text { CD-3 removed, CD-1, } 2,4,6 \downarrow, \mathrm{CD}-6 \downarrow \text {, all SD } \uparrow\end{array}$ \\
\hline hci2-3 & $\mathrm{H}_{2} \mathrm{O}$ & $\mathrm{H}_{2} \mathrm{O}$ & 12 & $\begin{array}{c}C D-5, \varphi=119.5^{\circ} \\
\text { the other } C D \text { and all } S D \uparrow\end{array}$ \\
\hline hci2-4 & $\mathrm{H}_{2} \mathrm{O}$ & $\mathrm{H}_{2} \mathrm{O}$ & 11 & $\begin{array}{c}C D-5, \varphi=95.5^{\circ} \\
\text { CD-3 removed, the other } C D \text { and all } S D \uparrow\end{array}$ \\
\hline hci2-5 & $\mathrm{H}_{2} \mathrm{O}$ & $\mathrm{H}_{2} \mathrm{O}$ & 10 & $\begin{array}{l}C D-5, \varphi=76^{\circ} \\
C D-3 \text { and } S D-3 \text { removed, } \\
\text { the other } C D \text { and all SD } \uparrow\end{array}$ \\
\hline
\end{tabular}

NOTES: ${ }^{1} \uparrow$-Control drums turned out $\left(\varphi=180^{\circ}\right)$,

$\downarrow$-Control drums turned in $\left(\varphi=0^{\circ}\right)$,

Rotation angle $\varphi$ is shown in Figure 3.1-1. 


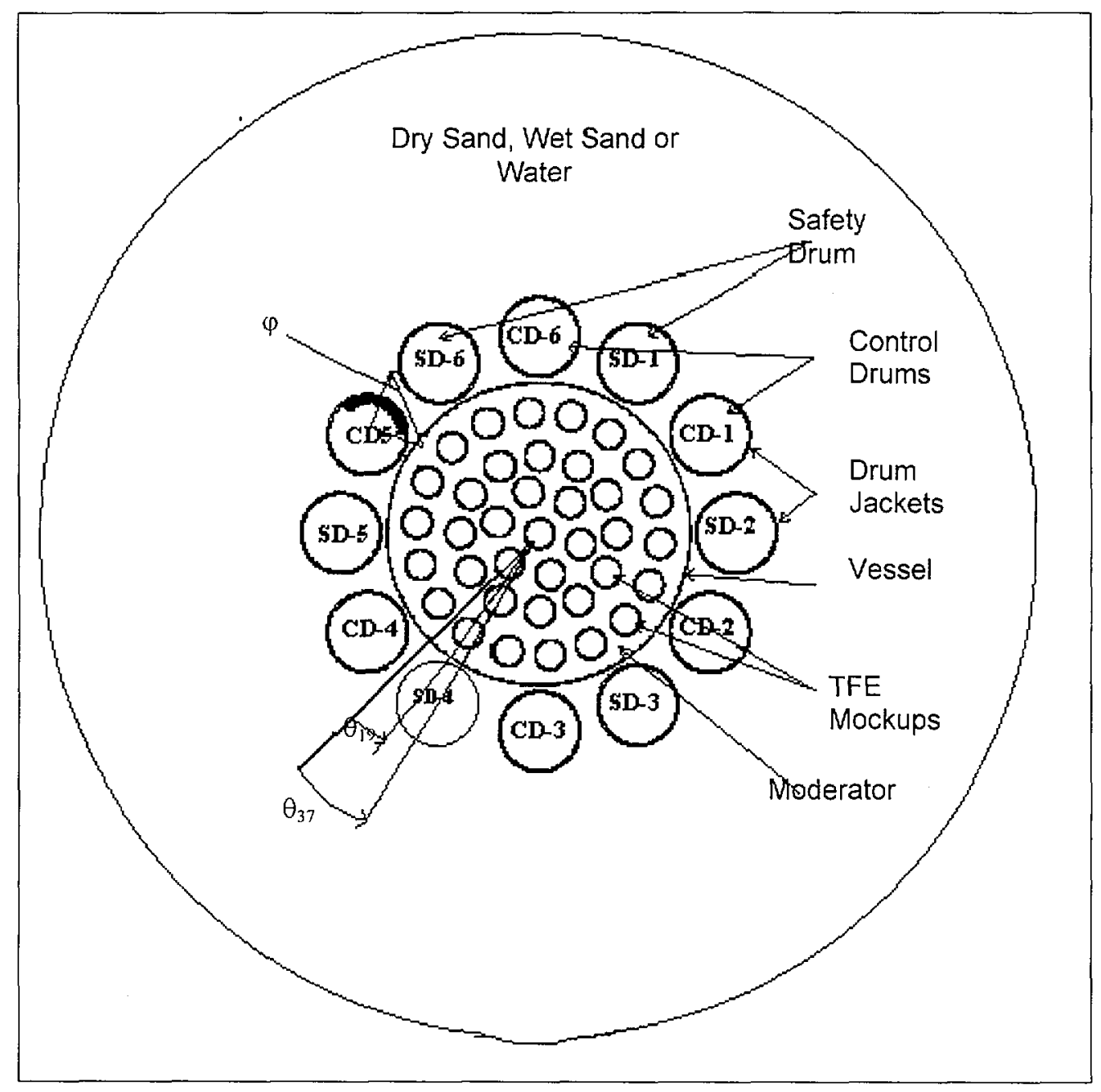

Figure 3.1-1. Cross Section of the Critical Assembly Representation Through the Core Center ( $\varphi$ is the angle of the drum rotation) (p. 3, OECD-NEA [1998], $\mathrm{HCl}-002$ )

\subsubsection{FFTF Fuel Pin Array Experiments}

These experiments were from predicted critical configurations extrapolated from near critical experiments performed by Bierman with plutonium oxide-uranium oxide fuel pins containing about $20 \mathrm{wt} \%$ plutonium with light water moderation and reflection (p. 1, OECD-NEA 1998, MIX-COMP-THERM-001 [MCT-001]). Six experiments were evaluated under this classification. These experiments were performed at the PNL Critical Mass Laboratory. The experimental configuration was comprised of an array of fast test reactor fuel pins within a large tank containing water. An axial description of the experimental arrangement is shown on page 4 of OECD-NEA (1998), MCT-001. In the case, the steel grids were replaced with polypropylene grids (p. 144, Bierman et al. 1979). Various lattice pitches were used in the array, resulting in different numbers of fuel rods being required to obtain criticality. The fuel used for the experimental program was a mixture of $\mathrm{PuO}_{2}$ and $\mathrm{UO}_{2}$, with the pins comprised of either 19.84 or $24.39 \mathrm{wt} \%$ plutonium (p. 141, Bierman et al. 1979). The plutonium contained $11.5 \mathrm{wt} \%$ ${ }^{240} \mathrm{Pu}$, and the uranium in the $\mathrm{PuO}_{2}-\mathrm{UO}_{2}$ mixture was natural uranium. The remainder of the pin consisted of end-caps, plenum, and other types of hardware (e.g., natural $\mathrm{UO}_{2}$ insulators and 
Inconel reflectors). Table 3.1-17 provides a brief description of these experiments along with their experiment identifier names.

Table 3.1-17. FFTF Bierman Array Critical Experiments

\begin{tabular}{|c|c|}
\hline Experiment identifier & Configuration description \\
\hline ffff001 & 18 pin lattice width, $1.2588 \mathrm{~cm}$ lattice spacing, 279 total pins \\
\hline ffff003r & 36 pin lattice width, $0.7671 \mathrm{~cm}$ lattice spacing, 1037 total pins \\
\hline fftf004 & 18 pin lattice width, $1.5342 \mathrm{~cm}$ lattice spacing, 205 total pins \\
\hline fftf005 & 28 pin lattice width, $0.9525 \mathrm{~cm}$ lattice spacing, 605 total pins \\
\hline fftf006 & 14 pin lattice width, $1.9050 \mathrm{~cm}$ lattice spacing, 162 total pins \\
\hline fftf029 & 28 pin lattice width, $0.9677 \mathrm{~cm}$ lattice spacing, 580 total pins \\
\hline
\end{tabular}

\subsubsection{High Enriched Uranium Metal Fast (HMF) Systems}

Reactivity calculations involving Fast Metal Fuel are presented in this section. In the two following sections, a series of critical experiments performed by the Institute for Experimental Physics of the Russian Federal Nuclear Center at Arzamas-16 and the Institute for Technical Physics of the Russian Federal Nuclear Center at Chelyabinsk-70 are described. Detailed experimental configurations and material compositions for these experiments are included in OECD-NEA (1998). The series of experiments studied in this report include uranium metal systems of intermediate enrichment, high enrichment, and plutonium systems reflected by the following materials: depleted uranium, steel, aluminum, graphite, and polyethylene. An experiment identifier for each configuration is provided for subsequent reference in this document in Tables 3.1-18 and 3.1-19.

Table 3.1-18. HMF Russian Criticality Safety Benchmark Experiments

\begin{tabular}{|c|c|c|c|c|c|c|}
\hline \multirow{2}{*}{$\begin{array}{l}\text { Reference } \\
\text { location }\end{array}$} & \multirow{2}{*}{${ }^{235} \mathrm{U} w t \%$} & \multicolumn{2}{|c|}{$\begin{array}{c}\text { Core dimensions } \\
(\mathrm{cm})\end{array}$} & \multirow{2}{*}{$\begin{array}{l}\text { Reflector } \\
\text { material }\end{array}$} & \multirow{2}{*}{$\begin{array}{l}\text { Reflector } \\
\text { thickness } \\
\text { (cm) }\end{array}$} & \multirow{2}{*}{ Experiment identifier } \\
\hline & & Radius & Height & & & \\
\hline HEU-MET-FAST-001 & 93.71 & 8.74 & -- & None & -- & HMF1G \\
\hline HEU-MET-FAST-003 & 93.5 & 6.463 & -- & Nickel & 20.32 & $\mathrm{HMF} 3 \mathrm{Ni}$ \\
\hline HEU-MET-FAST-008 & 90 & 10.150 & -- & None & -- & HMF8 \\
\hline HEU-MET-FAST-011 & 90 & 7.550 & -- & Polyethylene & 13.230 & HMF11 \\
\hline HEU-MET-FAST-012 & 90 & 9.150 & -- & Aluminum & $\begin{array}{l}0.850 \\
2.850\end{array}$ & HMF12 \\
\hline HEU-MET-FAST-013 & 90 & 8.350 & -- & Steel & 3.650 & HMF13 \\
\hline HEU-MET-FAST-014 & 90 & 7.750 & -- & Depleted U & 4.650 & HMF14 \\
\hline HEU-MET-FAST-015 & 96 & 9.995 & 11.130 & None & -- & HMF15 \\
\hline HEU-MET-FÁST-018 & 90 & 9.150 & -- & None & -- & HMF18 \\
\hline HEU-MET-FAST-019 & 90 & 9.150 & -- & Graphite & 3.450 & HMF19 \\
\hline HEU-MET-FAST-020 & 90 & 8.350 & -- & Polyethylene & 1.450 & HMF2O \\
\hline HEU-MET-FAST-021 & 90 & 7.550 & -- & Steel & 9.700 & HMF21 \\
\hline HEU-MET-FAST-022 & 90 & 8.350 & -- & Duralumin & 3.900 & HMF22 \\
\hline HEU-MET-FAST-024 & 90 & 7.550 & -- & $\begin{array}{c}\text { Steel, } \\
\text { polyethylene }\end{array}$ & $\begin{array}{l}0.850 \\
2.850\end{array}$ & HMF24 \\
\hline HEU-MET-FAST-028 & 93.27 & 6.116 & -- & $\begin{array}{l}\text { Natural } \\
\text { uranium }\end{array}$ & 18.009 & HMF28 \\
\hline
\end{tabular}




\subsubsection{Plutonium Metal Fast (PMF) Systems}

Table 3.1-19. PMF Russian Criticality Safety Benchmark Experiments

\begin{tabular}{|c|c|c|c|c|c|c|}
\hline \multirow{2}{*}{$\begin{array}{c}\text { Handbook } \\
\text { identifier }\end{array}$} & \multirow{2}{*}{$\begin{array}{c}{ }_{239} \mathbf{P u} \\
\text { at\% }\end{array}$} & \multicolumn{2}{|c|}{$\begin{array}{c}\text { Core dimensions } \\
(\mathbf{c m})\end{array}$} & \multirow{2}{*}{$\begin{array}{c}\text { Reflector } \\
\text { material }\end{array}$} & $\begin{array}{c}\text { Reflector } \\
\text { thickness (cm) }\end{array}$ & Case name \\
\cline { 3 - 5 } & & Radius & Height & & & \\
\hline PU-MET-FAST-020 & 89 & 5.350 & -- & Depleted U & 7.650 & PMF20 \\
\hline PU-MET-FAST-022 & 98 & 6.670 & -- & None & -- & PMF22 \\
\hline PU-MET-FAST-023 & 98 & 6.000 & -- & Graphite & 2.350 & PMF23 \\
\hline PU-MET-FAST-024 & 98 & 6.000 & -- & Polyethylene & 1.550 & PMF24 \\
\hline PU-MET-FAST-025 & 98 & 6.000 & -- & Steel & 1.550 & PMF25 \\
\hline PU-MET-FAST-026 & 98 & 5.350 & -- & Steel & 11.900 & PMF26 \\
\hline PU-MET-FAST-027 & 89 & 5.350 & -- & Polyethylene & 5.580 & PMF27 \\
\hline PU-MET-FAST-028 & 89 & 5.350 & -- & Steel & 19.650 & PMF28 \\
\hline PU-MET-FAST-029 & 88 & 6.670 & -- & None & -- & PMF29 \\
\hline PU-MET-FAST-030 & 88 & 4.660 & -- & Graphite & 4.490 & PMF30 \\
\hline PU-MET-FAST-031 & 88 & 4.660 & -- & Polyethylene & 3.690 & PMF31 \\
\hline PU-MET-FAST-032 & 88 & 4.660 & -- & Steel & 4.490 & PMF32 \\
\hline
\end{tabular}

Volume I, OECD-NEA 1998

NOTE: ' at $\%=$ atom percent

\subsubsection{Intermediate Enriched Uranium Metal Fast (IMF) Systems}

\subsubsection{The Early Jemima Experiments: Bare Cylindrical Configurations of Enriched and Natural Uranium}

The early Jemima experiments, performed at the Pajarito critical assembly facility at Los Alamos (1952-1954), was to determine critical conditions for bare uranium cylinders of intermediate enrichment. Vertical cylindrical columns were constructed by stacking thin disks of enriched uranium (Oralloy, or Oy, $93.4 \mathrm{wt} \%{ }^{235} \mathrm{U}$ ) and natural uranium (Tuballoy, or Tu) in different orders. A total of five critical cylindrical configurations of uranium disks, partial disks (in the shape of $45^{\circ}$ circular sectors), and layers of rectangular blocks were assembled. Documentation and detailed drawings of these experiments are shown on pages 16 through 37 of OECD-NEA (1998) IEU-MET-FAST-001 (IMF-001). For the four experiments, the reference listed detailed and idealized cases. Only the results of the detailed cases were reported in this report. The cases are identified as "IMF1-1", "IMF1-2", "IMF1-3", and "IMF1-4".

\subsubsection{Natural Uranium Reflected Assembly of Enriched and Natural Uranium Plates}

This critical experiment was a cylindrical assembly with a core of alternating plates of enriched and natural uranium surrounded by a natural uranium reflector. The core average enrichment was 16 wt $\%{ }^{235} \mathrm{U}$ (p. 1, OECD-NEA 1998, IMF-002). This experiment was performed at the Los Alamos Pajarito critical assembly facility and can be considered an extension of the earlier Jemima experiments that determined the critical conditions of bare natural and enriched uranium disks of combined intermediate enrichments (29-94 wt \% ${ }^{235} \mathrm{U}$; p. 1, OECD-NEA 1998, IMF002). This experiment was designated as "imf2-1". 


\subsubsection{Spherical Assembly of $36 \mathrm{wt} \%{ }^{235} \mathrm{U}$}

A series of critical experiments with a spherical assembly of $36 \mathrm{wt} \%{ }^{235} \mathrm{U}$ was performed over the course of several years (1993-1996) by the Institute for Experimental Physics of the Russian Federal Nuclear Center. The assembly core included different layers of fissile material (lower core limit) and could be covered by different layers of graphite, steel, or duralumin (upper core limit). The upper core layers are the reflector layers. Table 3.1-20 shows the descriptions for the experimental configurations. More detailed descriptions for this set of experiments is provided in Sections 3.1.22.4 through 3.1.22.8.

Table 3.1-20. IMF Experimental Description

\begin{tabular}{|c|c|c|}
\hline Reference identifier & Description & Experiment identifier \\
\hline IEU-MET-FAST-003 & Bare spherical assembly (detailed) & IMF3-1 \\
\hline IEU-MET-FAST-004 & Graphite reflected spherical assembly (detailed) & IMF4-1 \\
\hline IEU-MET-FAST-005 & Steel reflected spherical assembly (detailed) & IMF5-1 \\
\hline IEU-MET-FAST-006 & Duralumin reflected spherical assembly (detailed) & IMF6-1 \\
\hline IEU-MET-FAST-008 & Uranium depleted reflected spherical assembly & IMF8-1 \\
\hline
\end{tabular}

p. 14, OECD-NEA (1998), IEU-MET-FAST-003 (IMF-003)

p. 13, OECD-NEA (1998), IEU-MET-FAST-004 (IMF-004)

p. 13, OECD-NEA (1998), IEU-MET-FAST-005 (IMF-005)

p. 14, OECD-NEA (1998), IEU-MET-FAST-006 (IMF-006)

p. 14, OECD-NEA (1998), IEU-MET-FAST-007 (IMF-008)

\subsubsection{Bare Spherical Assembly of $36 \mathrm{wt} \%{ }^{235} \mathrm{U}$}

A criticality measurement of a bare spherical assembly of $36 \mathrm{wt} \%{ }^{235} \mathrm{U}$ was performed. The assembly had a core of $36 \mathrm{wt} \%{ }^{235} \mathrm{U}$ incorporating 10 spherical layers of fissile material. Characteristics for these core layers are presented in Table 3.1-21. This case is identified as "imf3-1".

Table 3.1-21. Dimensions and Mass Characteristics of the IMF-003 Critical Assembly

\begin{tabular}{|c|c|c|c|}
\hline \multicolumn{2}{|c|}{ Detailed 10 shell case } & \multirow{2}{*}{ Layer mass $(\mathbf{g})$} \\
\hline \multirow{2}{*}{ Layer no. } & \multicolumn{2}{|c|}{ Radius (cm) } & Outer \\
\hline 1 & Inner & 2.00 & 623.29 \\
\hline 2 & 0.00 & 6.00 & 16256 \\
\hline 3 & 2.00 & 7.55 & 16630 \\
\hline 4 & 6.00 & 9.15 & 25864 \\
\hline 5 & 7.55 & 11.00 & 43638 \\
\hline 7 & 9.15 & 12.25 & 39021 \\
\hline 8 & 11.00 & 13.25 & 37156 \\
\hline 9 & 12.25 & 14.00 & 31449 \\
\hline 10 & 13.25 & 15.00 & 48363 \\
\hline
\end{tabular}




\subsubsection{Graphite-Reflected Spherical Assembly of $36 \mathrm{wt} \%{ }^{235} \mathrm{U}$}

A criticality measurement of a graphite reflected spherical assembly of $36 \mathrm{wt} \%{ }^{235} \mathrm{U}$ was performed. The assembly core had a central cavity of $2-\mathrm{cm}$ radius and incorporated 7 spherical layers of fissile material. Characteristics of these core layers are presented in Table 3.1-22. The graphite reflector was a single spherical layer with an outer radius of $17.2 \mathrm{~cm}$. This case is identified as "imf4-1".

Table 3.1-22. Dimensions and Mass Characteristics of the IMF-004 Critical Assembly

\begin{tabular}{|c|c|c|c|}
\hline \multirow{2}{*}{ Layer no. } & \multicolumn{2}{|c|}{ Detailed 8 shell case } & \multirow{2}{*}{ Layer mass (g) } \\
\cline { 2 - 4 } & Inner & Outer & \\
\hline \multicolumn{4}{|c|}{ Fuel } \\
\hline 2 & 2.788 & 6.000 & 15267 \\
\hline 3 & 6.000 & 7.550 & 16791 \\
\hline 4 & 7.550 & 9.150 & 26169 \\
\hline 5 & 9.150 & 11.000 & 44087 \\
\hline 6 & 11.000 & 12.250 & 39542 \\
\hline 7 & 12.250 & 13.250 & 32214 \\
\hline \multicolumn{5}{|c|}{ Graphite reflector } \\
\hline 1 & 13.250 & 14.000 & 15222 \\
\hline
\end{tabular}

p. 11, OECD-NEA 1998, IMF-004

\subsubsection{Steel-Reflected Spherical Assembly of 36 wt $\%{ }^{235} U$}

A criticality measurement for a steel reflected spherical assembly of $36 \mathrm{wt} \%{ }^{235} \mathrm{U}$ was performed. The assembly core had a central cavity of $2.686-\mathrm{cm}$ radius and incorporated 6 spherical layers of fissile material. Characteristics of these core layers are presented in Table 3.1-23. Five spherical layers that differ slightly in density represented the steel reflector. The outermost layer had an outer radius of $21.5 \mathrm{~cm}$. The reflector was represented in as 2 spherical layers that differ slightly in density. This case was identified as "imf5-1".

Table 3.1-23. Dimension and Mass Characteristics of the IMF-005 Critical Assembly

\begin{tabular}{|c|c|c|c|}
\hline \multicolumn{3}{|c|}{ Detailed 8 shell case } & \multirow{2}{*}{ Layer mass (g) } \\
\hline \multirow{2}{*}{ Layer no. } & \multicolumn{2}{|c|}{ Radius (cm) } \\
\hline \multicolumn{2}{|c|}{ Fuel } \\
\hline 1 & 2.686 & 6.000 & 15366 \\
\hline 2 & 6.000 & 7.550 & 16630 \\
\hline 3 & 7.550 & 9.150 & 25864 \\
\hline 4 & 9.150 & 11.000 & 43638 \\
\hline 6 & 11.000 & 12.250 & 39021 \\
\hline & 12.250 & 13.250 & 37156 \\
\hline
\end{tabular}

p. 11, OECD-NEA 1998, IMF-005 


\subsubsection{Duralumin-Reflected Spherical Assembly of $36 \mathrm{wt} \%{ }^{235} \mathrm{U}$}

A criticality measurement for a duralumin reflected spherical assembly of $36 \mathrm{wt} \%{ }^{235} \mathrm{U}$ was performed. The assembly core had a central cavity of $2.1 \mathrm{~cm}$ radius and incorporated 6 spherical layers of fissile material. Characteristics of these core layers are presented in Table 3.1-24. Seven spherical layers that differ slightly in density represented the duralumin reflector. The outermost layer had an outer radius of $25 \mathrm{~cm}$. The reflector was represented as 2 spherical layers that differ slightly in density. This case was designated as "imf6-1".

Table 3.1-24. Dimensions and Mass Characteristics of the IMF-006 Critical Assembly

\begin{tabular}{|c|c|c|c|}
\hline \multicolumn{2}{|c|}{ Detailed 8 shell case } & \multirow{2}{*}{ Layer mass (g) } \\
\cline { 2 - 4 } Layer no. & \multicolumn{2}{|c|}{ Outer } \\
\hline \multicolumn{2}{|c|}{ Fuel } \\
\hline 1 & $2.10^{9}$ & 6.00 & 16157 \\
\hline 2 & 6.00 & 7.55 & 16630 \\
\hline 3 & 7.55 & 9.15 & 25864 \\
\hline 4 & 9.15 & 11.00 & 43638 \\
\hline 5 & 11.00 & 12.25 & 39021 \\
\hline 6 & 12.25 & 13.25 & 37156 \\
\hline 1 & 13.25 & Duralumin reflector & 11150 \\
\hline 2 & 15.00 & 15.00 & 129550 \\
\hline
\end{tabular}

pp. $11,12,13$, OECD-NEA 1998, IMF-006

\subsubsection{Depleted Uranium-Reflected Spherical Assembly of 36 wt $\%{ }^{235} \mathrm{U}$}

A criticality measurement for a depleted uranium reflected spherical assembly of $36 \mathrm{wt} \%{ }^{235} \mathrm{U}$ was performed. The assembly core had a central cavity of $2 \mathrm{~cm}$ radius and incorporated 6 spherical layers of fissile material. Characteristics of these core layers are presented in Table 3.1-25. Three spherical layers that differ slightly in density represented the depleted uranium reflector. The outermost layer had an outer radius of $16.5 \mathrm{~cm}$. This case was designated as "imf8-1".

Table 3.1-25. Dimensions and Mass Characteristics of the IMF-008 Critical Assembly

\begin{tabular}{|c|c|c|c|}
\hline \multicolumn{2}{|c|}{ Detailed 9 shells case } & \multirow{2}{*}{ Layer mass (g) } \\
\hline \multirow{2}{*}{ Layer no. } & \multicolumn{2}{|c|}{ Radius (cm) } \\
\cline { 2 - 4 } & \multicolumn{2}{|c|}{ Fuel } \\
\hline 0 & $1.40^{\mathrm{a}}$ & 2.00 & 395.7 \\
\hline 1 & 2.00 & 6.00 & 16256 \\
\hline 2 & 6.00 & 7.55 & 16630 \\
\hline 3 & 7.55 & 9.15 & 25864 \\
\hline 4 & 9.15 & 11.00 & 43638 \\
\hline 5 & 11.00 & 12.25 & 39021 \\
\hline 6 & 12.25 & 13.25 & 37156 \\
\hline 1 & Depleted uranium reflector & 31510 \\
\hline 2 & 13.25 & 14.00 & 48390 \\
\hline 3 & 14.00 & 15.00 & 85890 \\
\hline
\end{tabular}

p. 12, OECD-NEA 1998, IMF-008 


\subsection{HOMOGENEOUS SOLUTION EXPERIMENTS}

The LCEs presented in this section represent solutions containing uranium, plutonium, or both uranium and plutonium. Each of the LCE configurations described in this section have been analyzed with the MCNP code system using the cross section sets previously described in Section 2.2 of this document. An experiment identifier for each configuration is provided for subsequent reference in this document. With a few exceptions that are noted in the text, the vast majority of the assessed benchmarks come from the OECD compilation (OECD-NEA 1998).

The following sections briefly describe the LCEs according to the grouping in which the results are presented.

\subsubsection{Mixed Plutonium and Natural Uranium Nitrate Solutions}

The experiments involving plutonium and uranium with naturally occurring isotopic ratios are from OECD-NEA (1998), Volume VI and are listed in Table 3.2-1.

Table 3.2-1. Benchmark Problem Summary for Configurations Incorporating Mixed Plutonium and Natural Uranium Nitrate Solutions

\begin{tabular}{|c|c|}
\hline Reference Identifier & Experiment Identifier \\
\hline \multirow[t]{12}{*}{ MIX-SOL-THERM-001 } & PNL3187 \\
\hline & PNL3391 \\
\hline & PNL3492 \\
\hline & PNL3593 \\
\hline & PNL3694 \\
\hline & PNL3795 \\
\hline & PNL3896 \\
\hline & PNL3897 \\
\hline & PNL3898 \\
\hline & PNL3808 \\
\hline & PNL3999 \\
\hline & PNL5300 \\
\hline \multirow[t]{3}{*}{ MIX-SOL-THERM-002 } & PNL1158 \\
\hline & PNL1159 \\
\hline & PNL1161 \\
\hline \multirow{10}{*}{ MIX-SOL-THERM-003 } & awre1 \\
\hline & awre2 \\
\hline & awre3 \\
\hline & awre4 \\
\hline & awre5 \\
\hline & awre6 \\
\hline & awre7 \\
\hline & awre8 \\
\hline & awre9 \\
\hline & awre10 \\
\hline \multirow[t]{9}{*}{ MIX-SOL-THERM-004 } & PNL1577 \\
\hline & PNL1678 \\
\hline & PNL1783 \\
\hline & PNL1868 \\
\hline & PNL1969 \\
\hline & PNL2070 \\
\hline & PNL2565 \\
\hline & PNL2666 \\
\hline & PNL2767 \\
\hline
\end{tabular}




\subsubsection{Plutonium Nitrate Solutions}

The experiments involving plutonium are from OECD-NEA (1998), Volume I and are listed in Table 3.2-2.

Table 3.2-2. Benchmark Problem Summary for Configurations Incorporating Plutonium Nitrate Solutions

\begin{tabular}{|c|c|}
\hline Reference Identifier & Experiment Identifier \\
\hline \multirow{6}{*}{ PU-SOL-THERM-001 } & pust 1t1 \\
\hline & pust1t2 \\
\hline & pust1t3 \\
\hline & pust1t4 \\
\hline & pust1t5 \\
\hline & pust1t6 \\
\hline \multirow[t]{8}{*}{ PU-SOL-THERM-003 } & pu003-1 \\
\hline & pu003-2 \\
\hline & pu003-3 \\
\hline & pu003-4 \\
\hline & pu003-5 \\
\hline & pu003-6 \\
\hline & pu003-7 \\
\hline & pu003-8 \\
\hline \multirow[t]{13}{*}{ PU-SOL-THERM-004 } & pu004-1 \\
\hline & pu004-2 \\
\hline & pu004-3 \\
\hline & pu004-4 \\
\hline & pu004-5 \\
\hline & pu004-6 \\
\hline & pu004-7 \\
\hline & pu004-8 \\
\hline & pu004-9 \\
\hline & pu04-10 \\
\hline & pu04-11 \\
\hline & pu04-12 \\
\hline & pu04-13 \\
\hline \multirow[t]{9}{*}{ PU-SOL-THERM-005 } & pu005-1 \\
\hline & pu005-2 \\
\hline & puo05-3 \\
\hline & pu005-4 \\
\hline & pu005-5 \\
\hline & pu005-6 \\
\hline & pu005-7 \\
\hline & pu005-8 \\
\hline & pu005-9 \\
\hline \multirow[t]{8}{*}{ PU-SOL-THERM-007 } & pu007-2 \\
\hline & pu007-3 \\
\hline & pu007-5 \\
\hline & pu007-6 \\
\hline & pu007-7 \\
\hline & pu007-8 \\
\hline & pu007-9 \\
\hline & pu07-10 \\
\hline \multirow[t]{3}{*}{ PU-SOL-THERM-009 } & pust9-1 \\
\hline & pust9-2 \\
\hline & pust9-3 \\
\hline \multirow[t]{4}{*}{ PU-SOL-THERM-0010 } & pu10091 \\
\hline & pu10092 \\
\hline & pu10093 \\
\hline & pu10111 \\
\hline
\end{tabular}


Table 3.2-2. Benchmark Problem Summary for Configurations Incorporating Plutonium Nitrate Solutions

\begin{tabular}{|c|c|}
\hline Reference Identifier & Experiment Identifier \\
\hline & pu10112 \\
\hline & pu10113 \\
\hline & pu10114 \\
\hline & pu10115 \\
\hline & pu10116 \\
\hline & pu10117 \\
\hline & pu10121 \\
\hline & pu10122 \\
\hline & pu10123 \\
\hline & pu10124 \\
\hline \multirow{12}{*}{ PU-SOL-THERM-0011 } & pu11161 \\
\hline & pu11162 \\
\hline & pu11163 \\
\hline & pu11164 \\
\hline & pu11165 \\
\hline & pu11181 \\
\hline & pu11182 \\
\hline & pu11183 \\
\hline & pu11184 \\
\hline & pu11185 \\
\hline & pu11186 \\
\hline & pu11187 \\
\hline
\end{tabular}

\subsubsection{Highly Enriched Uranium Nitrate Solutions}

The experiments involving highly enriched uranium are from OECD-NEA (1998), Volume II and are listed in Table 3.2-3.

Table 3.2-3. Benchmark Problem Summary for Configurations Incorporating Highly Enriched Uranium Nitrate Solutions

\begin{tabular}{|c|c|}
\hline Reference Identifier & Experiment Identifier \\
\hline \multirow{10}{*}{ HEU-SOL-THERM-001 } & hest1-1 \\
\hline & hest1-2 \\
\hline & hest1-3 \\
\hline & hest1-4 \\
\hline & hest1-5 \\
\hline & hest1- 6 \\
\hline & hest1-7 \\
\hline & hest $1-8$ \\
\hline & hest1-9 \\
\hline & hest110 \\
\hline \multirow[t]{12}{*}{ HEU-SOL-THERM-002 } & hest2-1 \\
\hline & hest $2-2$ \\
\hline & hest2-3 \\
\hline & hest2-4 \\
\hline & hest2-5 \\
\hline & hest2-6 \\
\hline & hest2-7 \\
\hline & hest2-8 \\
\hline & hest $2-9$ \\
\hline & hest2-10 \\
\hline & hest2-11 \\
\hline & hest2-12 \\
\hline
\end{tabular}


Table 3.2-3. Benchmark Problem Summary for Configurations Incorporating Highly Enriched Uranium Nitrate Solutions

\begin{tabular}{|c|c|}
\hline Reference Identifier & Experiment Identifier \\
\hline & hest2-13 \\
\hline & hest2-14 \\
\hline \multirow{19}{*}{ HEU-SOL-THERM-003 } & heust31 \\
\hline & heust 32 \\
\hline & heust33 \\
\hline & heust34 \\
\hline & heust35 \\
\hline & heust36 \\
\hline & heust37 \\
\hline & heust 38 \\
\hline & heust39 \\
\hline & hest310 \\
\hline & hest311 \\
\hline & hest312 \\
\hline & hest313 \\
\hline & hest314 \\
\hline & hest315 \\
\hline & hest316 \\
\hline & hest317 \\
\hline & hest318 \\
\hline & hest319 \\
\hline \multirow[t]{17}{*}{ HEU-SOL-THERM-007 } & heust 71 \\
\hline & heust72 \\
\hline & heust73 \\
\hline & heust74 \\
\hline & heust75 \\
\hline & heust76 \\
\hline & heust77 \\
\hline & heust78 \\
\hline & heust79 \\
\hline & hest710 \\
\hline & hest711 \\
\hline & hest712 \\
\hline & hest713 \\
\hline & hest714 \\
\hline & hest715 \\
\hline & hest716 \\
\hline & hest717 \\
\hline \multirow[t]{5}{*}{ HEU-SOL-THERM-008 } & heust81 \\
\hline & heust83 \\
\hline & heust 86 \\
\hline & heust89 \\
\hline & hest813 \\
\hline \multirow[t]{4}{*}{ HEU-SOL-THERM-013 } & hest131 \\
\hline & hest132 \\
\hline & hest133 \\
\hline & hest134 \\
\hline \multirow[t]{3}{*}{ HEU-SOL-THERM-0014 } & hest141 \\
\hline & hest142 \\
\hline & hest143 \\
\hline \multirow[t]{5}{*}{ HEU-SOL-THERM-0015 } & hest151 \\
\hline & hest152 \\
\hline & hest153 \\
\hline & hest154 \\
\hline & hest155 \\
\hline
\end{tabular}


Table 3.2-3. Benchmark Problem Summary for Configurations Incorporating Highly Enriched Uranium Nitrate Solutions

\begin{tabular}{|c|c|}
\hline Reference Identifier & Experiment Identifier \\
\hline \multirow[t]{3}{*}{ HEU-SOL-THERM-0016 } & hest161 \\
\hline & hest162 \\
\hline & hest163 \\
\hline \multirow[t]{8}{*}{ HEU-SOL-THERM-0017 } & hest171 \\
\hline & hest172 \\
\hline & hest173 \\
\hline & hest174 \\
\hline & hest175 \\
\hline & hest176 \\
\hline & hest 177 \\
\hline & hest178 \\
\hline \multirow[t]{12}{*}{ HEU-SOL-THERM-0018 } & hest181 \\
\hline & hest182 \\
\hline & hest183 \\
\hline & hest184 \\
\hline & hest185 \\
\hline & hest186 \\
\hline & hest187 \\
\hline & hest188 \\
\hline & hest 189 \\
\hline & hst1810 \\
\hline & hst 1811 \\
\hline & hst1812 \\
\hline \multirow[t]{3}{*}{ HEU-SOL-THERM-0019 } & hest191 \\
\hline & hest192 \\
\hline & hest193 \\
\hline HEU-SOL-THERM-012 & hst-121 \\
\hline HEU-SOL-THERM-032 & hst-321 \\
\hline
\end{tabular}

\subsubsection{Intermediate-Enrichment Uranium Solutions}

The experiments involving intermediate-enrichment uranium are from OECD-NEA (1998), Volume III. All involve arrays of polyethylene-moderated $\mathrm{U}(30) \mathrm{F}_{4}$-polytetraflouroethlyene oneinch cubes. These experiments are denoted as IECT101 through IECT129.

\subsubsection{Intermediate-Enriched Uranium Nitrate Solutions}

A series of critical experiments with aqueous uranyl nitrate solutions with uranium enriched to $10 \mathrm{wt} \%{ }^{235} \mathrm{U}$ was performed at the Solution Critical Facility of the Institute of Physics and Power Engineering, Obninsk, Russia. These experiments are from (p.12, OECD-NEA 1998, LEUSOL-THERM-003 [LST-003]). Spheres with outer diameters of $66 \mathrm{~cm}, 88 \mathrm{~cm}$, and $120 \mathrm{~cm}$ were used. Experiments differed from one another in geometry, size, and in uranium concentration in the solution. These experiments are denoted as lst3-1 through lst3-9.

\subsubsection{Intermediate-Enriched Uranyl Sulfate Solutions}

These experiments were performed at the RRC "Kurchatov Institute" in 1980-1981, and were to investigate nuclear safety issues for a special-purpose compact reactor with an aqueous solution of uranyl-sulphate $\left(\sim 20.9\right.$ at $\left.\%{ }^{235} \mathrm{U}\right)$ and graphite reflector. These experiments are from (p. 1 , 
OECD-NEA 1998, IEU-SOL-THERM-001 [IST-001]). These experiments are denoted as cases "ist1-1" through "ist1-4".

\subsubsection{Low-Enrichment Uranium Solutions}

The first set of experiments involving low-enrichment uranium are from OECD-NEA (1998), Volume IV, the second set (case prefix "LEUJ") are from work at the Japan Atomic Energy Research Institute (Miyoshi et al. 1997), and the third set (case prefix SPHU9) are cases that look at $\mathrm{UO}_{3}-\mathrm{H}_{2} \mathrm{O}$ critical solutions (p. 43, Bierman et al. 1984). These problems are listed in Table $3.2-4$.

Table 3.2-4. Benchmark Problem Summary for Configurations Incorporating Low-Enrichment Uranium Solutions

\begin{tabular}{|c|c|}
\hline Reference Identifier & Experiment Identifier \\
\hline \multirow[t]{3}{*}{ LEU-SOL-THERM-002 } & LEUST21 \\
\hline & LEUST22 \\
\hline & LEUST23 \\
\hline \multirow[t]{12}{*}{ JAERI } & LEUJA01 \\
\hline & LEUJA29 \\
\hline & LEUJA33 \\
\hline & LEUJA34 \\
\hline & LEUJA46 \\
\hline & LEUJA51 \\
\hline & LEUJA54 \\
\hline & LEUJA14 \\
\hline & LEUJA30 \\
\hline & LEUJA32 \\
\hline & LEUJA36 \\
\hline & LEUJA49 \\
\hline \multirow{12}{*}{ SPHU9 } & SPHU9A \\
\hline & SPHU9B \\
\hline & SPHU9C \\
\hline & SPHU9D \\
\hline & SPHU9E \\
\hline & SPHU9F \\
\hline & SPHU9G \\
\hline & SPHU9H \\
\hline & SPHU9I \\
\hline & SPHU9J \\
\hline & SPHU9K \\
\hline & SPHUYL \\
\hline
\end{tabular}

\subsubsection{Low Enriched Uranyl Flouride Solutions}

This experiment involved an aqueous solution of about $5 \mathrm{wt} \%$ enriched uranyl fluoride and is taken from OECD-NEA (1998), LEU-SOL-THERM-001 (LST-001). This experiment used the SHEBA-II (Solution High Energy Burst Assembly-II), which is a critical assembly experiment that was operated at the Los Alamos Critical Experiments Facility. This experiment is identified as 1 st $1-1$. 


\subsection{9 ${ }^{233}$ U Fuel Homogeneous Criticals}

The experiments involving ${ }^{233} \mathrm{U}$ Fuel are from OECD-NEA (1998), Volume V. All involve spheres of enriched ${ }^{233} \mathrm{U}$ Fuel. The first ten are fast-metal systems. These experiments are denoted as u2331a through $\mathrm{u} 2336 \mathrm{a}$. The other six are thermal solution systems. These experiments are denoted as $\mathrm{u} 233 \mathrm{~s} 1$ through $\mathrm{u} 233 \mathrm{~s} 6$. 


\section{LCE ANALYSES RESULTS}

This section tabulates the MCNP $k_{\text {eff }}$ results from the three different cross section sets and the average energy of a neutron causing fission (AENCF) results for the LCEs from CRWMS M\&O (1999b), CRWMS M\&O (1999c), and CRWMS M\&O (1999d) according to experimental similarities. The cross section sets were the evaluated nuclear data file (ENDF)/B-V, ENDF/BVI, and a combination of the two as selected in CRWMS M\&O (1998c) referred to as the WPO Selected. Based on the AENCF values, the systems were divided into the following categories: Fast (1.0 Mev $\leq \mathrm{AENCF}$ ); Intermediate $(0.1 \mathrm{Mev} \leq \mathrm{AENCF} \leq 1.0 \mathrm{Mev})$; and Thermal (AENCF $\leq 0.1 \mathrm{Mev}$ ). The AENCF value is the average energy of all fissions - fast, thermal, and intermediate - that occur in a given configuration, and are calculated from the MCNP outputs as described on page 7 of CRWMS M\&O (1999c). It should be noted that due to the AENCF being an average over all energies, a system that has a small number of very high energy neutrons causing fission and a lot of low energy neutrons causing fission may have the same AENCF as a system that has many intermediate energy neutrons causing fission. Thus, this grouping structure is used for illustrative purposes only, and should not be considered the same as traditional spectrum nomenclature for fast, thermal, and intermediate systems.

In the following sections the index in the plots refers to the number (\#) designation in the tables for each case.

\subsection{LATTICE CRITICALS}

Tables 4.1-1 through 4.1-10 and Figures 4.1-1 through 4.1-10 present the results for the LCEs according to the following distinct experimental classifications:

- Table and Figure 4.1-1: Moderated lattices containing mixed oxide fuel (Thermal System)

- Table and Figure 4.1-2: Moderated lattices containing mixed oxide fuel (Intermediate System)

- Table and Figure 4.1-3: Moderated lattices containing HEU fuel pins (Thermal System)

- Table and Figure 4.1-4: Moderated lattices containing HEU fuel pins (Intermediate System)

- Table and Figure 4.1-5: Moderated lattices containing HEU fuel plates (Thermal System)

- Table and Figure 4.1-6: Moderated single-zone lattices containing HEU cruciform fuel pins (Thermal System)

- Table and Figure 4.1-7: Moderated dual-zone lattices containing HEU cruciform fuel pins (Thermal System)

- Table and Figure 4.1-8: Moderated lattices containing IEU fuel pins (Thermal System)

- Table and Figure 4.1-9: Moderated lattices containing LEU fuel pins (Thermal System)

- Table and Figure 4.1-10: Moderated lattices containing LEU fuel pins (Intermediate System)

Future revisions of this report may include additional LCEs.

The tables include the calculated values for $k_{\text {eff, }}$ standard deviation (sigma), and the average energy of a neutron causing fission (AENCF). The values are all taken from the MCNP output files as described in CRWMS M\&O (1999b), CRWMS M\&O (1999c), and CRWMS M\&O (1999d). 
Table 4.1-1. Mixed Oxide Fuel Pin Lattice Critical Experiments (Thermal)

\begin{tabular}{|c|c|c|c|c|c|c|c|c|c|c|}
\hline \multirow{2}{*}{$\#$} & \multirow{2}{*}{ Case } & \multicolumn{3}{|c|}{ WPO Selected } & \multicolumn{3}{c|}{ ENDF/B-V } & \multicolumn{3}{c|}{ ENDF/B-VI } \\
\cline { 3 - 11 } & & $\mathbf{k}_{\text {eff }}$ & $\sigma$ & AENCF & $k_{\text {eff }}$ & $\sigma$ & AENCF & $k_{\text {eff }}$ & $\sigma$ & AENCF \\
\hline 1 & ffff004 $^{\mathrm{a}}$ & 1.00635 & 0.00361 & 0.0819 & 0.99333 & 0.00348 & 0.0816 & 1.00137 & 0.00337 & 0.0779 \\
\hline 2 & ffffo06 $^{\mathrm{a}}$ & 1.00558 & 0.00313 & 0.0609 & 1.01291 & 0.00285 & 0.0635 & 0.99947 & 0.00313 & 0.0646 \\
\hline
\end{tabular}

NOTE: ${ }^{\mathrm{a}}$ Values based on TBV-1371

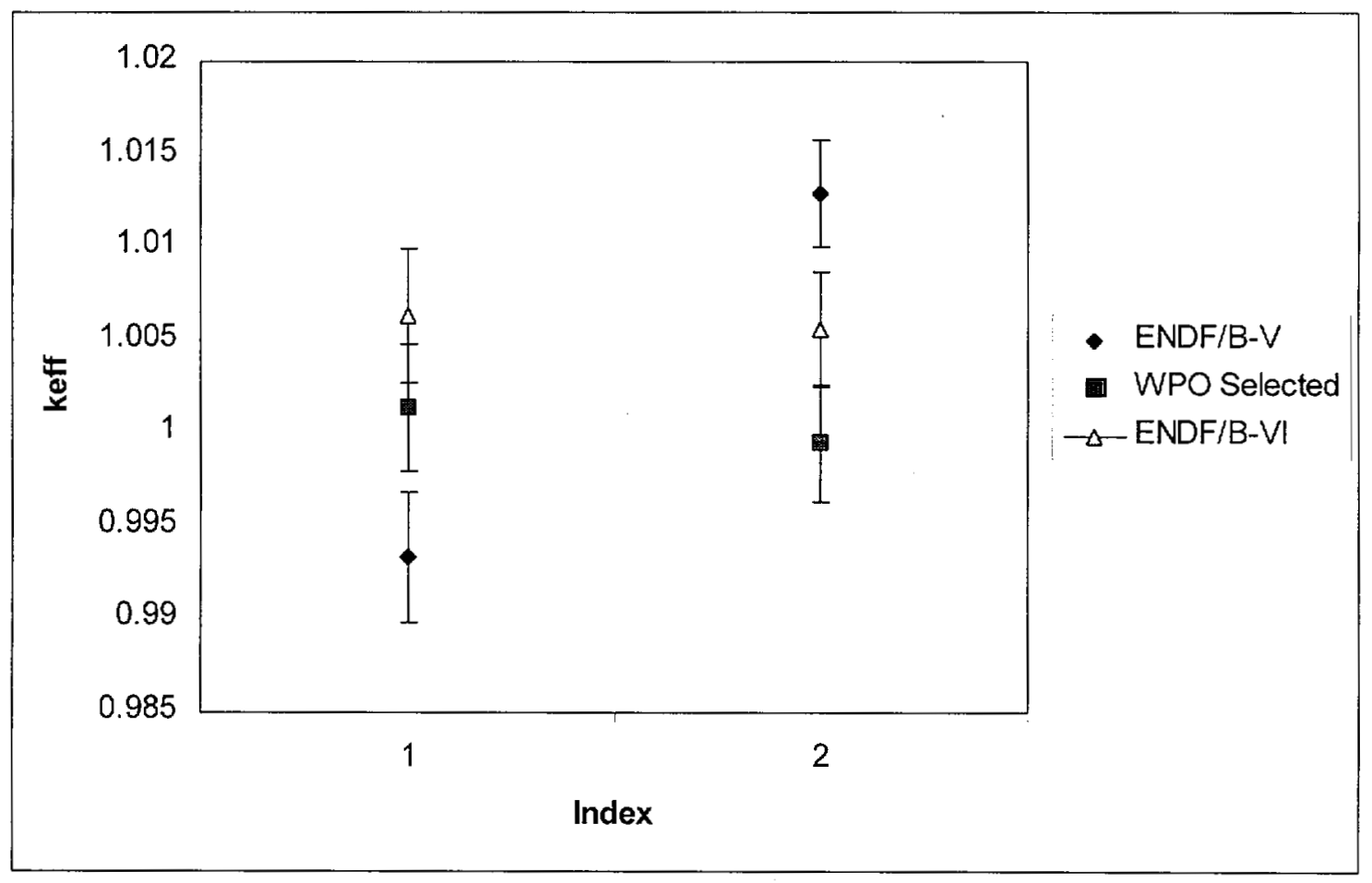

Figure 4.1-1. Mixed Oxide Fuel Pin Lattice Critical Experiments (Thermal) 
Table 4.1-2. Mixed Oxide Fuel Pin Lattice Critical Experiments (Intermediate)

\begin{tabular}{|c|c|c|c|c|c|c|c|c|c|c|}
\hline \multirow{2}{*}{ \# } & \multirow{2}{*}{ Case } & \multicolumn{3}{|c|}{ WPO Selected } & \multicolumn{3}{|c|}{ ENDF/B-V } & \multicolumn{3}{|c|}{ ENDF/B-VI } \\
\hline & & $\mathbf{k}_{\text {eff }}$ & $\sigma$ & AENCF & $\overline{\mathbf{k}_{\text {eff }}}$ & $\sigma$ & AENCF & $\mathbf{k}_{\mathrm{eff}}$ & $\bar{\sigma}$ & AENCF \\
\hline 1 & exp22e5 & 0.99624 & 0.00174 & 0.25557 & 0.99574 & 0.00153 & 0.2559 & 0.99267 & 0.00161 & 0.25764 \\
\hline 2 & exp23e5 & 1.0005 & 0.00169 & 0.27397 & 1.00004 & 0.00157 & 0.27645 & 0.99307 & 0.00176 & 0.2732 \\
\hline 3 & exp24e5 & 1.00302 & 0.00171 & 0.16128 & 1.00819 & 0.00177 & 0.16053 & 0.99653 & 0.00176 & 0.16065 \\
\hline 4 & exp25e5 & 1.00835 & 0.00161 & 0.18944 & 1.00635 & 0.00161 & 0.18898 & 1.00214 & 0.00167 & 0.19096 \\
\hline 5 & exp26e5 & 1.00709 & 0.0016 & 0.13192 & 1.00864 & 0.00158 & 0.13287 & 0.999 & 0.00162 & 0.13166 \\
\hline 6 & exp27e5 & 1.00752 & 0.00155 & 0.15372 & 1.0045 & 0.0016 & 0.15299 & 1.00186 & 0.00155 & 0.15393 \\
\hline 7 & ffffo01 & 1.00557 & 0.00355 & 0.1015 & 1.00567 & 0.00342 & 0.1044 & 0.99485 & 0.00344 & 0.1043 \\
\hline 8 & fftfo03r & 0.99049 & 0.00276 & 0.2453 & 0.98913 & 0.00307 & 0.2447 & 0.99388 & 0.00371 & 0.2388 \\
\hline 9 & ftto0s & 1.00373 & 0.0031 & 0.1728 & 0.99582 & 361 & 0.1717 & 0.99835 & 0.00316 & 0.1727 \\
\hline 10 & ffftfo029 & 0.99776 & 0.00278 & 0.1647 & 0.99891 & 0.00323 & 0.1694 & 0.9985 & 0.0032 & 0.1661 \\
\hline 11 & smr1 & 0.99783 & 0.00073 & 0.1715 & 0.99627 & 0.00072 & 0.1707 & 0.99302 & 0.00072 & 0.1705 \\
\hline 12 & smr5 & 0.99349 & 0.00073 & 0.1919 & 0.99442 & 0.00072 & 0.1928 & 0.99087 & 0.00074 & 0.1919 \\
\hline 13 & smr8 & 0.99956 & 0.00068 & 0.2051 & 0.99861 & 0.00064 & 0.2045 & 0.99444 & 0.00058 & 0.2037 \\
\hline 14 & smr9 & 0.99683 & 0.00078 & 0.1673 & 0.99468 & 0.00072 & 0.1683 & 0.99151 & 0.00074 & 0.1667 \\
\hline 15 & smr11 & 0.99783 & 0.00078 & 0.0205 & 0.99833 & 0.00072 & 0.2049 & 0.99247 & 079 & 0.2027 \\
\hline 16 & smr12 & 0.99992 & 0.0008 & 0.2049 & 0.99869 & 0.00073 & 0.2041 & 0.99358 & 0.00077 & 0.2024 \\
\hline 17 & ssr27 & 0.99881 & 0.00082 & 0.2015 & 0.99728 & 0.00077 & 0.2013 & 0.99195 & 0.00077 & 0.2017 \\
\hline 18 & ssr53 & 1.00454 & 0.00066 & 0.1065 & 1.0034 & 0.00065 & 0.1063 & 0.99503 & 0.00074 & 0.1064 \\
\hline 19 & ssr57 & 0.99807 & 0.00075 & 0.1938 & 0.99673 & 0.00076 & 0.1933 & 0.99009 & 0.00072 & 0.1928 \\
\hline 20 & ssr66 & 1.00308 & 0.00073 & 0.1183 & 1.00272 & 0.00074 & 0.1182 & 0.99383 & 0.00073 & 0.1189 \\
\hline 21 & $s s r 70$ & 0.99543 & 0.00072 & 0.2295 & 0.99369 & 0.00074 & 0.2294 & 0.98936 & 0.00071 & 0.229 \\
\hline 22 & ssr 74 & 1.00505 & 0.00068 & 0.079 & 1.00551 & 0.0 & 0.0799 & 0.99858 & 0.00072 & 0 \\
\hline 23 & exp34 & 0.9875 & 0.00168 & 0.37762 & 0.98999 & 0.00154 & 0.37796 & 0.99406 & 0.00152 & 0.37363 \\
\hline
\end{tabular}

NOTE: Index numbers 1 through 6 carry TBV-1368, index numbers 7 through 10 carry TBV-1371, and index numbers 11 through 23 carry TBV-1359 and TBV-1368

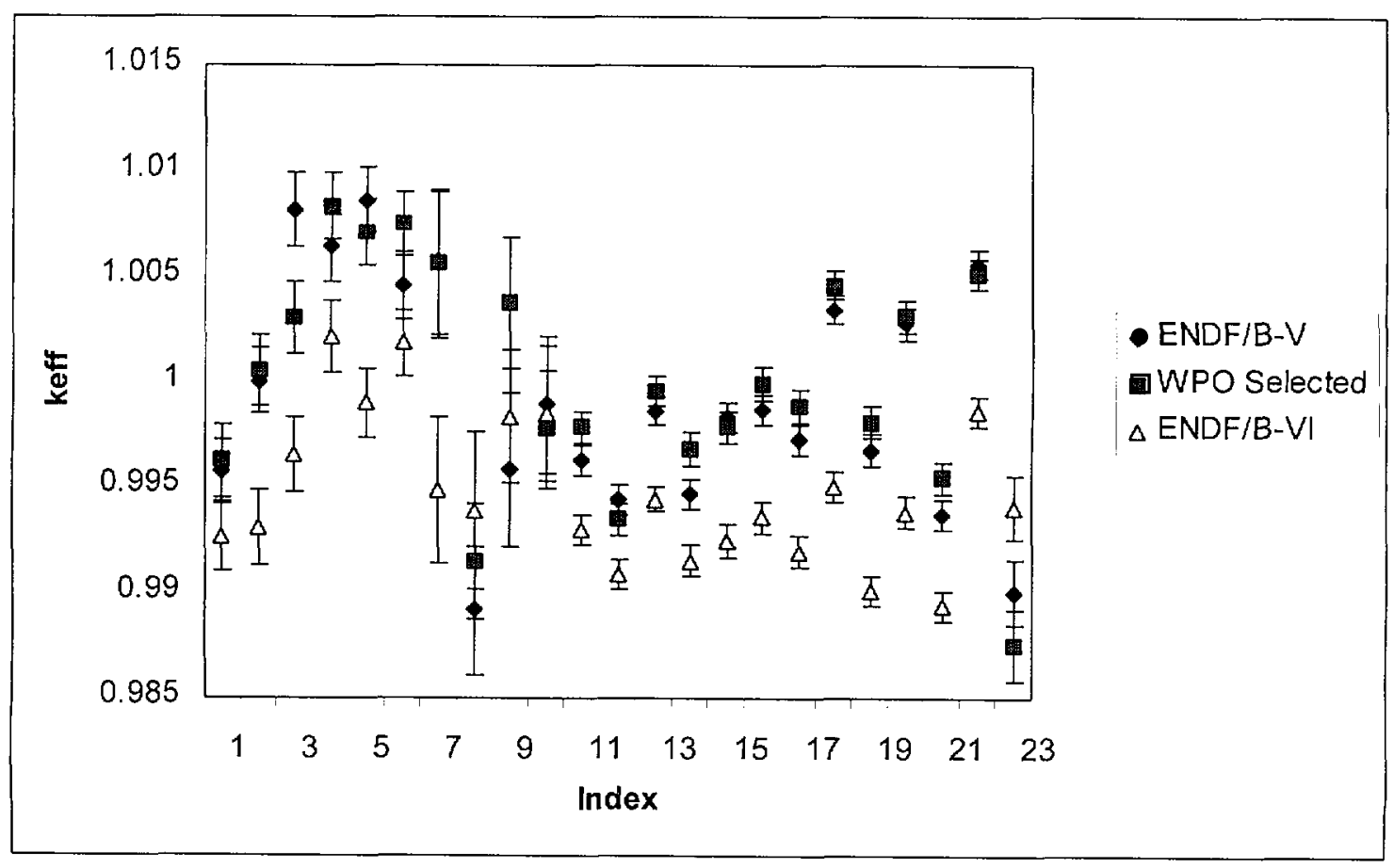

Figure 4.1-2. Mixed Oxide Fuel Pin Lattice Critical Experiments (Intermediate) 
Table 4.1-3. High Enriched Uranium Oxide Fuel Pin Lattice Critical Experiments (Thermal)

\begin{tabular}{|c|c|c|c|c|c|c|c|c|c|c|}
\hline \multirow{2}{*}{$\#$} & \multirow{2}{*}{ Case } & \multicolumn{3}{|c|}{ WPO Selected } & \multicolumn{3}{c|}{ ENDF/B-V } & \multicolumn{3}{c|}{ ENDF/B-VI } \\
\cline { 3 - 11 } & & $\mathbf{k}_{\text {eff }}$ & $\sigma$ & AENCF & $\mathbf{k}_{\text {eff }}$ & $\sigma$ & AENCF & $\mathbf{k}_{\text {eff }}$ & $\sigma$ & AENCF \\
\hline 1 & hct101 & 0.98849 & 0.00121 & 0.0793 & 0.98716 & 0.00118 & 0.0797 & 0.98784 & 0.00112 & 0.0783 \\
\hline 2 & hct102 & 0.98532 & 0.00116 & 0.0799 & 0.98361 & 0.00115 & 0.0797 & 0.98632 & 0.00117 & 0.08 \\
\hline 3 & hct103 & 0.99428 & 0.00127 & 0.0555 & 0.99328 & 0.00125 & 0.0557 & 0.98998 & 0.00117 & 0.0551 \\
\hline 4 & hct104 & 0.99478 & 0.00119 & 0.0439 & 0.99468 & 0.00125 & 0.0431 & 0.99397 & 0.00126 & 0.0423 \\
\hline 5 & hct105 & 0.99679 & 0.00115 & 0.0357 & 0.99734 & 0.00119 & 0.036 & 0.99568 & 0.00113 & 0.0358 \\
\hline 6 & hct106 & 0.99644 & 0.00113 & 0.0359 & 0.99239 & 0.00121 & 0.0361 & 0.99419 & 0.00113 & 0.0358 \\
\hline 7 & hct107 & 0.99679 & 0.00115 & 0.0357 & 0.99976 & 0.00105 & 0.0308 & 0.99841 & 0.00113 & 0.0307 \\
\hline 8 & hct108 & 1.00263 & 0.00108 & 0.032 & 0.9991 & 0.00122 & 0.0315 & 0.99853 & 0.00121 & 0.0309 \\
\hline 9 & hct109 & 0.99882 & 0.00113 & 0.0316 & 0.99777 & 0.00109 & 0.0314 & 0.99798 & 0.00116 & 0.031 \\
\hline 10 & hct110 & 1.00461 & 0.00106 & 0.0288 & 1.00198 & 0.00104 & 0.0287 & 1.00261 & 0.00102 & 0.0282 \\
\hline 11 & hct111 & 1.00002 & 0.00115 & 0.0285 & 0.99913 & 0.00109 & 0.0291 & 0.99882 & 0.00111 & 0.0283 \\
\hline 12 & hct112 & 1.00103 & 0.00111 & 0.0262 & 1.00052 & 0.00105 & 0.0262 & 0.99642 & 0.00107 & 0.0257 \\
\hline 13 & hct113 & 1.00366 & 0.00102 & 0.0252 & 1.00237 & 0.001 & 0.025 & 1.0006 & 0.001 & 0.0244 \\
\hline 14 & hct114 & 1.00135 & 0.00114 & 0.0284 & 1.00112 & 0.00112 & 0.0281 & 0.99823 & 0.00113 & 0.028 \\
\hline 15 & hct115 & 1.00368 & 0.00113 & 0.0288 & 1.00059 & 0.00113 & 0.0289 & 0.99844 & 0.00115 & 0.0286 \\
\hline 16 & hct116 & 1.00594 & 0.00109 & 0.0282 & 1.00378 & 0.00114 & 0.0289 & 0.99892 & 0.00115 & 0.0281 \\
\hline 17 & hct117 & 1.00448 & 0.00107 & 0.0286 & 1.00377 & 0.0011 & 0.0293 & 1.00117 & 0.00124 & 0.0281 \\
\hline 18 & hct118 & 1.00267 & 0.00116 & 0.0288 & 1.0018 & 0.00117 & 0.0287 & 0.99989 & 0.0012 & 0.0283 \\
\hline 19 & hct119 & 1.0037 & 0.00108 & 0.0296 & 1.00151 & 0.00105 & 0.0295 & 0.99935 & 0.00126 & 0.0294 \\
\hline 20 & hct120 & 1.00489 & 0.00101 & 0.0229 & 1.0024 & 0.001 & 0.0234 & 1.00295 & 0.00096 & 0.0228 \\
\hline 21 & hct121 & 1.00342 & 0.00115 & 0.0277 & 1.00416 & 0.0011 & 0.0278 & 1.0025 & 0.00111 & 0.0272 \\
\hline
\end{tabular}

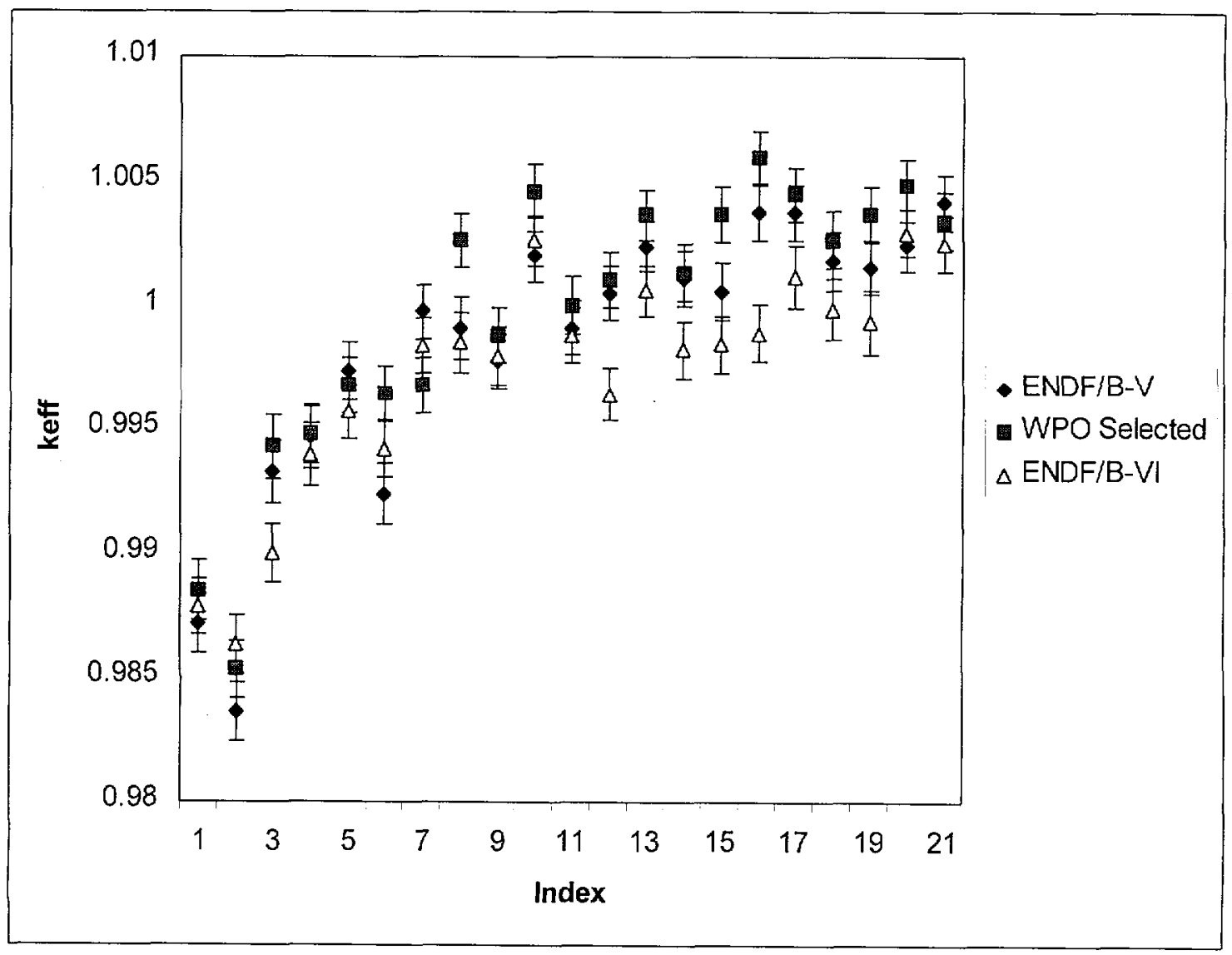

Figure 4.1-3. High Enriched Uranium Oxide Fuel Pin Lattice Critical Experiments (Thermal) 
Table 4.1-4. High Enriched Uranium Oxide Fuel Pin Lattice Critical Experiments (Intermediate)

\begin{tabular}{|c|c|c|c|c|c|c|c|c|c|c|}
\hline \multirow{2}{*}{$\#$} & \multirow{2}{*}{ Case } & \multicolumn{3}{|c|}{ WPO Selected } & \multicolumn{3}{c|}{ ENDF/B-V } & \multicolumn{3}{c|}{ ENDF/B-VI } \\
\cline { 3 - 11 } & & $\mathbf{k}_{\text {eff }}$ & $\sigma$ & AENCF & $\mathbf{k}_{\text {eff }}$ & $\sigma$ & AENCF & $\mathbf{k}_{\text {eff }}$ & $\sigma$ & AENCF \\
\hline 1 & hci2-1 & 0.99627 & 0.00079 & 0.2422 & 0.99236 & 0.00081 & 0.2430 & 0.99933 & 0.00081 & 0.2354 \\
\hline 2 & hci2-2 & 0.99614 & 0.00082 & 0.2413 & 0.99339 & 0.00107 & 0.2439 & 1.00136 & 0.00085 & 0.2357 \\
\hline 3 & hci2-3 & 0.99871 & 0.00083 & 0.2381 & 0.99603 & 0.00101 & 0.2377 & 1.00422 & 0.00087 & 0.2313 \\
\hline 4 & hci2-4 & 0.99892 & 0.00083 & 0.2376 & 0.99676 & 0.00101 & 0.2394 & 1.00469 & 0.00081 & 0.2312 \\
\hline 5 & hci2-5 & 1.00059 & 0.00078 & 0.2376 & 0.99736 & 0.001 & 0.2391 & 1.00278 & 0.00081 & 0.2313 \\
\hline
\end{tabular}

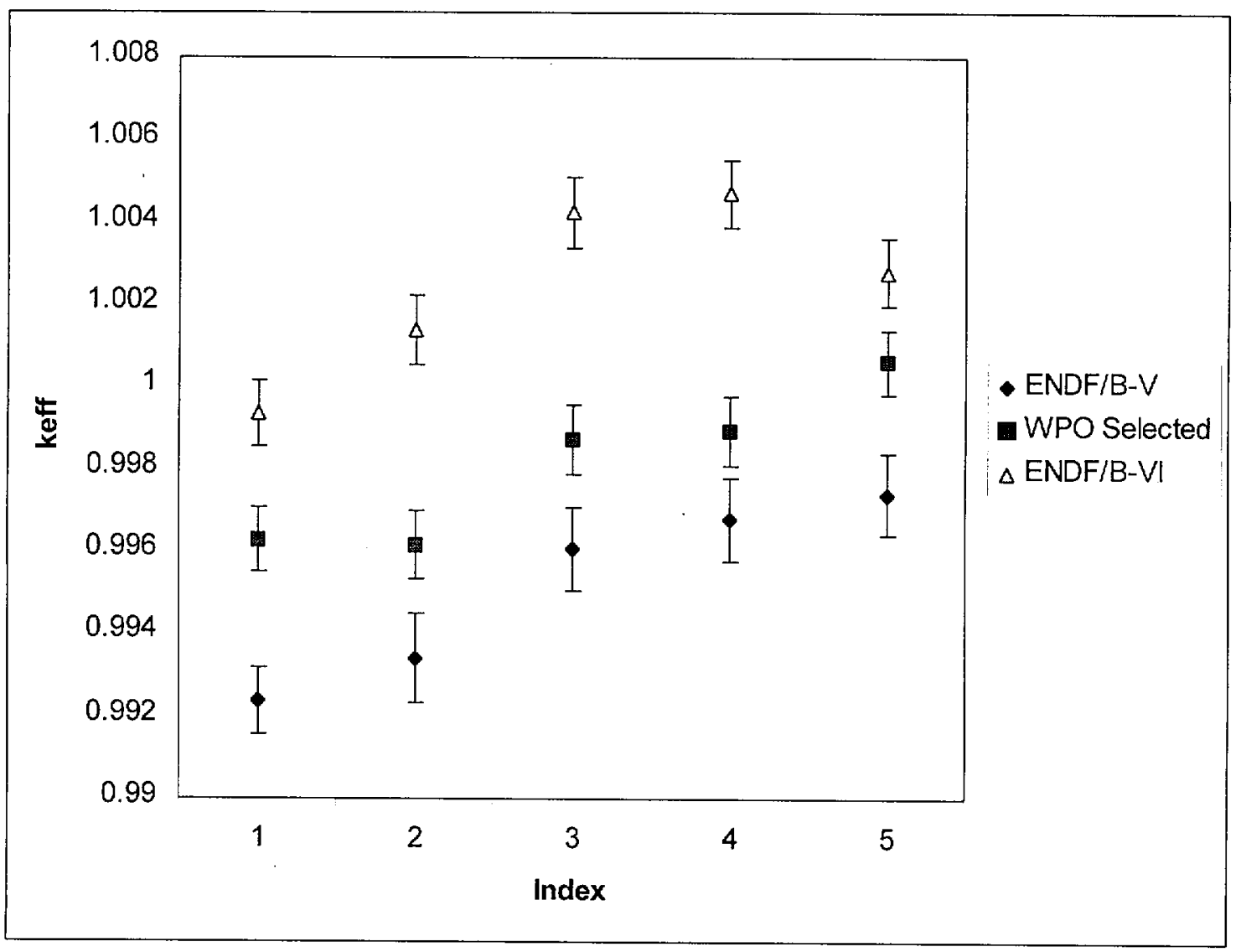

Figure 4.1-4. High Enriched Uranium Oxide Fuel Pin Lattice Critical Experiments (Intermediate) 
Table 4.1-5. High Enriched Uranium Oxide Fuel Plate Lattice Critical Experiments (Thermal)

\begin{tabular}{|c|c|c|c|c|c|c|c|c|c|c|}
\hline \multirow{2}{*}{ \# } & \multirow{2}{*}{ Case } & \multicolumn{3}{|c|}{ WPO Selected } & \multicolumn{3}{|c|}{ ENDF/B-V } & \multicolumn{3}{|c|}{ ENDF/B-VI } \\
\hline & & $\mathbf{k}_{\text {eff }}$ & $\sigma$ & AENCF & $\overline{k_{\text {eff }}}$ & $\sigma$ & AENCF & $k_{\text {eff }}$ & $\bar{\sigma}$ & AENCF \\
\hline 1 & spert1 & 0.99792 & 0.00184 & 0.0147 & 0.99792 & 0.00184 & 0.0147 & 0.99727 & 0.00176 & 0.014 \\
\hline 2 & spert2 & 0.99952 & 0.0019 & 0.0126 & 0.99952 & 0.0019 & 0.0126 & 0.99732 & 0.00186 & 0.0125 \\
\hline 3 & ert3 & 00676 & 0.00114 & 0.0117 & 1.00676 & 0.00114 & 0.0117 & 1.00384 & 0.00095 & 0.0112 \\
\hline 4 & ert4 & 99542 & 0.00173 & 0.011 & 0.99542 & 0.00173 & 0.011 & 0.98908 & 0.00179 & 0.0113 \\
\hline 5 & spert5 & 1.00104 & 0.00162 & 0.0105 & 1.00104 & 0.00162 & 0.0105 & 1.00072 & 0.00183 & 0.011 \\
\hline 6 & 10 & .00133 & 0.00168 & 0.0102 & 1.00133 & 0.0 & 0.0102 & 0.99683 & 0.00152 & 0.0098 \\
\hline 7 & & 99923 & 0.00163 & 0.0097 & 0.99923 & & & 0.9952 & 0.00147 & 0.0104 \\
\hline 8 & spert8 & 0.99843 & 0.00154 & 0.0098 & 0.99843 & 0.00154 & 0.0098 & 0.99009 & 0.0015 & 0.0096 \\
\hline 9 & spert9 & 1.00003 & 0.00143 & 0.0099 & 1.00003 & 0.00143 & 0.0 & 0.99697 & 0.00149 & 0.0098 \\
\hline 10 & spert10 & 1.00608 & 0.00177 & 0.0147 & 1.00608 & 0.00177 & 0.0147 & 1.00534 & 0.0019 & 0.014 \\
\hline 11 & spert11 & 1.00565 & 0.00163 & 0.0115 & 1.00565 & 0.00163 & 0.0115 & 1.00283 & 0.00171 & 0.0113 \\
\hline 12 & spert12 & .00676 & 0.00 & 0.0101 & 1.00676 & 0.0 & & 1.00466 & 0.00175 & 0.0102 \\
\hline 13 & spert13 & 1.03289 & 0.00181 & 0.0143 & 1.03289 & 0.00181 & 0.0143 & 1.02936 & 0.00189 & 0.0141 \\
\hline 14 & spert14 & 0.99451 & 0.00158 & 0.0106 & 0.99451 & 0.00158 & 0.0106 & 0.99427 & 0.00159 & 0.0107 \\
\hline 15 & spert15 & 0.99355 & 0.00 & 0.0106 & 0.99355 & 0.0 & 0.0 & 0.99179 & 0.00103 & 0.0105 \\
\hline 16 & spert16 & 1.00791 & 0.00175 & 0.012 & 1.00791 & 0.00175 & 0.012 & 1.00549 & 0.00183 & 0.0118 \\
\hline 17 & spert17 & 1.00569 & 0.00188 & 0.0131 & 1.00569 & 0.00 & 0.0131 & 1.00206 & 0.00179 & 0.0133 \\
\hline 18 & spert18 & 1.00028 & 0.0 & 0.014 & 1.00028 & & 0.014 & 1.00615 & 0.00181 & 0.0135 \\
\hline 19 & spert19 & 0.99482 & 0.00148 & 0.0097 & 0.99482 & 0.0 & 0.0 & 0.98982 & 0.00158 & 0.009 \\
\hline 20 & spert20 & 0.99652 & 0.00158 & 0.0114 & 0.99652 & 0.00158 & 0.0114 & 0.99315 & 0.00166 & 0.0115 \\
\hline 21 & spert21 & 1.00113 & 0.00186 & 0.0124 & 1.00113 & 0.0 & 0.0126 & 1.00086 & 0.00178 & 0.0127 \\
\hline 22 & spert22 & 1.00272 & 0.00194 & & 1.0 & 0.0 & 0.0 & 0.9984 & 0.00175 & 0.0131 \\
\hline 23 & spert23 & 1.00695 & 0.0011 & 0.0133 & 1.00695 & 0.0011 & 0.0132 & 1.00426 & 0.00099 & 0.0131 \\
\hline
\end{tabular}

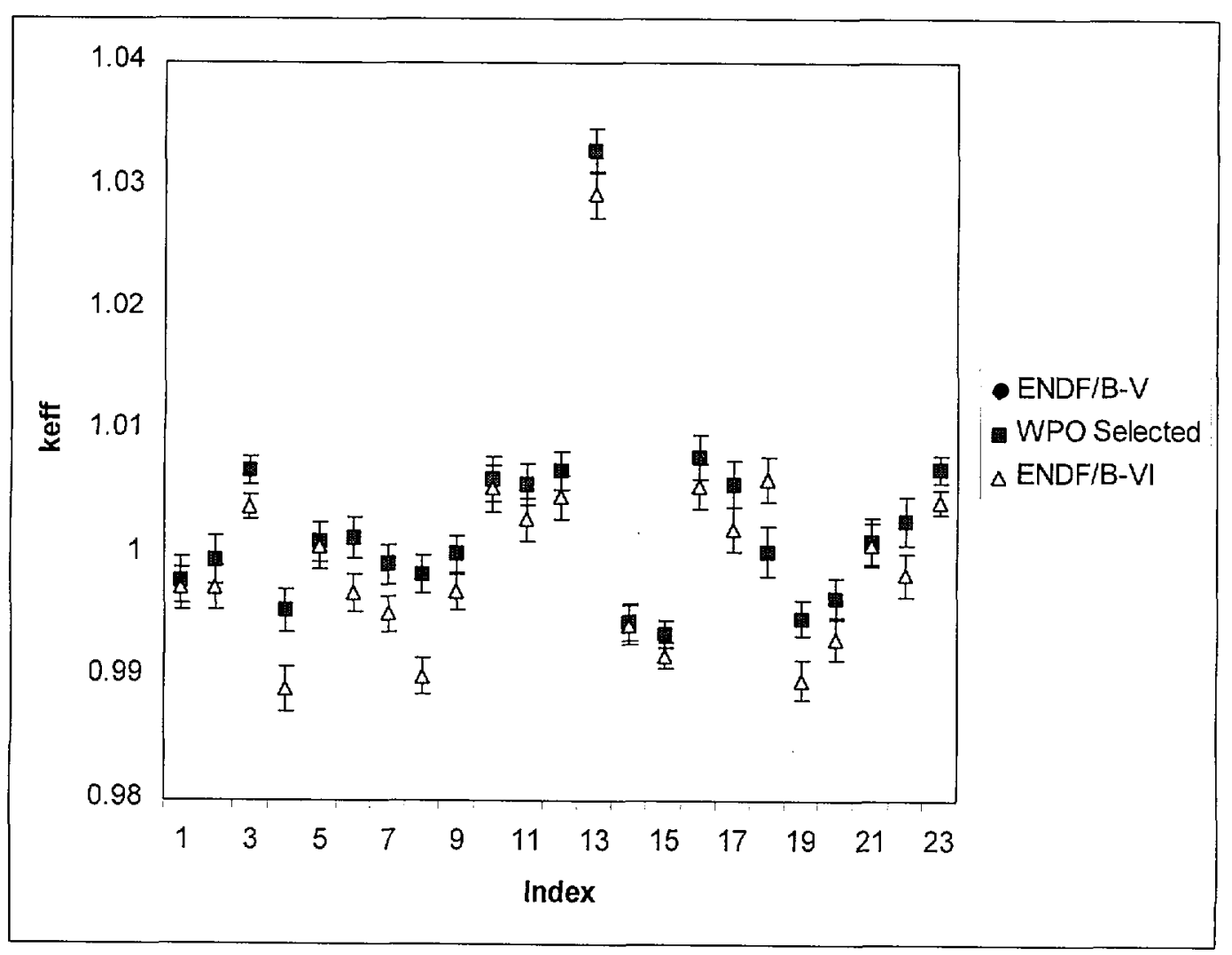

Figure 4.1-5. High Enriched Uranium Oxide Fuel Plate Lattice Critical Experiments (Thermal) 
Table 4.1-6. High Enriched Uranium Oxide Single-Zone Cruciform Rod Lattice Critical Experiments (Thermal)

\begin{tabular}{|c|c|c|c|c|c|c|c|c|c|c|}
\hline \multirow{2}{*}{$\#$} & \multirow{2}{*}{ Case } & \multicolumn{3}{|c|}{ WPO Selected } & \multicolumn{3}{c|}{ ENDF/B-V } & \multicolumn{3}{c|}{ ENDF/B-VI } \\
\cline { 3 - 10 } & & $\mathbf{k}_{\text {eff }}$ & $\sigma$ & AENCF & $\mathbf{k}_{\text {eff }}$ & $\sigma$ & AENCF & $\mathbf{k}_{\text {eff }}$ & $\sigma$ & AENCF \\
\hline 1 & hct4-1 & 0.98875 & 0.00126 & 0.0740 & 0.98756 & 0.00122 & 0.0744 & 0.99143 & 0.00122 & 0.0735 \\
\hline 2 & hct4-2 & 0.98977 & 0.00124 & 0.0732 & 0.9889 & 0.0012 & 0.0736 & 0.99042 & 0.00123 & 0.0716 \\
\hline 3 & hct4-3 & 0.99049 & 0.00123 & 0.0765 & 0.99157 & 0.00119 & 0.0756 & 0.99272 & 0.00121 & 0.0747 \\
\hline 4 & hct4-4 & 0.99036 & 0.00118 & 0.0748 & 0.99116 & 0.00114 & 0.0742 & 0.98934 & 0.00122 & 0.0729 \\
\hline 5 & hct5-2 & 0.98493 & 0.0018 & 0.0776 & 0.98455 & 0.00128 & 0.0764 & 0.98887 & 0.00115 & 0.0765 \\
\hline 6 & hct6-t1 & 0.99034 & 0.00125 & 0.0715 & 0.98952 & 0.00137 & 0.0720 & 0.99212 & 0.00136 & 0.0718 \\
\hline 7 & hct6-t2 & 1.01252 & 0.00127 & 0.0231 & 1.0104 & 0.0013 & 0.0232 & 1.00798 & 0.00128 & 0.0229 \\
\hline 8 & hct6-t3 & 0.9993 & 0.001 & 0.0106 & 0.99557 & 0.00095 & 0.0104 & 0.99612 & 0.00099 & 0.0106 \\
\hline 9 & hct7-4 & 1.00086 & 0.00149 & 0.0340 & 0.99932 & 0.00164 & 0.0339 & 0.99992 & 0.00148 & 0.0334 \\
\hline 10 & hct7-5 & 0.99902 & 0.00164 & 0.0448 & 0.99492 & 0.00156 & 0.0458 & 0.99969 & 0.00152 & 0.0445 \\
\hline 11 & hct7-6 & 0.99556 & 0.00154 & 0.0486 & 0.99487 & 0.00154 & 0.0475 & 0.99545 & 0.00159 & 0.0470 \\
\hline 12 & hct8-1 & 0.98915 & 0.0011 & 0.0882 & 0.99042 & 0.00106 & 0.0882 & 0.99281 & 0.00108 & 0.0856 \\
\hline 13 & hct8-2 & 0.99273 & 0.00108 & 0.0919 & 0.98954 & 0.00112 & 0.0922 & 0.99117 & 0.00116 & 0.0912 \\
\hline
\end{tabular}

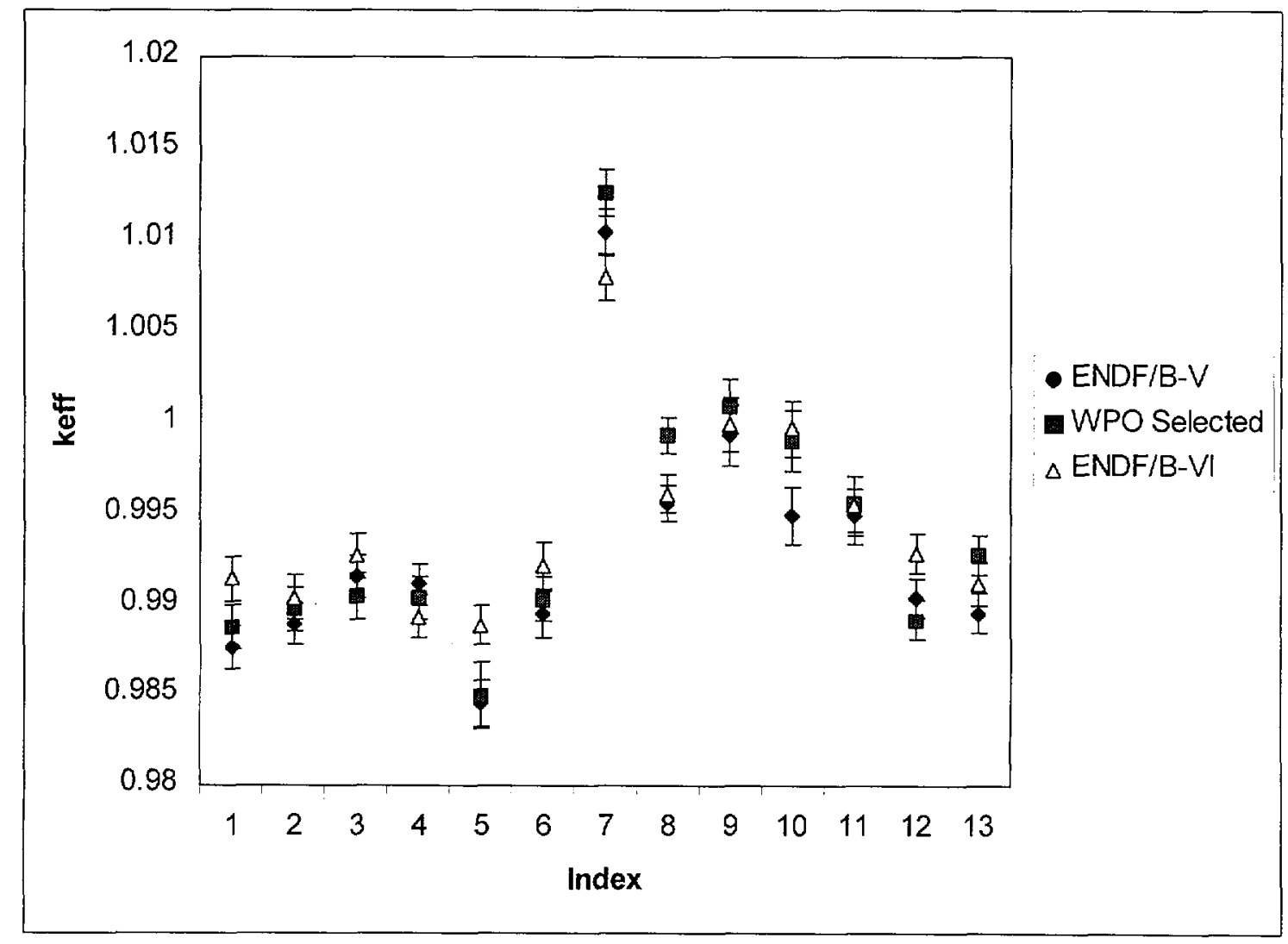

Figure 4.1-6. High Enriched Uranium Oxide Single-Zone Cruciform Rod Lattice Critical Experiments (Thermal) 
Table 4.1-7. High Enriched Uranium Oxide Dual-Zone Cruciform Rod Lattice Critical Experiments (Thermal)

\begin{tabular}{|c|c|c|c|c|c|c|c|c|c|c|}
\hline \multirow{2}{*}{$\#$} & \multirow{2}{*}{ Case } & \multicolumn{3}{|c|}{ WPO Selected } & \multicolumn{3}{c|}{ ENDF/B-V } & \multicolumn{3}{c|}{ ENDF/B-VI } \\
\cline { 3 - 10 } & & $\mathbf{k}_{\text {eff }}$ & $\sigma$ & AENCF & $\mathbf{k}_{\text {eff }}$ & $\sigma$ & AENCF & $\mathbf{k}_{\text {eff }}$ & $\sigma$ & AENCF \\
\hline 1 & hct3-1 & 0.99475 & 0.0015 & 0.0466 & 0.9981 & 0.00136 & 0.0467 & 0.99473 & 0.00138 & 0.0460 \\
\hline 2 & hct3-2 & 0.99147 & 0.00152 & 0.0417 & 0.99746 & 0.00144 & 0.0404 & 0.9956 & 0.00144 & 0.0405 \\
\hline 3 & hct3-3 & 0.99699 & 0.00132 & 0.0330 & 0.99637 & 0.00144 & 0.0337 & 0.99473 & 0.00149 & 0.0333 \\
\hline 4 & hct3-4 & 1.00159 & 0.00141 & 0.0262 & 0.99796 & 0.00148 & 0.0259 & 0.99688 & 0.00148 & 0.0261 \\
\hline 5 & hct3-5 & 1.00175 & 0.00146 & 0.0207 & 1.00253 & 0.00137 & 0.0202 & 1.0006 & 0.00151 & 0.0199 \\
\hline 6 & hct3-6 & 1.00947 & 0.00153 & 0.0419 & 1.00616 & 0.00152 & 0.0405 & 1.00706 & 0.0016 & 0.0398 \\
\hline 7 & hct3-7 & 1.01327 & 0.00144 & 0.0345 & 1.01132 & 0.00143 & 0.0339 & 1.009 & 0.00145 & 0.0339 \\
\hline 8 & hct3-8 & 1.01001 & 0.0015 & 0.0342 & 1.00988 & 0.00155 & 0.0329 & 1.01081 & 0.00143 & 0.0334 \\
\hline 9 & hct3-9 & 1.01332 & 0.00147 & 0.0265 & 1.01309 & 0.00154 & 0.0263 & 1.01355 & 0.00145 & 0.0260 \\
\hline 10 & hct3-10 & 1.01014 & 0.00143 & 0.0202 & 1.00962 & 0.0014 & 0.0209 & 1.01004 & 0.00149 & 0.0200 \\
\hline 11 & hct3-11 & 1.01347 & 0.00137 & 0.0177 & 1.0133 & 0.0014 & 0.0177 & 1.01317 & 0.00152 & 0.0173 \\
\hline 12 & hct3-12 & 0.9933 & 0.00136 & 0.0263 & 0.98956 & 0.00133 & 0.0265 & 0.98921 & 0.00135 & 0.0265 \\
\hline 13 & hct3-13 & 1.00022 & 0.00126 & 0.0140 & 0.99677 & 0.00119 & 0.0139 & 0.99588 & 0.00126 & 0.0133 \\
\hline 14 & hct3-14 & 1.00853 & 0.00143 & 0.0305 & 1.005 & 0.00157 & 0.0300 & 1.00682 & 0.0015 & 0.0301 \\
\hline 15 & hct3-15 & 1.00648 & 0.00128 & 0.0185 & 1.00775 & 0.00142 & 0.0183 & 1.003 & 0.00141 & 0.0179 \\
\hline
\end{tabular}

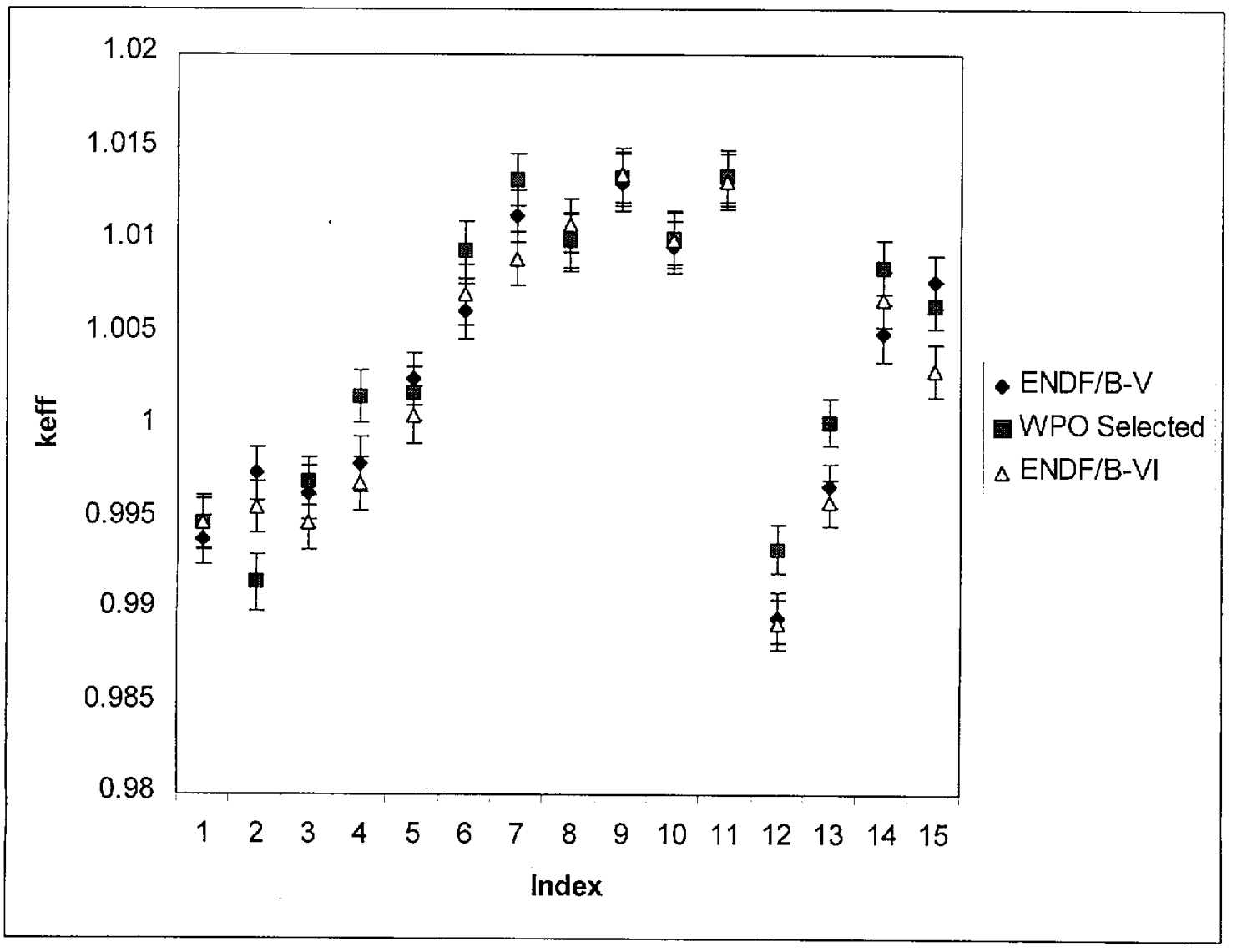

Figure 4.1-7. High Enriched Uranium Oxide Dual-Zone Cruciform Rod Lattice Critical Experiments (Thermal) 
Table 4.1-8. Intermediate Enriched Uranium Oxide Fuel Pin Lattice Critical Experiments (Thermal)

\begin{tabular}{|c|c|c|c|c|c|c|c|c|c|c|}
\hline \multirow{2}{*}{$\#$} & \multirow{2}{*}{ Case } & \multicolumn{3}{|c|}{ WPO Selected } & \multicolumn{3}{c|}{ ENDF/B-V } & \multicolumn{3}{c|}{ ENDF/B-VI } \\
\cline { 3 - 11 } & & $\mathbf{k}_{\text {eff }}$ & $\sigma$ & AENCF & $\mathbf{k}_{\text {eff }}$ & $\sigma$ & AENCF & $\mathbf{k}_{\text {eff }}$ & $\sigma$ & AENCF \\
\hline 1 & tri17 & 1.00897 & 0.00141 & 0.0236 & 1.00737 & 0.00129 & 0.0233 & 1.00740 & 0.00132 & 0.0236 \\
\hline 2 & tri18 & 1.01314 & 0.00126 & 0.0240 & 1.00921 & 0.00132 & 0.0234 & 1.01195 & 0.00143 & 0.0238 \\
\hline
\end{tabular}

NOTE: Values in table carry TBV-1369

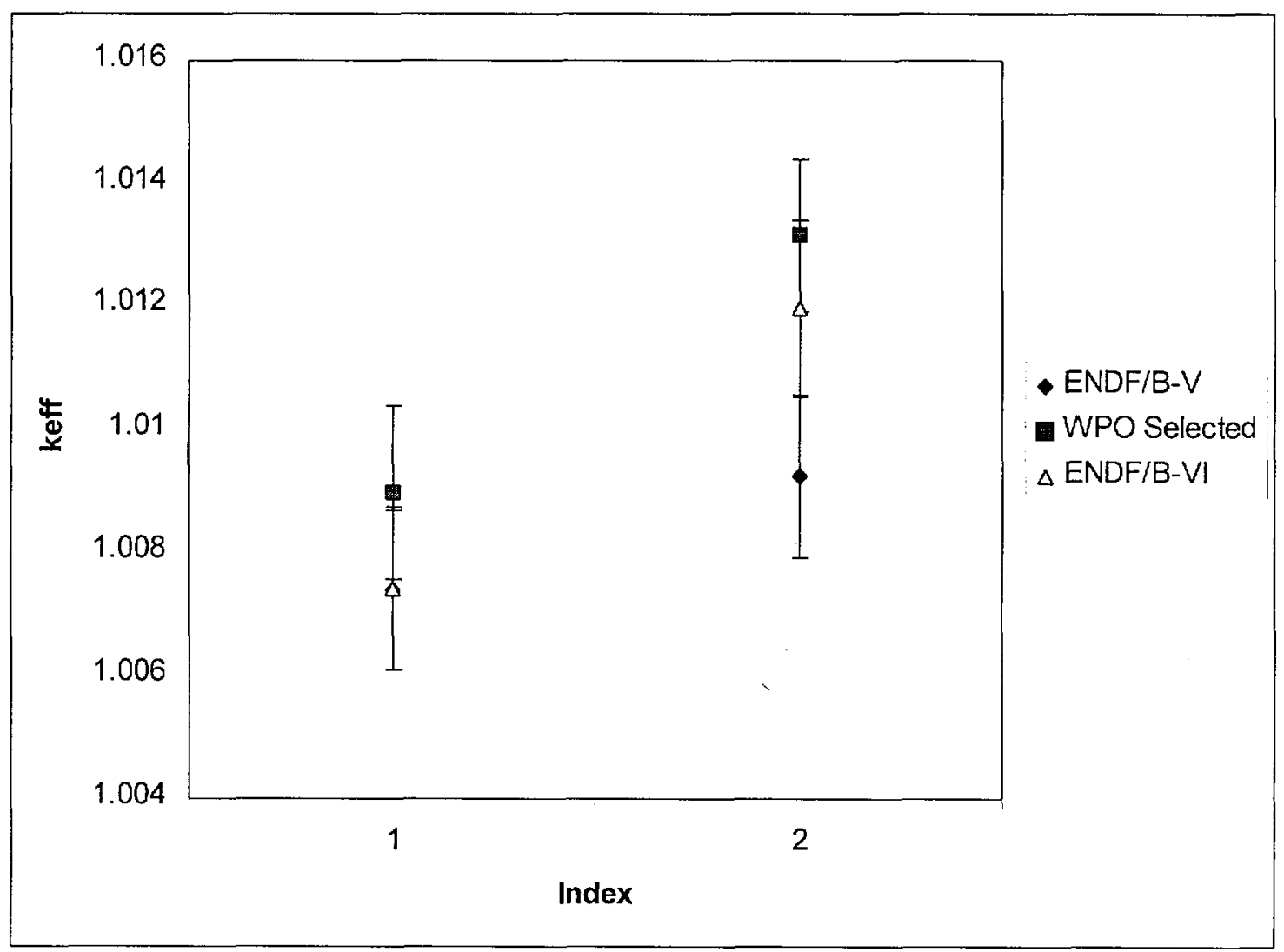

Figure 4.1-8. Intermediate Enriched Uranium Oxide Fuel Pin Lattice Critical Experiments (Thermal) 
Table 4.1-9. Low Enriched Uranium Oxide Fuel Pin Lattice Critical Experiments (Thermal)

\begin{tabular}{|c|c|c|c|c|c|c|c|c|c|c|}
\hline \multirow{2}{*}{$\#$} & \multirow{2}{*}{ Case } & \multicolumn{3}{|c|}{ WPO Selected } & \multicolumn{3}{c|}{ ENDF/B-V } & \multicolumn{3}{c|}{ ENDF/B-VI } \\
\cline { 3 - 11 } & & $\mathbf{k}_{\text {eff }}$ & $\sigma$ & AENCF & $\mathbf{k}_{\text {eff }}$ & $\sigma$ & AENCF & $\mathbf{k}_{\text {eff }}$ & $\sigma$ & AENCF \\
\hline 1 & $\exp 18$ & 1.00503 & 0.00167 & 0.08863 & 1.00192 & 0.00168 & 0.08861 & 0.99716 & 0.00169 & 0.08890 \\
\hline
\end{tabular}

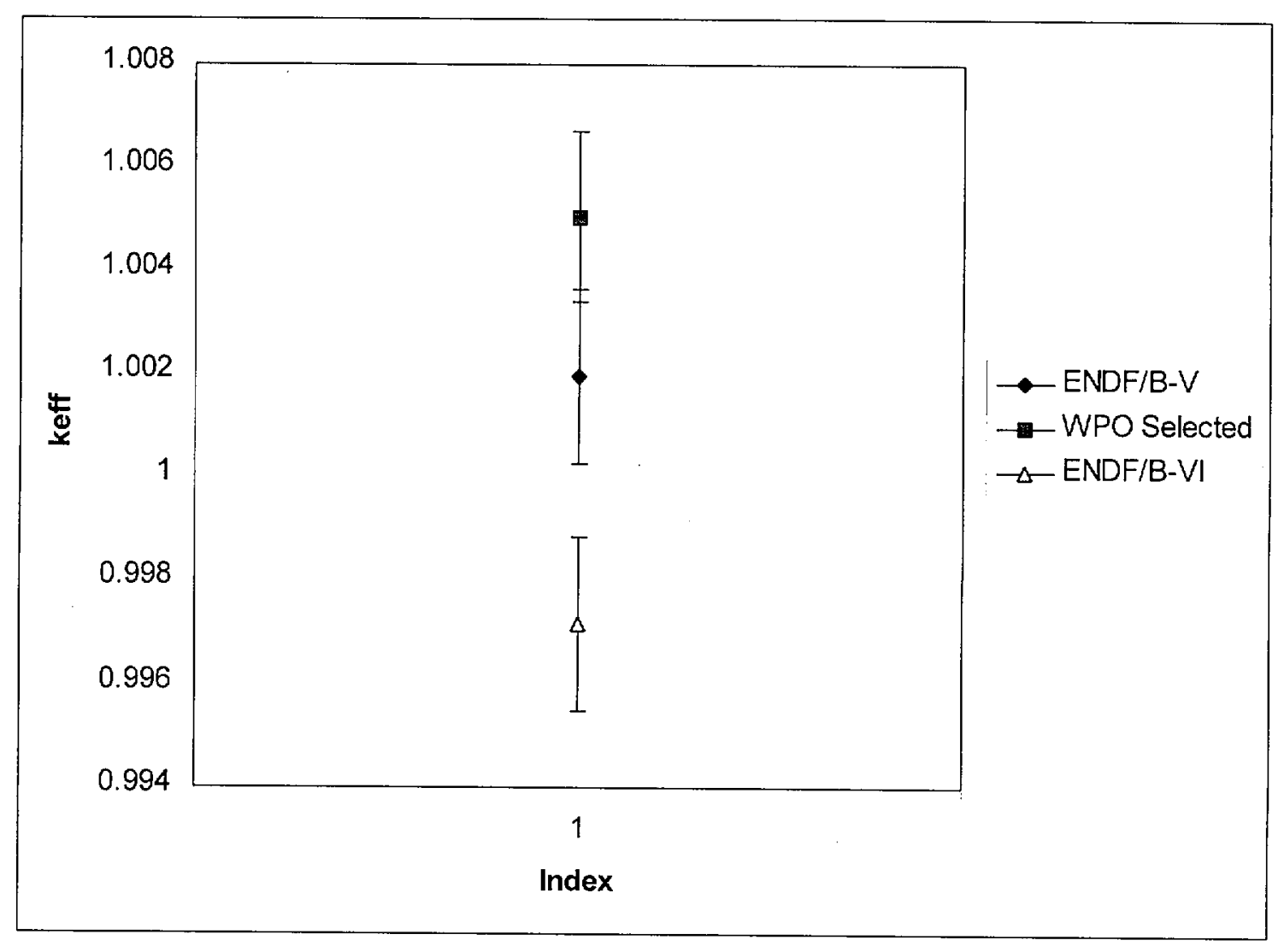

Figure 4.1-9. Low Enriched Uranium Oxide Fuel Pin Lattice Critical Experiments (Thermal) 
Table 4.1-10. Low Enriched Uranium Oxide Fuel Pin Lattice Critical Experiments (Intermediate)

\begin{tabular}{|c|c|c|c|c|c|c|c|c|c|c|}
\hline \multirow{2}{*}{ \# } & \multirow{2}{*}{ Case } & \multicolumn{3}{|c|}{ WPO Selected } & \multicolumn{3}{|c|}{ ENDF/B-V } & \multicolumn{3}{|c|}{ ENDF/B-VI } \\
\hline & & $k_{\text {eft }}$ & $\sigma$ & AENCF & $\mathbf{k}_{\mathrm{eff}}$ & $\sigma$ & AENCF & $\mathbf{k}_{\mathrm{eff}}$ & $\sigma$ & AENCF \\
\hline 1 & core2 & 1.00058 & 0.00159 & \begin{tabular}{|l}
0.19988 \\
\end{tabular} & 1.00029 & 0.00147 & 0.19859 & 0.99441 & 0.00156 & 0.19779 \\
\hline 2 & core 3 & 1.00019 & 0.00148 & 0.18078 & 0.99991 & 0.00147 & 0.18029 & 0.99389 & 0.00152 & 0.17831 \\
\hline 3 & core4 & 0.9948 & 0.0015 & 0.17908 & 0.99429 & 0.00157 & 0.18206 & 0.99094 & 0.00149 & 0.17962 \\
\hline 4 & core5 & 0.99445 & 0.00153 & 0.16919 & 0.99226 & 0.00149 & 0.16804 & 0.99118 & 0.00157 & 0.16845 \\
\hline 5 & core6 & 0.99556 & 0.00152 & 0.17216 & 0.9924 & 0.00152 & 0.17097 & 0.98847 & 0.00155 & 0.17213 \\
\hline 6 & core7 & 0.99463 & 0.00151 & 0.15963 & 0.99357 & 0.00153 & 0.16113 & 0.99004 & 0.00155 & 0.15992 \\
\hline 7 & core8 & 0.98895 & 0.00149 & 0.16496 & 0.99294 & 0.00158 & 0.16116 & 0.99107 & 0.00154 & 0.16043 \\
\hline 8 & core9 & 0.99298 & 0.00144 & \begin{tabular}{|l|}
0.15528 \\
\end{tabular} & 0.9939 & 0.00152 & 0.15725 & 0.98803 & 0.00152 & 0.15449 \\
\hline 9 & core10 & 0.99511 & 0.00148 & 0.16036 & 0.99523 & 0.00147 & 0.1597 & 0.99204 & 0.00146 & 0.15896 \\
\hline 10 & core11 & 0.99699 & 0.00148 & 0.17893 & 0.99789 & 0.00153 & 0.17801 & 0.99693 & 0.00149 & 0.17822 \\
\hline 11 & core12 & 0.99549 & 0.00151 & \begin{tabular}{|l|}
0.16671 \\
\end{tabular} & 0.99658 & 0.00155 & 0.1677 & 0.99442 & 0.00148 & 0.16679 \\
\hline 12 & core13 & 0.99933 & 0.00151 & 0.18075 & 0.99594 & 0.00159 & 0.17945 & 0.99702 & 0.00154 & 0.17772 \\
\hline 13 & core15 & 0.99107 & 0.00157 & 0.18348 & 0.98476 & 0.0015 & 0.18301 & 0.98498 & 0.00151 & 0.18146 \\
\hline 14 & core16 & 0.99041 & 0.0015 & 0.16952 & 0.98967 & 0.00154 & 0.1703 & 0.98719 & 0.00162 & 0.16862 \\
\hline 15 & core17 & 0.99365 & 0.00151 & 0.18187 & 0.99534 & 0.00148 & 0.18122 & 0.98957 & 0.00153 & 0.18184 \\
\hline 16 & core18 & 0.9947 & 0.0015 & 0.16855 & 0.9938 & 0.0016 & $0 . \overline{16945}$ & 0.98602 & 0.00155 & 0.16933 \\
\hline 17 & core19 & 0.99383 & 0.00153 & 0.18354 & 0.99637 & 0.00146 & 0.18256 & 0.98955 & 0.00159 & 0.18185 \\
\hline 18 & core20 & 0.99392 & 0.00151 & 0.16933 & 0.99247 & 0.00157 & 0.17024 & 0.98777 & 0.00151 & 0.17006 \\
\hline 19 & core21 & 0.9916 & 0.0014 & 0.16225 & 0.99318 & 0.00146 & 0.16143 & 0.99135 & 0.00152 & 0.16011 \\
\hline 20 & $\exp 1$ & 1.00084 & 0.00088 & 0.12095 & 0.99958 & 0.00087 & 0.12037 & 0.99657 & 0.00093 & 0.12075 \\
\hline 21 & $\operatorname{exp2}$ & 0.99842 & 0.00088 & 0.12469 & 0.99762 & 0.00086 & 0.12291 & 0.99351 & 0.00097 & 0.12334 \\
\hline 22 & $\exp 3$ & 0.99898 & 0.00089 & 0.12172 & 1.00103 & 0.00091 & 0.12005 & 0.99613 & 0.00095 & 0.12083 \\
\hline 23 & $\exp 4$ & 1.00104 & 0.00087 & 0.12003 & 1.00241 & 0.00091 & 0.12057 & 0.99582 & 0.0009 & 0.12186 \\
\hline 24 & exp5 & 1.00037 & 0.00107 & 0.27968 & 0.9969 & 0.00103 & 0.28386 & 0.99295 & 0.00104 & 0.28018 \\
\hline 25 & exp6 & 0.99675 & 0.00103 & 0.17662 & 0.99772 & 0.00105 & 0.17775 & 0.9944 & 0.00111 & 0.17643 \\
\hline 26 & exp7 & 0.99724 & 0.00111 & 0.1784 & 0.99821 & 0.0011 & 0.17822 & 0.99144 & 0.00105 & 0.1773 \\
\hline 27 & $\exp 8$ & 1.00719 & 0.0011 & 0.17735 & 1.007 & 0.00102 & 0.17807 & 1.0033 & 0.00105 & 0.17769 \\
\hline 28 & exp9 & 1.00827 & 0.00099 & 0.22171 & 1.00687 & 0.00109 & 0.22393 & 1.00496 & 0.00105 & 0.22242 \\
\hline 29 & $\operatorname{exp10}$ & 1.0066 & 0.00174 & 0.2239 & 1.00499 & 0.00173 & 0.2225 & 1.00454 & 0.00182 & 0.22149 \\
\hline 30 & $\exp 11$ & 1.00358 & 0.00157 & 0.26643 & 1.00046 & 0.00177 & 0.26803 & 0.99995 & 0.00162 & 0.26652 \\
\hline 31 & $\operatorname{exp12}$ & 1.00546 & 0.00108 & 0.19461 & 1.00113 & 0.00105 & 0.19577 & 1.00189 & 0.00111 & 0.19235 \\
\hline 32 & $\exp 13$ & 1.00371 & 0.00113 & \begin{tabular}{|l|l|l|l}
0.19421 \\
\end{tabular} & 1.00363 & 0.00109 & 365 & 0.99936 & 0.00109 & 0.1936 \\
\hline 33 & exp14 & 0.99593 & 0.00099 & 0.20945 & 0.99534 & 0.00099 & 0.20881 & 0.98998 & 0.00099 & 0.20806 \\
\hline 34 & exp15 & 1.00074 & 0.00087 & 0.10984 & 1.00105 & 0.00088 & 0.10995 & 0.99603 & 0.00089 & 0.10902 \\
\hline 35 & exp17 & 1.00218 & 0.00186 & 0.15637 & 0.99815 & 173 & 34 & 0.99216 & 0.00173 & 0.15603 \\
\hline 36 & ugd1 & 1.00033 & 0.00143 & 0.20132 & 0.99717 & 0.0014 & 0.20069 & $0.9 \overline{9688}$ & 0.00149 & 0.19672 \\
\hline 37 & ugd20 & 1.00322 & 0.0 & & 1.00179 & 0.00159 & & 0.9971 & 0.00155 & 0.20429 \\
\hline 38 & ugd2 & 0.99945 & 0.00145 & 0.19828 & 0.99892 & 0.0015 & 0.20018 & 0.9947 & 0.00151 & 0.19858 \\
\hline 39 & ugd3 & 1.00054 & 0.00147 & 0.19948 & 0.99846 & 0.00145 & 0.19736 & 0.99449 & 0.00151 & 0.19988 \\
\hline 40 & ugd4 & 1.00193 & 0.0015 & 0.19985 & 0.99911 & 0.00144 & 0.19744 & 1.00031 & 0.00149 & 0.1993 \\
\hline 41 & ugd5 & 0.99955 & 0.00154 & & 0.99958 & 147 & & 0.99686 & 0.0015 & 0.19842 \\
\hline 42 & ugd6 & 0.99996 & 0.00152 & 0.19775 & 1.00229 & 0.00149 & 0.19897 & 0.9952 & 0.00154 & 0.19894 \\
\hline 43 & ugd7 & 1.0041 & 0.00148 & 0.19675 & 0.99807 & 0.00144 & 0.19896 & 0.99287 & 0.00147 & 0.19687 \\
\hline 44 & ugd 8 & 0.99929 & & & 0.99904 & 151 & & 0.99722 & 0.00147 & 0.19833 \\
\hline 45 & ugdg & 1.00135 & 0.00156 & 0.1 & 1.00042 & 159 & 63 & 0.99743 & 0.00148 & 0.19651 \\
\hline 46 & ugd10 & 0.9979 & 0.00144 & 0.2011 & 1.00115 & 0.00145 & 0.20029 & 0.99696 & 0.00151 & 0.19695 \\
\hline 47 & ugd12 & 0.9994 & 0.00161 & 0.20965 & 1.00178 & 0.00146 & 0.20785 & 1.00134 & 0.00149 & 0.2088 \\
\hline 48 & ugd13 & 1.00049 & & 0.20841 & 0.99887 & & & 1.00037 & 0.00148 & 0.2066 \\
\hline 49 & ugd14 & 1.00066 & 0.00156 & 0.20416 & 1.00069 & 0.00144 & 0.20585 & 0.99761 & 0.00153 & 0.20711 \\
\hline 50 & ugd15 & 1.00158 & 0.00151 & 0.2056 & 0.99927 & 0.00147 & 0.20333 & 0.9983 & 0.00156 & 0.20342 \\
\hline 51 & ugd 16 & 1.00335 & 0.00151 & 0.20648 & 0.99904 & 0.0015 & 947 & 0.99903 & 0.00158 & 0.20601 \\
\hline 52 & ugd17 & 0.99912 & 0.00151 & 0.20341 & 0.99909 & 0.00153 & 0.20572 & 0.998 & 0.00149 & 0.2024 \\
\hline 53 & ugd18 & 0.99876 & 0.0015 & 0.20851 & 0.99741 & 0.00156 & 0.21013 & 0.99819 & 0.00155 & 0.20862 \\
\hline 54 & ugd19 & 1.00133 & 0.00153 & 0.21011 & 0.99908 & 0.00155 & 0.20757 & 1.00098 & 0.00151 & 0.20506 \\
\hline 55 & Case_1 & 0.99436 & 0.00167 & 0.1229 & 0.9987 & 0.00191 & & 0.99248 & 0.00153 & 0.1227 \\
\hline 56 & Case_2 & 0.99445 & 0.00158 & 0.1223 & 0.99557 & 0.00185 & 0.1208 & 0.9923 & 0.00161 & 0.121 \\
\hline
\end{tabular}


Table 4.1-10. Low Enriched Uranium Oxide Fuel Pin Lattice Critical Experiments (Intermediate)

\begin{tabular}{|c|c|c|c|c|c|c|c|c|c|c|}
\hline \multirow{2}{*}{ Case } & \multicolumn{3}{|c|}{ WPO Selected } & \multicolumn{3}{c|}{ ENDF/B-V } & \multicolumn{3}{c|}{ ENDF/B-VI } \\
\cline { 3 - 11 } & & $\mathbf{k}_{\text {eff }}$ & $\sigma$ & AENCF & $\mathbf{k}_{\text {eff }}$ & $\sigma$ & AENCF & $\mathbf{k}_{\text {eff }}$ & $\sigma$ & AENCF \\
\hline 57 & Case_3 & 0.99982 & 0.00159 & 0.12 & 0.9957 & 0.00175 & 0.122 & 0.99637 & 0.00172 & 0.1221 \\
\hline 58 & Case_4 & 0.99313 & 0.00161 & 0.1222 & 0.99907 & 0.00144 & 0.1208 & 0.98949 & 0.00156 & 0.1207 \\
\hline 59 & Case_5 & 0.9931 & 0.00169 & 0.1204 & 0.99313 & 0.00157 & 0.1218 & 0.99429 & 0.00172 & 0.1187 \\
\hline 60 & Case_6 & 0.99831 & 0.00158 & 0.1221 & 0.99882 & 0.00143 & 0.1208 & 0.99161 & 0.00158 & 0.1219 \\
\hline 61 & Case_7 & 0.99261 & 0.00138 & 0.1211 & 0.99677 & 0.00143 & 0.1186 & 0.99578 & 0.00155 & 0.1176 \\
\hline 62 & Case_8 & 0.99888 & 0.00151 & 0.1209 & 1.00246 & 0.00162 & 0.1201 & 0.99597 & 0.00149 & 0.1214 \\
\hline 63 & subc2p8h & 1.00887 & 0.0032 & 0.4085 & 1.0048 & 0.00294 & 0.4085 & 1.01057 & 0.00335 & 0.4005 \\
\hline 64 & subc3p1h & 1.0335 & 0.00287 & 0.3417 & 1.03902 & 0.00248 & 0.3516 & 1.04014 & 0.0031 & 0.3447 \\
\hline 65 & subc3p4h & 1.01929 & 0.00238 & 0.3153 & 1.02088 & 0.00277 & 0.3145 & 1.01971 & 0.00266 & 0.3165 \\
\hline 66 & ssr83 & 0.99299 & 0.00074 & 0.18197 & 0.9928 & 0.00069 & 0.1821 & 0.98821 & 0.00073 & 0.18115 \\
\hline 67 & ssr48 & 0.9939 & 0.00071 & 0.15568 & 0.99396 & 0.00074 & 0.1564 & 0.99136 & 0.00072 & 0.15464 \\
\hline 68 & Ict27-1 & 1.0157 & 0.0005 & 0.1025 & 1.0139 & 0.0005 & 0.1024 & 1.0102 & 0.0006 & 0.1023 \\
\hline
\end{tabular}

NOTE: Index numbers 1 through 19 carry TBV-1357, index numbers 20 through 23 carry TBV-1362, index numbers 24 through 26 carry TBV-1363 and 1364, index numbers 27 through 30 carry TBV-1365, index numbers 31 and 32 carry TBV-1361, index numbers 33 and 34 carry TBV-1368, index numbers 36 through 54 carry TBV-1358, index numbers 63 through 65 carry TBV-1360, and index numbers 66 and 67 carry TBV-1359 and 1368

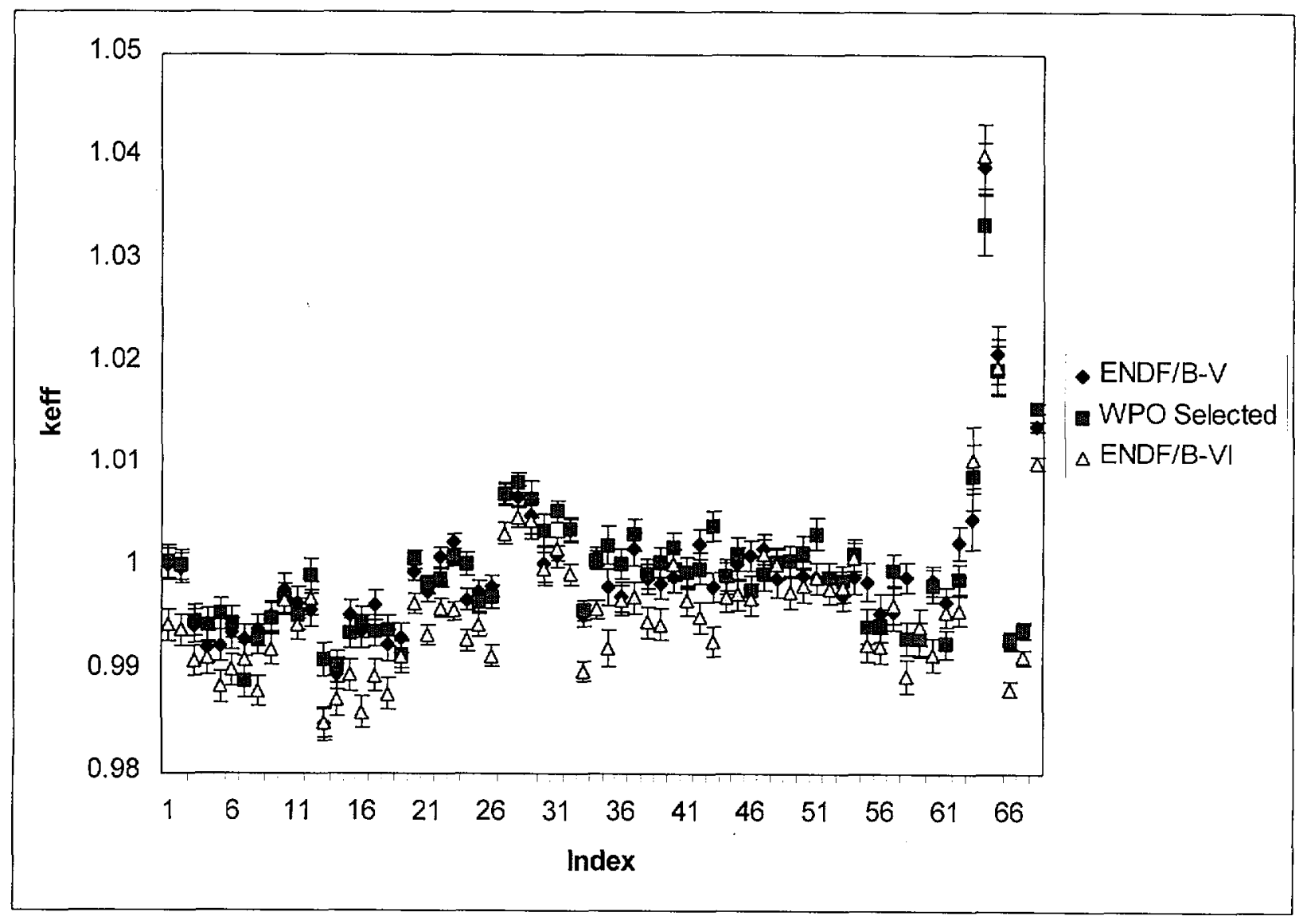

Figure 4.1-10. Low Enriched Uranium Oxide Fuel Pin Lattice Critical Experiments (Intermediate) 


\subsection{HOMOGENEOUS CRITICALS}

This section tabulates the MCNP $\mathrm{k}_{\text {eff }}$ results for the LCEs from CRWMS M\&O (1999b), CRWMS M\&O (1999c), and CRWMS M\&O (1999d) according to experimental similarities. Tables 4.2-1 through 4.2-12 and Figures 4.2-1 through 4.1-12 present the results for the LCEs according to the following distinct experimental classifications:

- Table and Figure 4.2-1: Homogeneous critical experiments using mixed Pu nitrate and U nitrate solutions (Thermal Systems)

- Table and Figure 4.2-2: Homogeneous critical experiments using Pu nitrate solutions (Thermal Systems)

- Table and Figure 4.2-3: Pu metal fast experiments (Fast Systems)

- Table and Figure 4.2-4: Homogeneous critical experiments using HEU nitrate solutions (Thermal Systems)

- Table and Figure 4.2-5: HEU metal fast experiments (Fast Systems)

- Table and Figure 4.2-6: Homogeneous critical experiments using IEU nitrate solutions (Thermal Systems)

- Table and Figure 4.2-7: Homogeneous critical experiments using IEU nitrate solutions (Intermediate Systems)

- Table and Figure 4.2-8: IEU metal fast experiments (Fast Systems)

- Table and Figure 4.2-9: Homogeneous critical experiments using LEU nitrate solutions (Thermal Systems)

- Table and Figure 4.2-10: Homogeneous critical experiments using LEU nitrate solutions (Intermediate Systems)

- Table and Figure 4.2-11: Homogeneous critical experiments using ${ }^{233} \mathrm{U}$ fuel (Thermal Systems)

- Table and Figure 4.2-12: Homogeneous critical experiments using ${ }^{233} \mathrm{U}$ fuel (Fast Systems)

The column identified as AENCF contains the average energy of the neutron causing fission. It is a measure of the energy spectrum of the neutrons and has units of $\mathrm{MeV}$.

It should be noted that unaccepted data were used in the development of the results presented in Table 4.2-9 for the LEUJA cases. These values carry TBV-1370. 
Table 4.2-1. Homogeneous Critical Experiments Using Mixed Plutonium and Natural Uranium Nitrate Solutions (Thermal)

\begin{tabular}{|c|c|c|c|c|c|c|c|c|c|c|}
\hline \multirow[b]{2}{*}{$\#$} & \multirow{2}{*}{ Case } & \multicolumn{3}{|c|}{ WPO Selected } & \multicolumn{3}{|c|}{ ENDF/B-V } & \multicolumn{3}{|c|}{ ENDF/B-VI } \\
\hline & & $k_{\text {eff }}$ & $\sigma$ & AENCF & $k_{\text {eff }}$ & 0 & AENCF & $\mathbf{k}_{\text {eff }}$ & 0 & AENCF \\
\hline 1 & 87 & 0.99821 & 00116 & 04158 & 0.99762 & 0.00116 & .04174 & 0.98843 & 0.00105 & 0.04181 \\
\hline 2 & & 00318 & & & 0.99425 & 0.00116 & & 0.98609 & 0.00104 & 0.0413 \\
\hline 3 & & & & & 44 & 0.00 & & (1000ח & 000140 & \\
\hline 4 & & 9694 & & & 0.99727 & $\overline{111}$ & & & & \\
\hline 5 & & 00275 & $\overline{00113}$ & 0.04483 & 1.00255 & 0.00118 & 0.04452 & 0.99364 & 0.00116 & .04427 \\
\hline 6 & & & & 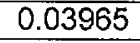 & & & & & & \\
\hline 7 & & & & & & & & 0.9928 & 0.00107 & .02061 \\
\hline 8 & & 1.00263 & & & 1.00235 & 0.00124 & 0.02319 & 0.99527 & & \\
\hline 9 & & & & & & & & & & 1426 \\
\hline 10 & & & & & & & & 28 & 16 & 0.03 \\
\hline 11 & & 1.00 & & 0.02 & & & & & & 0.02906 \\
\hline 12 & & & & & & & & & & 0.02891 \\
\hline 13 & & & & & & & & & & 0.00386 \\
\hline 14 & & 1. & & & 1.00 & & & 1.00244 & 0.00069 & \\
\hline 15 & & & & 000 & & & & & 0.0006 & 0.00605 \\
\hline 16 & & 1.01 & & & & & & & & \\
\hline 17 & & & & & & & & 67 & 15 & \\
\hline 18 & & & & & & & & 81 & & \\
\hline 19 & & & & & & & & & & 0.0 \\
\hline 20 & & & & & 47 & & & & & 28 \\
\hline 21 & & & & & & & & & 07 & 41 \\
\hline 22 & & & & & & & & 0.9 & & 0.0 \\
\hline 23 & & & & 0.0 & 1.0 & & & & & 0.00682 \\
\hline 24 & & & & & & & & 207 & & 0.0 \\
\hline 25 & & & & & 1.0 & & & 1.00221 & & 352 \\
\hline 26 & & 5 & & & & & & & & \\
\hline 27 & & 9976 & & & & & & & & 0.05 \\
\hline 28 & & & & & 0.99 & & & 0.99258 & 0.0 & \\
\hline 29 & & & & & & & & & & 0.0 \\
\hline 30 & & 0.99967 & & & & & & & & 334 \\
\hline 31 & & & & 0.03 & 0.99956 & & & 0.99312 & & \\
\hline 32 & & & & & 1.00 & & & 0.99786 & 0.00119 & 0.01298 \\
\hline 33 & & & & & & & & 0.99694 & $\overline{09}$ & 0.0 \\
\hline & & 1.00629 & 0.00113 & 0.01197 & 1.00607 & 0.00 & & & & \\
\hline
\end{tabular}




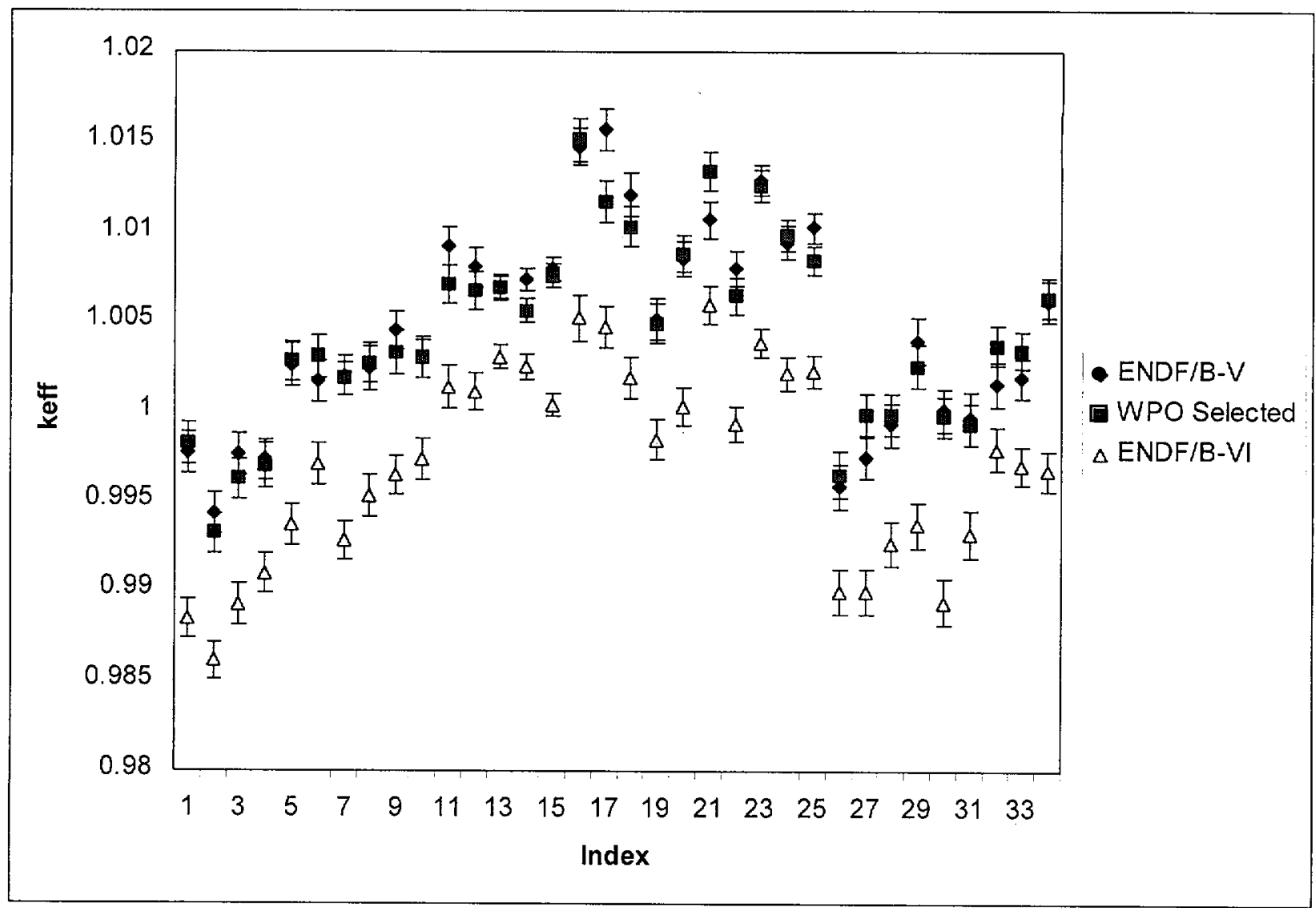

Figure 4.2-1. Homogeneous Critical Experiments Using Mixed Plutonium and Natural Uranium Nitrate Solutions (Thermal) 
Table 4.2-2. Homogeneous Critical Experiments Using Plutonium Nitrate Solutions (Thermal)

\begin{tabular}{|c|c|c|c|c|c|c|c|c|c|c|}
\hline \multirow{2}{*}{ \# } & \multirow{2}{*}{ Case } & \multicolumn{3}{|c|}{ WPO Selected } & \multicolumn{3}{|c|}{ ENDF/B-V } & \multicolumn{3}{|c|}{ ENDF/B-VI } \\
\hline & & $\overline{\mathbf{k}_{\text {eff }}}$ & $\sigma$ & AENCF & $\overline{\mathbf{k}_{\text {eff }}}$ & $\sigma$ & AENCF & $\overline{k_{\text {eff }}}$ & $\sigma$ & AENCF \\
\hline 1 & pust1t1 & 1.00995 & 0.00102 & 0.01252 & 1.01064 & 0.00101 & 0.0126 & 1.00058 & \begin{tabular}{|l|}
0.00102 \\
\end{tabular} & 0.01301 \\
\hline 2 & pust1t2 & 1.01109 & 0.001 & 0.01702 & 1.01278 & 0.001 & 0.01722 & 1.00408 & \begin{tabular}{|l|}
0.00104 \\
\end{tabular} & 0.01715 \\
\hline 3 & pust1t3 & 1.01396 & 0.00094 & 0.02159 & 1.01447 & 0.00105 & 0.02086 & 1.00692 & 0.00106 & 0.02172 \\
\hline 4 & pust1t4 & 1.00643 & 0.00104 & 0.02397 & 1.00766 & 0.00105 & 0.02374 & 0.99921 & \begin{tabular}{|l}
0.00107 \\
\end{tabular} & 0.02405 \\
\hline 5 & pust 1t5 & 1.01014 & 0.00101 & .0 .02479 & 1.01107 & 0.00099 & 0.02464 & 1.00222 & \begin{tabular}{|l}
0.00103 \\
\end{tabular} & 0.02514 \\
\hline 6 & pust 1t6 & 1.00831 & 0.00104 & 0.04809 & 1.01003 & 0.00104 & 0.04883 & 1.00585 & \begin{tabular}{|l}
0.00105 \\
\end{tabular} & 0.0481 \\
\hline 7 & pu003-1 & 1.00962 & 0.00091 & 0.00623 & 1.0089 & 0.0009 & 0.00634 & 1.00208 & 0.00095 & 0.00631 \\
\hline 8 & pu003-2 & 1.00885 & 0.00091 & 0.00651 & 1.00764 & 0.00091 & 0.00655 & 1.00029 & 0.00091 & 0.00664 \\
\hline 9 & \begin{tabular}{|l|} 
pu003-3 \\
\end{tabular} & 228 & 0.00092 & 0.00693 & 1.0116 & 0.00095 & 0.00696 & 1.00324 & 0.00097 & 0.00711 \\
\hline 10 & \begin{tabular}{|l|} 
pu003-4 \\
\end{tabular} & 1.00965 & 0.00094 & 0.0072 & 1.01162 & 0.00097 & 0.00723 & 1.00401 & 0.00092 & 0.00731 \\
\hline 11 & pu003-5 & 1.01393 & 0.00092 & 0.00785 & 1.01162 & 0.00091 & 0.00772 & 1.00371 & 0.0009 & 0.00736 \\
\hline 12 & \begin{tabular}{|l|} 
pu003-6 \\
\end{tabular} & 1.01214 & 0.00091 & 0.00845 & 1.01275 & 0.00097 & 0.00858 & 1.00425 & 0.00094 & 0.00863 \\
\hline 13 & \begin{tabular}{|l|} 
pu003-7 \\
\end{tabular} & 1.01369 & 0.00093 & 0.00678 & 1.01438 & 0.00092 & 0.00669 & 1.00545 & 0.00092 & 0.00667 \\
\hline 14 & \begin{tabular}{|l} 
pu003-8 \\
\end{tabular} & 1.01175 & 0.00095 & 0.00703 & 1.01194 & 0.00093 & 0.00681 & 1.00196 & 0.00096 & 0.007 \\
\hline 15 & pu004-1 & 1.01134 & 0.00088 & 0.00524 & 1.01168 & 0.00086 & 0.00515 & 1.00302 & 0.00087 & 0.00521 \\
\hline 16 & \begin{tabular}{|l|} 
pu004-2 \\
\end{tabular} & 1.00448 & 0.00082 & 0.00541 & 1.00671 & 0.00085 & 0.00534 & 0.99646 & 0.00095 & 0.00517 \\
\hline 17 & \begin{tabular}{|l|} 
pu004-3 \\
\end{tabular} & 1.00916 & 0.00087 & 0.00538 & 1.0087 & 0.00091 & 0.00555 & 0.9994 & 0.00085 & 0.00542 \\
\hline 18 & \begin{tabular}{|l|} 
pu004-4 \\
\end{tabular} & 1.00712 & 0.00086 & 0.00561 & 1.00559 & 0.0009 & 0.00563 & 0.99678 & 0.00094 & 0.00569 \\
\hline 19 & pu004-5 & 1.00753 & 0.00091 & 0.00543 & 1.00684 & 0.00088 & 0.00544 & 1.00082 & 0.00087 & 0.00538 \\
\hline 20 & pu004-6 & 1.00862 & 0.00087 & 0.00564 & 1.00867 & 0.00089 & 0.00572 & 1.00092 & 0.00088 & 0.00549 \\
\hline 21 & pu004-7 & 1.01248 & 0.0009 & 0.0056 & 1.01179 & 0.00086 & 0.00582 & 1.00513 & 0.00087 & 0.00582 \\
\hline 22 & pu004-8 & $1 . \overline{00778}$ & 0.00086 & 0.0062 & 1.00786 & 0.00088 & 0.00593 & 0.99815 & 0.00089 & 0.00599 \\
\hline 23 & pu004-9 & 1.00965 & 0.00089 & 0.00619 & 1.0091 & 0.00087 & 0.00615 & 0.99749 & 0.00089 & 0.00643 \\
\hline 24 & pu005-1 & 1.0086 & 0.00088 & 0.00571 & 1.00871 & 0.00089 & 0.00568 & 1.00322 & 0.00087 & 0.00583 \\
\hline 25 & $\mathrm{puc}$ & 1.00908 & 0.00088 & 0.00589 & 1.01075 & 0.00091 & 0.00579 & 0.99995 & 0.00088 & 0.00587 \\
\hline 26 & pu005-3 & 1.01116 & 0.00091 & 0.0062 & 1.01227 & 0.00087 & 0.00622 & 1.00236 & 0.00092 & 0.00614 \\
\hline 27 & \begin{tabular}{|l|} 
pu005-4 \\
\end{tabular} & 1.01197 & 0.00093 & 0.00664 & 1.01183 & 0.00088 & 0.00678 & 1.00279 & 0.00088 & 0.00665 \\
\hline 28 & puc & 1.01367 & 0.0009 & 0.00723 & 1.01254 & 0.00088 & 0.00725 & 1.00389 & 0.00093 & 0.00758 \\
\hline 29 & pu005-6 & 1.0102 & 0.00095 & 0.00766 & 1.01279 & 0.00092 & 0.0078 & 1.00338 & 0.00092 & 0.00771 \\
\hline 30 & \begin{tabular}{|l|} 
pu005-7 \\
\end{tabular} & 1.01073 & 0.00094 & 0.00838 & 1.01031 & 0.00094 & 0.00837 & 1.00194 & 093 & 0.00845 \\
\hline 31 & pu005-8 & $1 . \overline{00799}$ & 0.00091 & 0.00593 & 1.00559 & 0.0009 & 0.00608 & 0.99915 & 0.00089 & 0.006 \\
\hline 32 & pu005-9 & 1.01023 & 0.00089 & 0.00631 & 1.00929 & 0.00086 & 0.00638 & 0.99937 & 0.00088 & 0.00618 \\
\hline 33 & \begin{tabular}{|l|} 
pu007-2 \\
\end{tabular} & 1.01024 & 0.00102 & 0.04021 & 1.01358 & 0.00109 & 0.04098 & 1.00561 & 0.00106 & 0.0412 \\
\hline 34 & pu007-3 & 1.00591 & 0.00111 & 0.03928 & 1.00535 & 0.00104 & 0.03969 & 0.99948 & 0.00105 & 0.03932 \\
\hline 35 & $\mathrm{put}$ & 1.01502 & 0.00106 & 0.01764 & 1.01438 & 0.0 & 0.01754 & 1.00665 & 0.00104 & 0.01758 \\
\hline 36 & pu007-6 & 1.00873 & 0.00101 & 0.01799 & 1.00808 & 0.00106 & 0.01773 & 1.00134 & 0.001 & 0.01757 \\
\hline 37 & pu007-7 & 1.01053 & 0.00103 & 0.01783 & 1.01039 & 0.00105 & 0.0177 & 1.00333 & 0.00101 & 0.01747 \\
\hline 38 & $\begin{array}{l}\text { pu007-8 } \\
\end{array}$ & 1.00254 & 0.00103 & 0.0181 & 1.00512 & 0.00102 & 0.01796 & 0.99316 & 0.00105 & 0.01783 \\
\hline 39 & pu007-9 & 1.00327 & 0.00106 & 0.01815 & 1.00267 & 0.00108 & 0.01795 & 0.99427 & 0.00106 & 0.01774 \\
\hline 40 & pu04-10 & 1.00987 & 0.00092 & 0.00715 & 1.00979 & 0.00092 & 0.0072 & 1.00196 & 093 & 0.00734 \\
\hline 41 & $\mathrm{pu0}$ & 1.0095 & 0.00 & 0.00805 & 1.00799 & 0.00096 & 0.00849 & 0.99716 & 0.00092 & 0.00836 \\
\hline 42 & pul & 1.01108 & 0.00087 & 0.00594 & 1.01028 & 0.00092 & 0.0 & 1.0028 & 0.00087 & 0.00572 \\
\hline 43 & pu04-13 & 1.00856 & 0.00091 & 0.00579 & 1.00634 & 0.00089 & 0.0 & 0.99942 & 0.00091 & 0.00585 \\
\hline 44 & pu07-10 & 1.00706 & 0.00104 & 0.01653 & 1.00643 & 0.00101 & 0.01711 & 0.99653 & 0.00106 & 0.0162 \\
\hline 45 & put & 1.02337 & 0.00101 & 0.01675 & 1.02188 & 0.00105 & 0.01658 & 1.01378 & 0.00102 & 0.01672 \\
\hline 46 & pu10092 & 1.02091 & 0.00097 & 0.01299 & 1.01932 & 0.00103 & 0.0127 & 1.01053 & 0.00097 & 0.01272 \\
\hline 47 & pu10093 & 1.01316 & 0.00097 & 0.00994 & 1.01428 & 0.00099 & 0.0093 & 1.00474 & 0.00096 & 0.00969 \\
\hline 48 & & 1.01879 & 0.00099 & 0.01001 & 1.01833 & 0.00095 & 0.01026 & 1.01211 & 0.00102 & 0.00985 \\
\hline 49 & 112 & 1.01543 & 0.00098 & 0.00873 & 1.01691 & 0.00096 & 0.00888 & 1.00964 & 0.00097 & 0.00862 \\
\hline 50 & pu10113 & 1.01615 & 0.00092 & 0.00852 & 1.01378 & 0.00097 & 0.00867 & 1.00701 & 0.00097 & 0.00876 \\
\hline 51 & pu1 & 1.00903 & 0.00091 & 0.0079 & 1.00854 & 0.00093 & 0.00798 & 0.99799 & 0.00096 & 0.0081 \\
\hline 52 & pu10115 & 1.01069 & 0.00093 & 0.00755 & 1.01003 & 0.0009 & 0.00753 & 1.00213 & 0.00093 & 0.00734 \\
\hline 53 & pu10116 & 1.01992 & 0.00101 & 0.01114 & 1.01922 & 0.001 & 0.01109 & 1.01027 & 0.00102 & 0.01128 \\
\hline 54 & pu10117 & 1.01146 & 0.00092 & 0.00879 & 1.00973 & 0.001 & 0.00901 & 1.0005 & 0.00094 & 0.0092 \\
\hline 55 & pu10121 & 1.0156 & 0.00097 & 0.00896 & 1.01726 & 0.00096 & 0.00892 & 1.00876 & 0.00094 & 0.00896 \\
\hline 56 & pu10122 & 1.01616 & 0.00095 & 0.00776 & 1.0153 & 0.00098 & 0.00795 & 1.0067 & 0.00096 & 0.00776 \\
\hline
\end{tabular}


Table 4.2-2. Homogeneous Critical Experiments Using Plutonium Nitrate Solutions (Thermal)

\begin{tabular}{|l|c|c|c|c|c|c|c|c|c|c|}
\hline \multirow{2}{*}{$\#$} & \multirow{2}{*}{ Case } & \multicolumn{3}{|c|}{ WPO Selected } & \multicolumn{3}{c|}{ ENDF/B-V } & \multicolumn{3}{c|}{ ENDF/B-VI } \\
\cline { 3 - 11 } & & $\mathbf{k}_{\text {eff }}$ & $\sigma$ & AENCF & $\mathbf{k}_{\text {eff }}$ & $\sigma$ & AENCF & $\mathbf{k}_{\text {eff }}$ & $\sigma$ & AENCF \\
\hline 57 & pu10123 & 1.02352 & 0.00094 & 0.00691 & 1.02207 & 0.00095 & 0.00671 & 1.01591 & 0.00093 & 0.00699 \\
\hline 58 & pu10124 & 1.01642 & 0.00087 & 0.0061 & 1.01695 & 0.00089 & 0.00594 & 1.00717 & 0.0009 & 0.00599 \\
\hline 59 & pu11161 & 1.01661 & 0.00103 & 0.00738 & 1.01669 & 0.00101 & 0.00737 & 1.0111 & 0.001 & 0.00744 \\
\hline 60 & pu11162 & 1.02377 & 0.00101 & 0.00777 & 1.02064 & 0.00103 & 0.00759 & 1.01343 & 0.00098 & 0.00773 \\
\hline 61 & pu11163 & 1.02224 & 0.00101 & 0.00827 & 1.02545 & 0.001 & 0.00829 & 1.01656 & 0.00104 & 0.00794 \\
\hline 62 & pu11164 & 1.01688 & 0.00105 & 0.00845 & 1.01704 & 0.00101 & 0.00851 & 1.00895 & 0.00101 & 0.00808 \\
\hline 63 & pu11165 & 1.01338 & 0.00104 & 0.00973 & 1.01318 & 0.00104 & 0.00955 & 1.00576 & 0.00102 & 0.00988 \\
\hline 64 & pu11181 & 1.00169 & 0.00089 & 0.00505 & 1.00317 & 0.00088 & 0.00501 & 0.99468 & 0.00091 & 0.00503 \\
\hline 65 & pu11182 & 1.0068 & 0.00088 & 0.00549 & 1.00894 & 0.00091 & 0.00527 & 1.00073 & 0.00088 & 0.0051 \\
\hline 66 & pu11183 & 1.00336 & 0.00097 & 0.00514 & 1.0051 & 0.00091 & 0.00528 & 0.99776 & 0.00092 & 0.00512 \\
\hline 67 & pu11184 & 1.00285 & 0.00088 & 0.00547 & 1.00198 & 0.00088 & 0.00525 & 0.99428 & 0.00087 & 0.00545 \\
\hline 68 & pu11185 & 1.01131 & 0.00093 & 0.00593 & 1.00964 & 0.00095 & 0.00588 & 1.0044 & 0.00089 & 0.00574 \\
\hline 69 & pu11186 & 1.00796 & 0.00097 & 0.00633 & 1.00717 & 0.00094 & 0.00634 & 1.00011 & 0.00093 & 0.0062 \\
\hline 70 & pu11187 & 1.00792 & 0.00088 & 0.00548 & 1.00729 & 0.00091 & 0.0054 & 0.99943 & 0.00087 & 0.00533 \\
\hline 71 & pust9-1 & 1.01886 & 0.00088 & 0.00257 & 1.01992 & 0.00082 & 0.00294 & 1.01103 & 0.00074 & 0.00259 \\
\hline 72 & pust9-2 & 1.0239 & 0.00089 & 0.00266 & 1.02331 & 0.00083 & 0.00262 & 1.01723 & 0.00078 & 0.00259 \\
\hline 73 & pust9-3 & 1.02176 & 0.00089 & 0.00246 & 1.0209 & 0.00083 & 0.00251 & 1.01755 & 0.00076 & 0.00245 \\
\hline
\end{tabular}

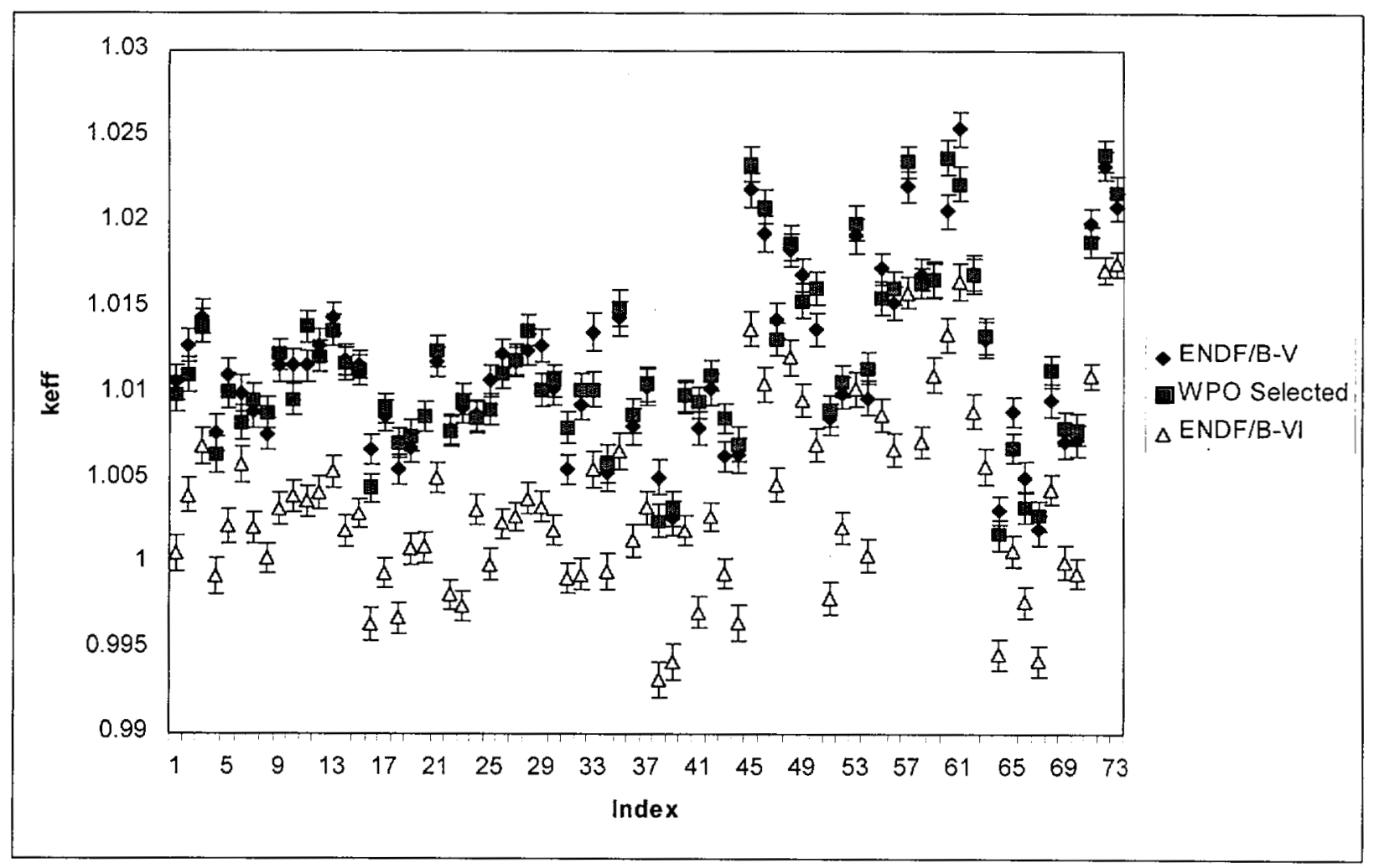

Figure 4.2-2. Homogeneous Critical Experiments Using Plutonium Nitrate Solutions (Thermal) 
Table 4.2-3. Plutonium Metal Critical Experiments (Fast)

\begin{tabular}{|c|c|c|c|c|c|c|c|c|c|c|}
\hline \multirow{2}{*}{$\#$} & \multirow{2}{*}{ Case } & \multicolumn{3}{|c|}{ WPO Selected } & \multicolumn{3}{c|}{ ENDF/B-V } & \multicolumn{3}{c|}{ ENDF/B-VI } \\
\cline { 3 - 11 } & & $\mathbf{k}_{\text {eff }}$ & $\sigma$ & AENCF & $\mathbf{k}_{\text {eff }}$ & $\sigma$ & AENCF & $\mathbf{k}_{\text {eff }}$ & $\sigma$ & AENCF \\
\hline 1 & PMF20 & 0.99968 & 0.00065 & 1.8886 & 1.00085 & 0.00064 & 1.8895 & 0.99878 & 0.00062 & 1.8960 \\
\hline 2 & PMF22 & 0.99459 & 0.00055 & 1.8932 & 0.99627 & 0.00057 & 1.8914 & 0.99707 & 0.00051 & 1.9004 \\
\hline 3 & PMF23 & 0.99681 & 0.00058 & 1.8011 & 0.99742 & 0.00059 & 1.7988 & 0.99869 & 0.00061 & 1.8070 \\
\hline 4 & PMF24 & 0.99756 & 0.00066 & 1.7421 & 0.99781 & 0.00065 & 1.7418 & 1.00122 & 0.00064 & 1.7414 \\
\hline 5 & PMF25 & 0.99601 & 0.00057 & 1.8316 & 0.99835 & 0.00062 & 1.8293 & 0.9971 & 0.00064 & 1.8431 \\
\hline 6 & PMF26 & 0.99551 & 0.00064 & 1.7318 & 1.00167 & 0.00059 & 1.7250 & 0.99754 & 0.00057 & 1.7407 \\
\hline 7 & PMF27 & 1.00113 & 0.00076 & 1.4768 & 1.00178 & 0.00078 & 1.4726 & 1.00258 & 0.00073 & 1.4768 \\
\hline 8 & PMF28 & 0.99739 & 0.00065 & 1.7166 & 1.00324 & 0.00063 & 1.7100 & 0.99891 & 0.0006 & 1.7229 \\
\hline 9 & PMF29 & 0.9933 & 0.00055 & 1.9188 & 0.99309 & 0.00056 & 1.9154 & 0.99463 & 0.00058 & 1.9254 \\
\hline 10 & PMF30 & 1.00129 & 0.00063 & 1.8152 & 1.00078 & 0.00066 & 1.8138 & 1.00176 & 0.00057 & 1.8213 \\
\hline 11 & PMF31 & 1.00104 & 0.0007 & 1.6059 & 1.00208 & 0.00073 & 1.6057 & 1.00305 & 0.00074 & 1.6082 \\
\hline 12 & PMF32 & 0.99667 & 0.00061 & 1.8192 & 0.99938 & 0.0006 & 1.8113 & 0.9964 & 0.00065 & 1.8263 \\
\hline
\end{tabular}

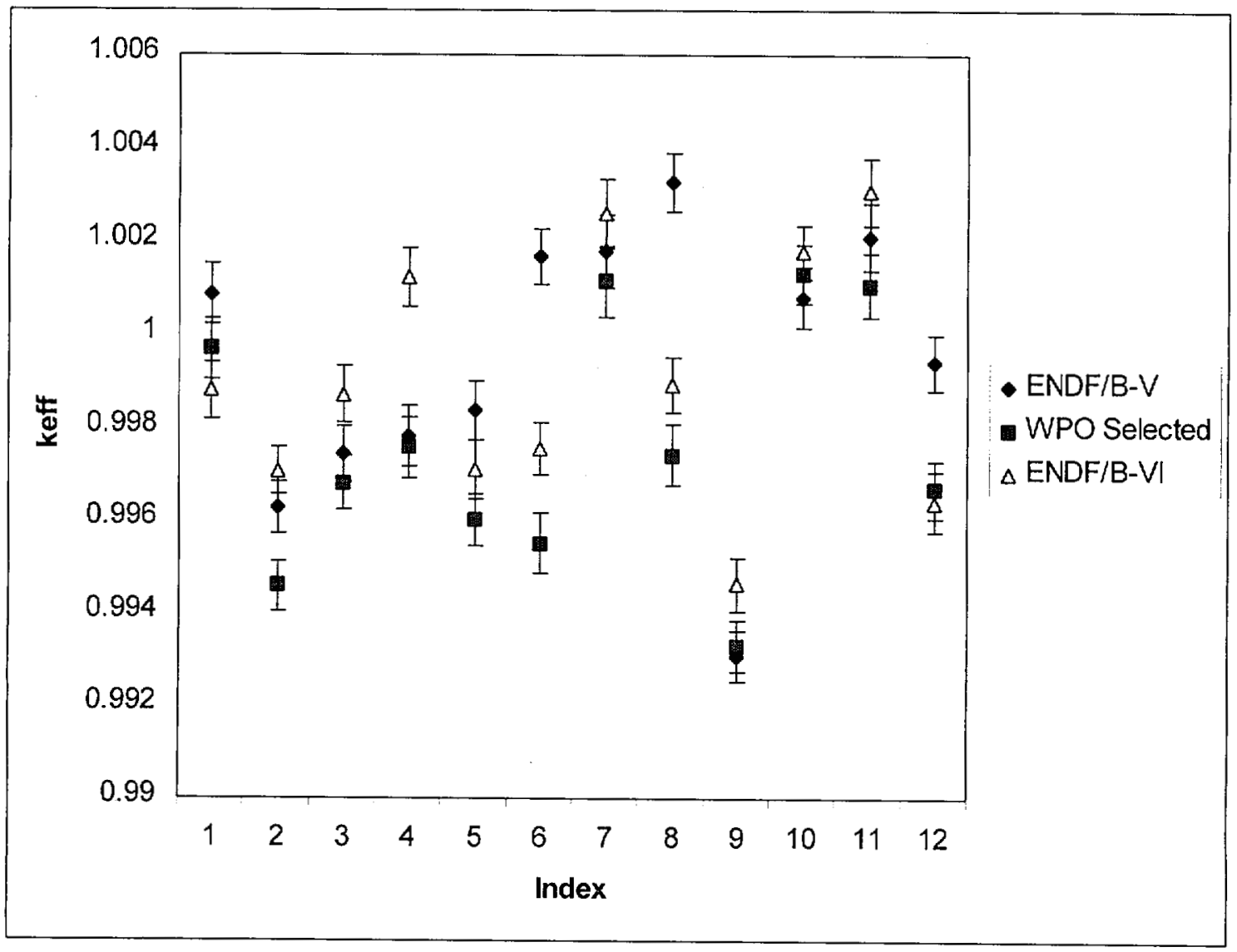

Figure 4.2-3. Plutonium Metal Critical Experiments (Fast) 
Table 4.2-4. Homogenous Critical Experiments Using High Enriched Uranium Nitrate Solutions (Thermal)

\begin{tabular}{|c|c|c|c|c|c|c|c|c|c|c|}
\hline \multirow[b]{2}{*}{ \# } & \multirow{2}{*}{ Ise } & \multicolumn{3}{|c|}{ WPO Selected } & \multicolumn{3}{|c|}{ ENDF/B-V } & \multicolumn{3}{|c|}{ ENDF/B-VI } \\
\hline & & $\mathbf{k}_{\text {eff }}$ & 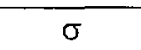 & AENCF & $\overline{\mathbf{k}_{\text {eff }}}$ & $x_{-1}$ & AENCF & $\mathrm{k}_{\text {eff }}$ & $\sigma$ & AENCF \\
\hline 1 & $t 1-1$ & 1.00187 & 0.00144 & 0.01576 & 1.00241 & 0.00131 & 0.01582 & 0.99683 & .00138 & 0.01567 \\
\hline 2 & & 99468 & 0.00178 & 00757 & 0.99468 & 0.00178 & 00757 & 0.98954 & 0.0018 & 00750 \\
\hline 3 & & & & & & & & & & 779 \\
\hline 4 & & 0453 & & 1546 & 00453 & & & & & \\
\hline 5 & & 00138 & 0.00053 & 00265 & 1.00135 & 0.0005 & .00267 & 0.99705 & .00055 & \\
\hline 6 & & & 00057 & & 1.0002 & & 307 & 0.99678 & 056 & \\
\hline 7 & & 99521 & & & & & 0378 & 0.99282 & & \\
\hline 8 & & 99824 & 0.00066 & 00379 & 0.99777 & 0.00061 & .00374 & 0.99519 & 0.00062 & 0.00381 \\
\hline 9 & & & & & 1.0013 & & 405 & 00107 & & \\
\hline 10 & & & & 0.00727 & 0.99854 & 0.00119 & .00716 & 0.99204 & & \\
\hline 11 & & 01252 & 0.00121 & 0.00737 & 1.01307 & 0.00115 & 0.0073 & 1.00965 & 0.00106 & 0.0071 \\
\hline 12 & & & 0.0 & & 02137 & 0.00109 & 0.00775 & .01882 & & \\
\hline 13 & & 0361 & 0.00166 & & 1.00361 & 0.00166 & .00651 & 0.99849 & & \\
\hline 14 & & & 0.00 & 47 & 1.0058 & 0.00123 & 0.01056 & 0.99834 & 0.00128 & 048 \\
\hline 15 & & & 0. & & 99295 & 0.00125 & .00998 & 98944 & & \\
\hline 16 & & & 0.00 & & .00874 & & 01127 & .00941 & & \\
\hline 17 & & & 0.00121 & 0.01077 & 1.01579 & & 0.0104 & 1.01185 & 0122 & 032 \\
\hline 18 & & & & & 77 & & & 01178 & & \\
\hline 19 & & & & & & & & 00073 & & \\
\hline 20 & & & 0.00131 & 0.01517 & 0.9922 & & & 98628 & 0.00129 & \\
\hline 21 & & & & & 8 & & & 1.01039 & & \\
\hline 22 & & & & & & & & 723 & & \\
\hline 23 & & 0023 & 0.00201 & & 1.0023 & & & 0.99985 & 0.002 & \\
\hline 24 & & & & & 32 & & & 0.9909 & 0.00118 & \\
\hline 25 & & & & & & & & 97993 & & \\
\hline 26 & & & & & 77 & & & 985 & & \\
\hline 27 & & & & & & & & 1.0005 & & 377 \\
\hline 28 & & & & & & & & & & \\
\hline 29 & & & & & & & & & & \\
\hline 30 & & & & & & & 87 & 984 & & \\
\hline 31 & & & & & & & & & & \\
\hline 32 & & & & & & & & & & \\
\hline 33 & & & & & & & & 0.9897 & & \\
\hline 34 & & & & & & & & & & \\
\hline 35 & & & & & & & & & & \\
\hline 36 & & & & & & & & & & \\
\hline 37 & & & & & & & & & & \\
\hline 38 & & & & & & & & & & \\
\hline 39 & & & & & & & & & & \\
\hline 40 & & & & & & & & & & \\
\hline 41 & & & & & & & & & & \\
\hline 42 & & & & & & & & & & \\
\hline 43 & & & & & & & & & & \\
\hline 44 & & & & & & & & & & \\
\hline 45 & & & & & & & & 0.99996 & & \\
\hline 46 & & & & & & & & 1.00211 & & \\
\hline 47 & & & & & & & & & & \\
\hline 48 & & & 24 & & 1.0 & & & & & \\
\hline 49 & & & & & & & & 1.00489 & 11 & \\
\hline 50 & & & & & & & & 1.00223 & & \\
\hline 51 & & & 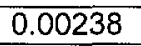 & & & & & & & \\
\hline 52 & & & & & 1.00773 & 0.0 & 0.01516 & 1.00627 & 37 & \\
\hline 53 & & & & & & & & & & \\
\hline 54 & & 1. & 0.00 & & & & & & & \\
\hline 55 & & & $0.00<10$ & 0.0158 & 1.01049 & & 0.01622 & 1.00531 & 17 & \\
\hline 56 & home & & 0.00228 & 0.01469 & 1.00968 & 0.00215 & 0.01496 & 1.00976 & 0.00233 & 0.01493 \\
\hline
\end{tabular}


Table 4.2-4. Homogenous Critical Experiments Using High Enriched Uranium Nitrate Solutions (Thermal)

\begin{tabular}{|c|c|c|c|c|c|c|c|c|c|c|}
\hline \multirow{2}{*}{ \# } & \multirow[b]{2}{*}{ ase } & \multicolumn{3}{|c|}{ WPO Selected } & \multicolumn{3}{|c|}{ ENDF/B-V } & \multicolumn{3}{|c|}{ ENDF/B-VI } \\
\hline & & $\mathbf{k}_{\mathbf{e f f}}$ & 0 & $A$ & $k_{\text {eff }}$ & $\sigma$ & AENCF & $\mathbf{k}_{\text {eff }}$ & - & $\overline{A E N C}$ \\
\hline 57 & $s+2-7$ & 1.00383 & 0021 & 03659 & .00691 & 022 & .03747 & .99994 & 00248 & 0.03548 \\
\hline 58 & st $2-8$ & 100883 & 00244 & 03423 & .01131 & 0.00206 & .03511 & 1.00552 & 0.0026 & 0.03454 \\
\hline 59 & & & & & & & & & & 0658 \\
\hline 60 & & & & & 00102 & 0243 & 3817 & & & \\
\hline 61 & & 00606 & 0.00232 & 03566 & .00606 & 0.00232 & 0.03566 & 1.00244 & .00231 & 0.03476 \\
\hline 62 & & & 00204 & & & .00204 & & & 0.00233 & \\
\hline 63 & & & & & & & & & 183 & 0.00634 \\
\hline 64 & & 1.00822 & 0.00205 & 00704 & 1.00822 & 0.00205 & 0.00704 & 0.99809 & 0.00207 & 0.0068 \\
\hline 65 & & 0.9962 & 6 & & 75 & 0.0015 & & & & \\
\hline 66 & & & & & & & & 92 & & \\
\hline 67 & & 1.00604 & 0.00213 & & 1.00604 & 0.00213 & & 1.00364 & .00237 & 149 \\
\hline 68 & & - & anch & & & 0.00225 & & & & \\
\hline 69 & & & & & & & & & & \\
\hline 70 & & 1.0 & 0.00 & & & 111 & & 1.01111 & 117 & \\
\hline 71 & & $\pi$ & 4 & & & & & & & \\
\hline 72 & & & & & & & & & & \\
\hline 73 & & 1.00897 & 0.0 & & 1.0 & & & 233 & 0.0012 & 392 \\
\hline 74 & & & & & & & & & & \\
\hline 75 & & & & & & & & & & \\
\hline 76 & & & & & & & & & & \\
\hline 77 & & & & & & & & & & \\
\hline 78 & & & & & & & & & & \\
\hline 79 & & 1. & & & & & & & & \\
\hline 80 & & & & & & & & & 215 & 0.00702 \\
\hline 81 & & & & & & & & & & \\
\hline 82 & & & & & & & & & & \\
\hline 83 & & & & & & & & & & 667 \\
\hline 84 & & & & & & & & & & \\
\hline 85 & & & & & & & & & & \\
\hline 86 & & & & & & & & 51 & & \\
\hline 87 & & & & & & & & & & \\
\hline 88 & & & & & & & & & & \\
\hline 89 & & & & & & & & & & \\
\hline 90 & & & & & & & & & & \\
\hline 91 & & & & & & & & & & \\
\hline 92 & & & & & & & & & & \\
\hline 93 & & & & & & & & & & \\
\hline 94 & & & & & & & & & & \\
\hline 95 & & & & & 8 & & & & & \\
\hline 96 & & & & & & & & & & \\
\hline 97 & & & & & & & & & & \\
\hline 98 & & & & & & & & 85 & & \\
\hline 99 & & & & & & & & 00546 & & \\
\hline 100 & & & & & & & & & & \\
\hline 101 & & 5 & & & 1.0 & & & & & \\
\hline 102 & & & & & & & & 2 & & \\
\hline . & & & & & & & & 1.02152 & & \\
\hline 10 & & 1.0035 & & & & & & & & \\
\hline & hst321 & 0.9991 & 0.0003 & 0.0 & 16 & 0.0003 & 0.0021 & 0.9972 & 0.0003 & 0.0021 \\
\hline
\end{tabular}




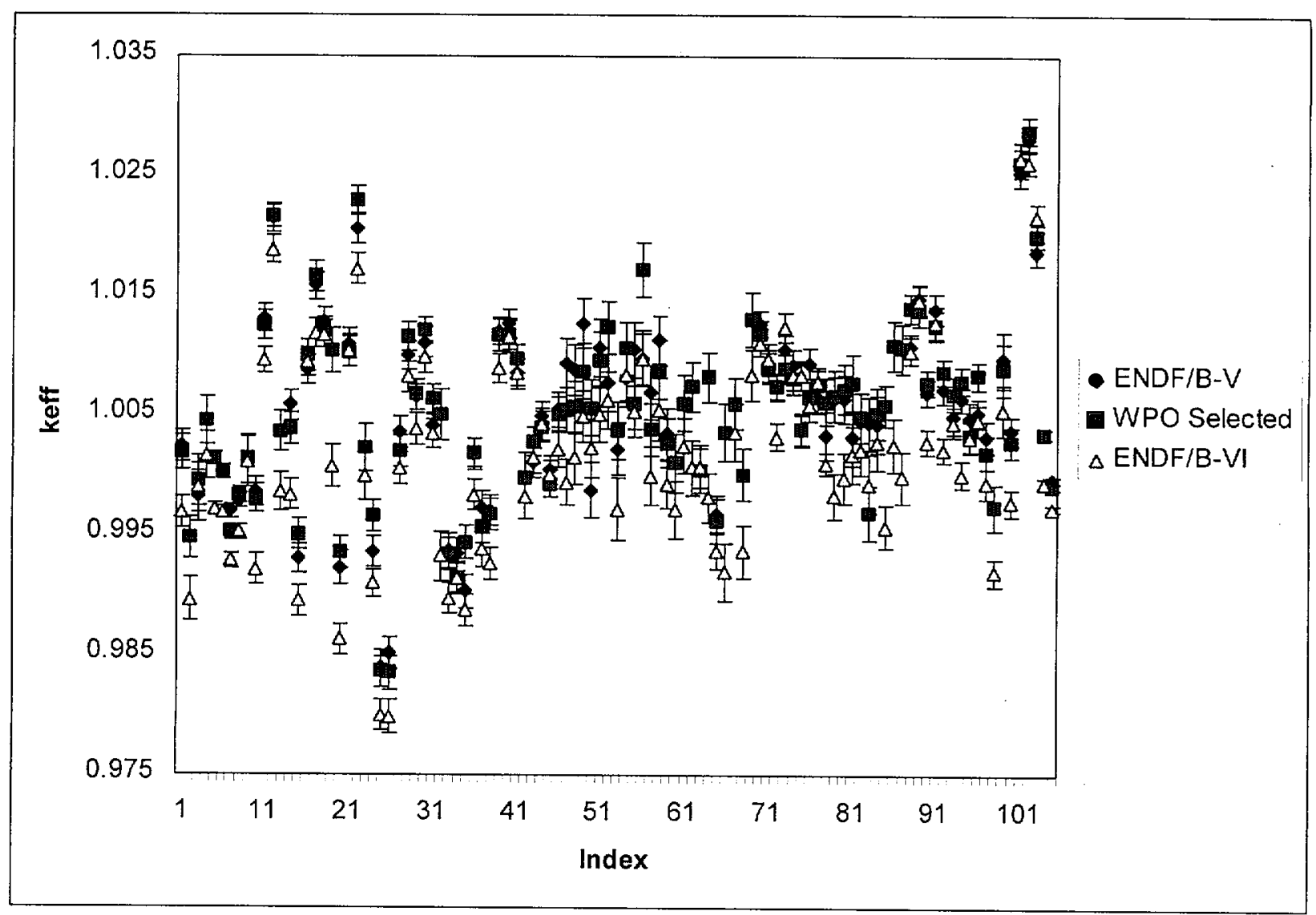

Figure 4.2-4. Homogenous Critical Experiments Using High Enriched Uranium Nitrate Solutions (Thermal) 
Table 4.2-5. High Enriched Uranium Metal Critical Experiments (Fast)

\begin{tabular}{|c|c|c|c|c|c|c|c|c|c|c|}
\hline \multirow{2}{*}{$\#$} & \multirow{2}{*}{ Case } & \multicolumn{3}{|c|}{ WPO Selected } & \multicolumn{3}{c|}{ ENDF/B-V } & \multicolumn{3}{c|}{ ENDF/B-VI } \\
\cline { 3 - 10 } & & $\mathbf{k}_{\text {eff }}$ & $\sigma$ & AENCF & $\mathbf{k}_{\text {eff }}$ & $\sigma$ & AENCF & $\mathbf{k}_{\text {eff }}$ & $\sigma$ & AENCF \\
\hline 1 & HMF1G & 0.9986 & 0.0004 & 1.5681 & 0.9986 & 0.0004 & 1.5681 & 0.9970 & 0.0004 & 1.4893 \\
\hline 2 & HMF3Ni & 1.0036 & 0.0005 & 1.3649 & 1.0145 & 0.0005 & 1.3555 & 1.0045 & 0.0005 & 1.2964 \\
\hline 3 & HMF8 & 0.99477 & 0.00059 & 1.5503 & 0.9951 & 0.00058 & 1.5501 & 0.99281 & 0.00059 & 1.4766 \\
\hline 4 & HMF11 & 0.99264 & 0.00078 & 1.1620 & 0.99348 & 0.00079 & 1.1607 & 0.99717 & 0.00081 & 1.1026 \\
\hline 5 & HMF12 & 0.99446 & 0.00044 & 1.5222 & 0.99399 & 0.00043 & 1.5237 & 0.9944 & 0.00043 & 1.4486 \\
\hline 6 & HMF13 & 0.9962 & 0.00061 & 1.4860 & 0.99997 & 0.00061 & 1.4838 & 0.99478 & 0.00063 & 1.4155 \\
\hline 7 & HMF14 & 0.99773 & 0.00058 & 1.5443 & 0.99831 & 0.00062 & 1.5465 & 0.99501 & 0.00063 & 1.4893 \\
\hline 8 & HMF15 & 0.9936 & 0.00062 & 1.5808 & 0.99263 & 0.00056 & 1.5813 & 0.99172 & 0.00061 & 1.5000 \\
\hline 9 & HMF18 & 0.9978 & 0.00056 & 1.5522 & 0.99805 & 0.00056 & 1.5515 & 0.99837 & 0.00058 & 1.4753 \\
\hline 10 & HMF19 & 1.00306 & 0.0006 & 1.4765 & 1.00277 & 0.0006 & 1.4793 & 1.00328 & 0.0006 & 1.4018 \\
\hline 11 & HMF20 & 0.99643 & 0.0006 & 1.4333 & 0.99574 & 0.00061 & 1.4341 & 0.99839 & 0.00069 & 1.3635 \\
\hline 12 & HMF21 & 0.99727 & 0.0006 & 1.4481 & 1.00192 & 0.0006 & 1.4431 & 0.99463 & 0.00061 & 1.3807 \\
\hline 13 & HMF22 & 0.99252 & 0.00064 & 1.5039 & 0.99272 & 0.0006 & 1.5049 & 0.99188 & 0.0006 & 1.4299 \\
\hline 14 & HMF24 & 0.99401 & 0.00108 & 1.2504 & 0.99521 & 0.00109 & 1.2553 & 0.99443 & 0.00109 & 1.1917 \\
\hline 15 & HMF28 & 1.0040 & 0.0005 & 1.5979 & 1.0040 & 0.0005 & 1.5979 & 1.0026 & 0.0005 & 1.5498 \\
\hline
\end{tabular}

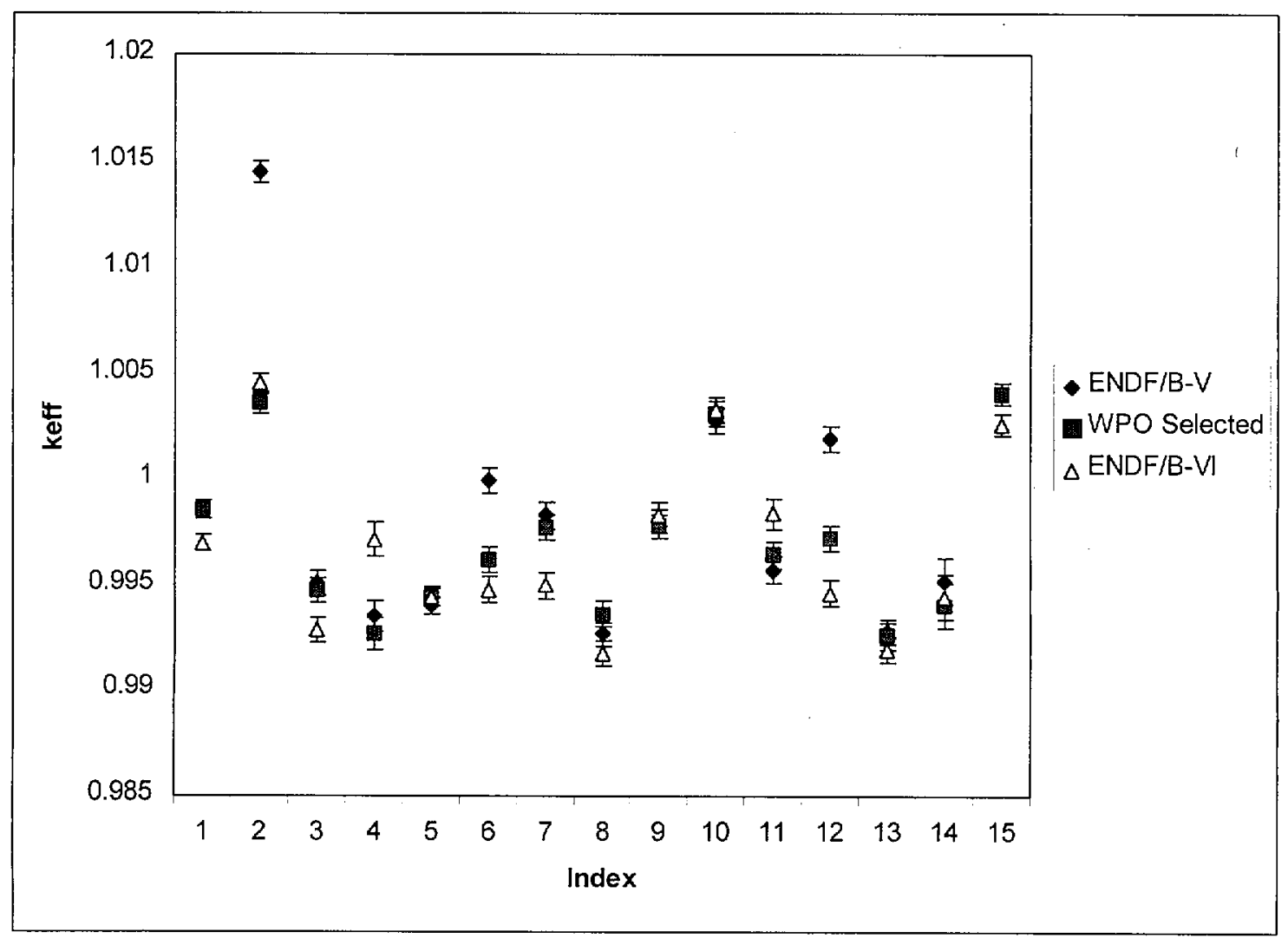

Figure 4.2-5. High Enriched Uranium Metal Critical Experiments (Fast) 
Table 4.2-6. Homogenous Critical Experiments Using Intermediate Enriched Uranium Fuel (Thermal)

\begin{tabular}{|c|c|c|c|c|c|c|c|c|c|c|}
\hline \multirow{2}{*}{$\#$} & \multirow{2}{*}{ Case } & \multicolumn{3}{|c|}{ WPO Selected } & \multicolumn{3}{c|}{ ENDF/B-V } & \multicolumn{3}{c|}{ ENDF/B-VI } \\
\cline { 3 - 10 } & & $\mathbf{k}_{\text {eff }}$ & $\sigma$ & AENCF & $\mathbf{k}_{\text {eff }}$ & $\sigma$ & AENCF & $\mathbf{k}_{\text {eff }}$ & $\sigma$ & AENCF \\
\hline 1 & IECT104 & 0.99735 & 0.00105 & 0.07405 & 0.99735 & 0.00105 & 0.07405 & 1.00316 & 0.00102 & 0.07270 \\
\hline 2 & IECT105 & 1.00847 & 0.00091 & 0.04552 & 1.00847 & 0.00091 & 0.04552 & 1.00785 & 0.00082 & 0.04520 \\
\hline 3 & IECT113 & 0.99674 & 0.00103 & 0.07430 & 0.99674 & 0.00103 & 0.07430 & 1.00295 & 0.00096 & 0.07350 \\
\hline 4 & IECT114 & 0.99787 & 0.00094 & 0.07375 & 0.99787 & 0.00094 & 0.07375 & 1.00358 & 0.00098 & 0.07261 \\
\hline 5 & IECT115 & 0.99811 & 0.00099 & 0.07400 & 0.99811 & 0.00099 & 0.07400 & 1.00365 & 0.001 & 0.07309 \\
\hline 6 & IECT116 & 1.0021 & 0.00093 & 0.05547 & 1.0021 & 0.00093 & 0.05547 & 1.00414 & 0.00092 & 0.05435 \\
\hline 7 & IECT119 & 1.00255 & 0.00089 & 0.06026 & 1.0045 & 0.00101 & 0.06114 & 1.00479 & 0.00096 & 0.06006 \\
\hline 8 & IECT125 & 0.99874 & 0.0009 & 0.05992 & 0.99874 & 0.0009 & 0.05992 & 1.00527 & 0.00096 & 0.05891 \\
\hline 9 & IECT126 & 1.0057 & 0.00099 & 0.05695 & 1.00443 & 0.00095 & 0.05663 & 1.00838 & 0.00089 & 0.05559 \\
\hline 10 & IECT127 & 1.00328 & 0.00084 & 0.05616 & 1.0032 & 0.00086 & 0.05633 & 1.00637 & 0.00094 & 0.05607 \\
\hline
\end{tabular}

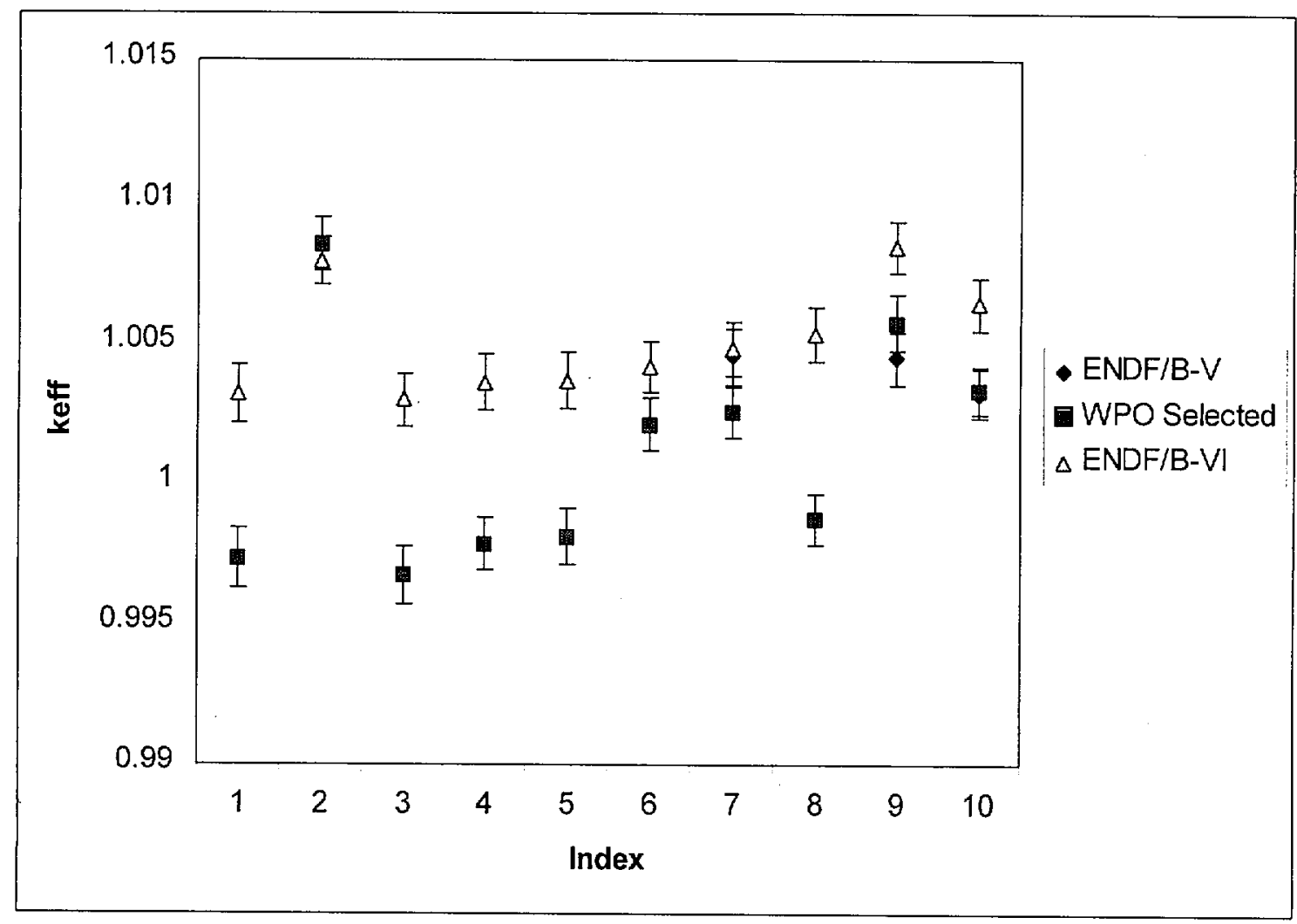

Figure 4.2-6. Homogenous Critical Experiments Using Intermediate Enriched Uranium Fuel (Thermal) 
Table 4.2-7. Homogenous Critical Experiments Using Intermediate Enriched Uranium Fuel (Intermediate)

\begin{tabular}{|c|c|c|c|c|c|c|c|c|c|c|}
\hline \multirow{2}{*}{ \# } & \multirow{2}{*}{ Case } & \multicolumn{3}{|c|}{ WPO Selected } & \multicolumn{3}{|c|}{ ENDF/B-V } & \multicolumn{3}{|c|}{ ENDF/B-VI } \\
\hline & & $\mathbf{k}_{\text {eff }}$ & $\sigma$ & AENCF & $\mathbf{k}_{\text {eff }}$ & $\sigma$ & AENCF & $\mathbf{k}_{\text {elf }}$ & $\sigma$ & AENCF \\
\hline 1 & IECT101 & 0.99735 & 0.00092 & 0.21679 & 0.99735 & 0.00092 & 0.2168 & 1.01062 & 0.00088 & 0.21085 \\
\hline 2 & IECT102 & 0.99601 & 0.00092 & 0.15817 & 0.99601 & 0.00092 & 0.15817 & 1.00748 & 0.00097 & 0.15427 \\
\hline 3 & IECT103 & 0.99305 & 0.00104 & 0.10412 & 0.99305 & 0.00104 & 0.10412 & 1.0024 & 0.00103 & 0.10243 \\
\hline 4 & IECT106 & 1.00026 & 0.00103 & 0.10793 & 1.00026 & 0.00103 & 793 & 1.00871 & 0.00099 & 4467 \\
\hline 5 & IECT107 & 0.998 & 0.00101 & 0.11064 & 0.998 & 0.00101 & 0.11064 & 1.00645 & 0.00099 & 0.10997 \\
\hline 6 & IECT1 & 0.99604 & 0.00101 & 0.11867 & 0.99604 & 0.0 & 367 & 1.00358 & 0.00088 & 611 \\
\hline 7 & IECT109 & 1.00043 & 0.00084 & 0.1679 & 1.00043 & 0.00084 & & 01287 & 0.00094 & \\
\hline 8 & IECT110 & 0.99672 & 0.00099 & 0.15756 & 0.99672 & 0.00099 & 0.15756 & 1.00845 & 0.00097 & 0.15359 \\
\hline 9 & IEC & 0.99579 & 0.0 & 0.1 & 0.99579 & 0.0 & & 1.00818 & 0.00105 & 255 \\
\hline 10 & IECT112 & 0.99642 & 0.00101 & 0.15568 & 0.99642 & 0.00101 & & 1.00601 & 095 & 347 \\
\hline 11 & IECT117 & 0.99503 & 0.00113 & 0.20838 & 0.99651 & 0.00102 & 0.20814 & 1.01029 & 0.00102 & 0.20117 \\
\hline 12 & IEC & 0.99852 & 0.0 & 0.1 & 0.99756 & 0.0 & & 1.00986 & 106 & 125 \\
\hline 13 & IECT120 & 1.0005 & 0.00094 & 0.15539 & 1.0005 & 0.00094 & & 1.01303 & 101 & 118 \\
\hline 14 & IECT121 & 0.99884 & 0.00087 & 0.21334 & 0.99884 & 0.00087 & 334 & 1.01392 & 0.00088 & 0.20757 \\
\hline 15 & $\mathrm{IEC}$ & 0.999 & & 0.1 & 0.999 & & & 1.0 & & 0.19125 \\
\hline 16 & IECT123 & .99516 & 0.0 & 0.12 & 0.99516 & 0.0 & 26 & 1.00429 & 0.00111 & 0.12582 \\
\hline 17 & IECT124 & 1.00036 & 0.00105 & 0.13305 & 1.00036 & 0.00105 & 305 & 1.0123 & 0.001 & 0.12898 \\
\hline 18 & IECT & 1.00637 & 0.0 & & 1.00506 & 0.00091 & 0.1 & 1.01497 & 0.00092 & 0.1536 \\
\hline 19 & IEC & 1.00472 & & 0.15 & 1.00123 & 0.0 & & 1.01219 & 0.00 & 0.1472 \\
\hline 20 & ist1-1 & 0.98509 & 0.00111 & 0.015 & 0.98074 & 0.00108 & 49 & 0.97915 & 0.00106 & 146 \\
\hline 21 & ist1-2 ${ }^{\mathrm{a}}$ & 0.97695 & 0.0012 & 0.0209 & 0.97596 & 0.00121 & 0.0207 & 0.97348 & 0.00118 & 0.0208 \\
\hline 22 & & 0.97306 & 0.00113 & 0.02 & 0.97222 & 0.00119 & 0.0 & 0.97079 & 0.00117 & 0.0208 \\
\hline 23 & ist1- & 0.97124 & 0.00 & 0.0273 & 0.97105 & 0.00124 & & 0.96757 & 0.00126 & 0.0271 \\
\hline
\end{tabular}

NOTE: ${ }^{a}$ Cases ist $1-1$ through ist $1-4$ were homogenous critical experiments using uranyl-sulphate solutions

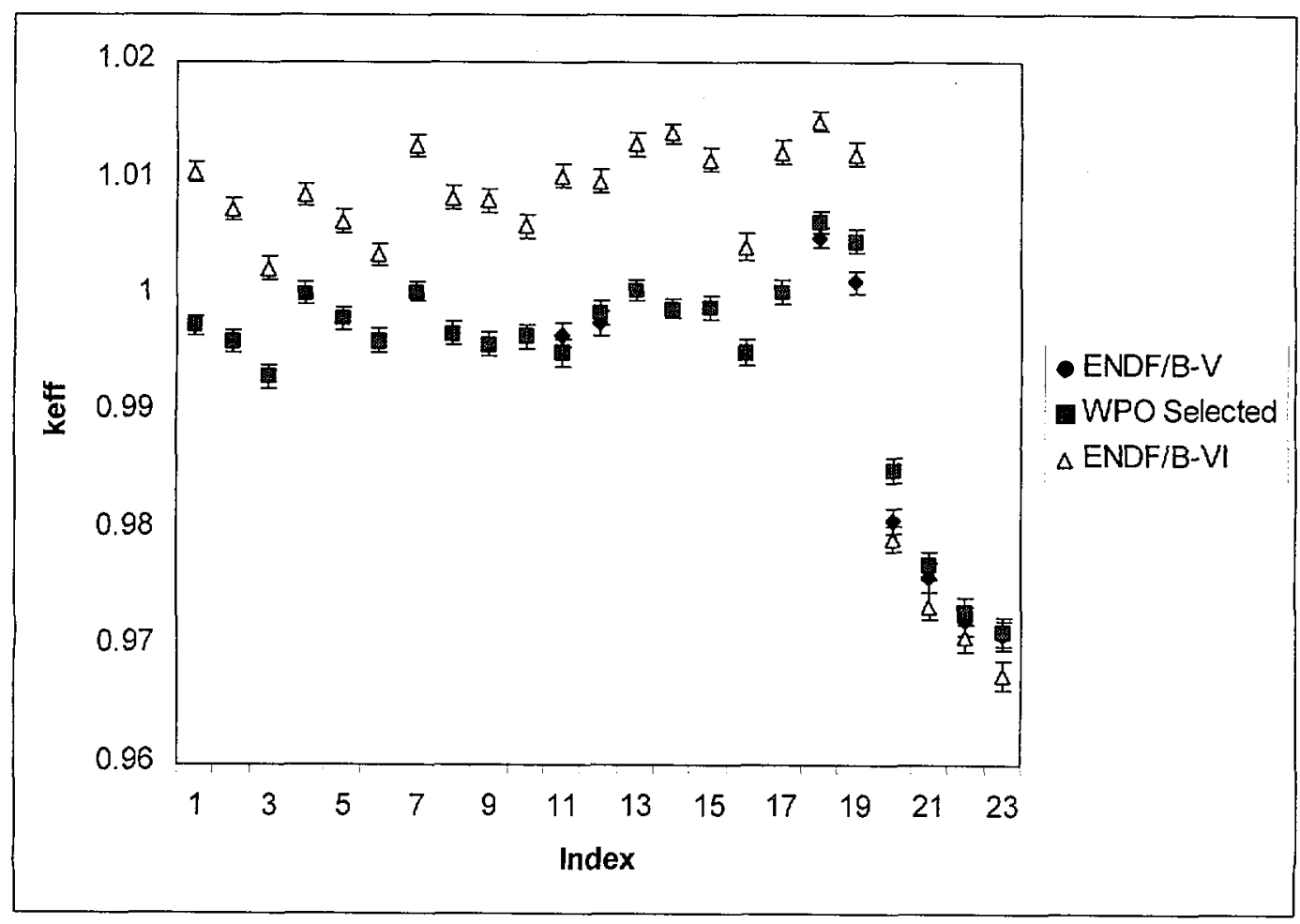

Figure 4.2-7. Homogenous Critical Experiments Using Intermediate Enriched Uranium Fuel (Intermediate) 
Table 4.2-8. Intermediate Enriched Uranium Metal Critical Experiments (Fast)

\begin{tabular}{|c|c|c|c|c|c|c|c|c|c|c|}
\hline \multirow{2}{*}{$\#$} & \multirow{2}{*}{ Case } & \multicolumn{3}{|c|}{ WPO Selected } & \multicolumn{3}{c|}{ ENDF/B-V } & \multicolumn{3}{c|}{ ENDF/B-VI } \\
\cline { 3 - 10 } & & $\mathbf{k}_{\text {eff }}$ & $\sigma$ & AENCF & $\mathbf{k}_{\text {eff }}$ & $\sigma$ & AENCF & $\mathbf{k}_{\text {eff }}$ & $\sigma$ & AENCF \\
\hline 1 & imf1-1 & 1.00183 & 0.00028 & 1.4395 & 1.00224 & 0.00029 & 1.4394 & 0.99714 & 0.00028 & 1.3910 \\
\hline 2 & imf1-2 & 1.00254 & 0.00028 & 1.4403 & 1.00225 & 0.00028 & 1.4398 & 0.99666 & 0.00027 & 1.3919 \\
\hline 3 & imf1-3 & 1.004 & 0.00027 & 1.3862 & 1.00401 & 0.00029 & 1.3860 & 0.9986 & 0.00028 & 1.3515 \\
\hline 4 & imf1-4 & 1.00459 & 0.00028 & 1.3848 & 1.00477 & 0.00028 & 1.3859 & 0.999 & 0.00026 & 1.3495 \\
\hline 5 & imf2-1 & 1.00594 & 0.0006 & 1.2784 & 1.00594 & 0.0006 & 1.2784 & 1.00327 & 0.00056 & 1.2650 \\
\hline 6 & imf3-1 & 1.00096 & 0.0008 & 1.3526 & 0.99925 & 0.00076 & 1.3502 & 0.99539 & 0.00076 & 1.3242 \\
\hline 7 & imf4-1 & 1.00884 & 0.00078 & 1.3076 & 1.01048 & 0.00084 & 1.3071 & 1.00446 & 0.00081 & 1.2768 \\
\hline 8 & imf5-1 & 1.00632 & 0.00082 & 1.2872 & 1.00881 & 0.00079 & 1.2852 & 1.00053 & 0.00081 & 1.2597 \\
\hline 9 & imf6-1 & 0.99727 & 0.00083 & 1.2915 & 0.99597 & 0.00081 & 1.2892 & 0.99173 & 0.00083 & 1.2610 \\
\hline 10 & imf8-1 & 1.00845 & 0.00079 & 1.3639 & 1.0087 & 0.00084 & 1.3650 & 1.0038 & 0.00081 & 1.3337 \\
\hline
\end{tabular}

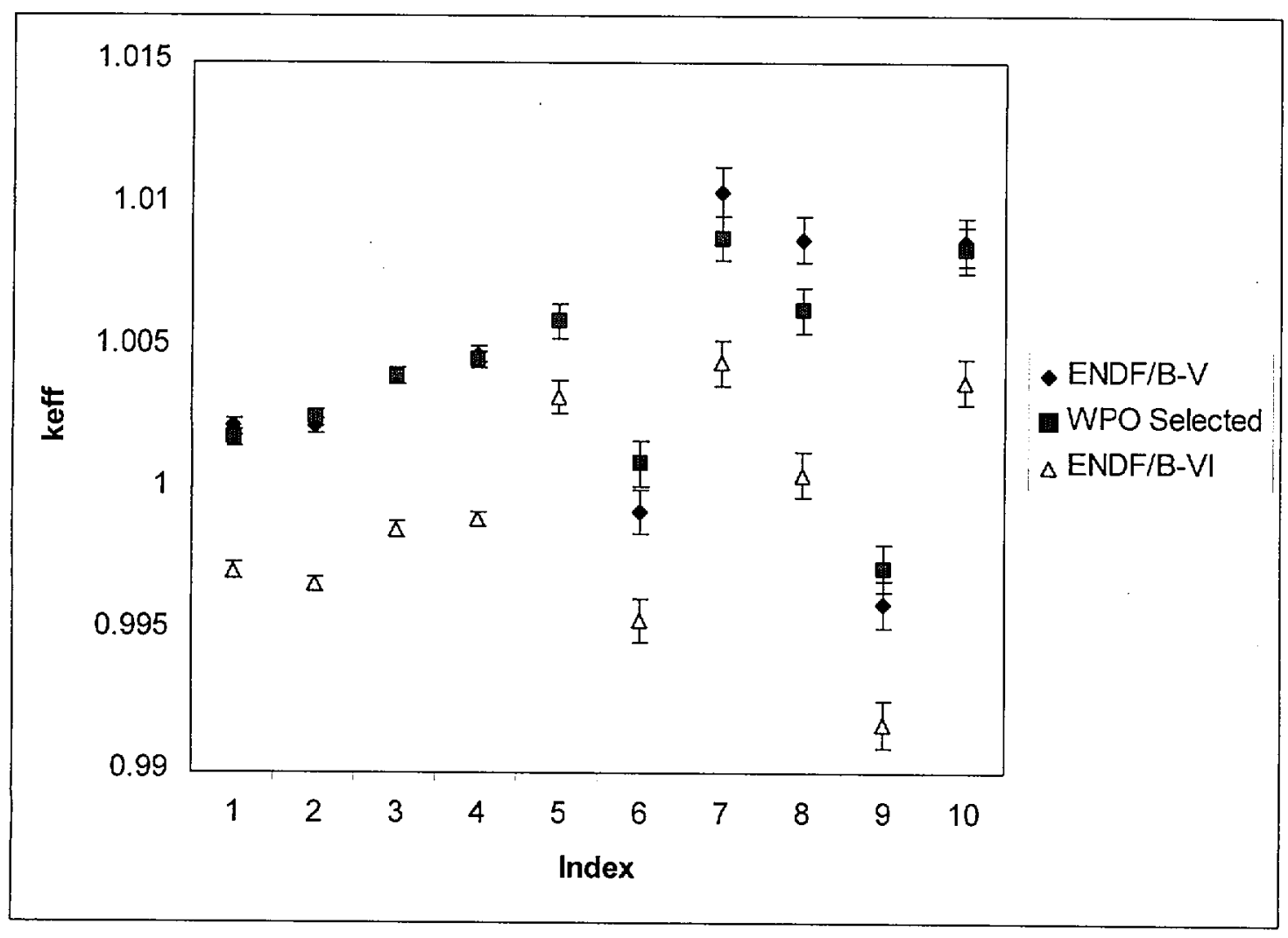

Figure 4.2-8. Intermediate Enriched Uranium Metal Critical Experiments (Fast) 
Table 4.2-9. Homogenous Critical Experiments Using Low Enriched Uranium Nitrate Solutions (Thermal)

\begin{tabular}{|c|c|c|c|c|c|c|c|c|c|c|}
\hline \multirow{2}{*}{ \# } & \multirow{2}{*}{ Case } & \multicolumn{3}{|c|}{ WPO Selected } & \multicolumn{3}{|c|}{ ENDF/B-V } & \multicolumn{3}{|c|}{ ENDF/B-VI } \\
\hline & & $k_{\text {eff }}$ & $\bar{\sigma}$ & AENCF & $\mathbf{k}_{\text {eff }}$ & $\sigma$ & AENCF & $\mathbf{k}_{\text {eff }}$ & 0 & AENCF \\
\hline 1 & leuja01 & 1.00425 & 0.00085 & 0.01896 & 1.00354 & 0.00076 & 0.01899 & .99826 & 0.00091 & 0.01905 \\
\hline 2 & 更 & 99755 & 0.00094 & 0.02001 & 0.99809 & 0.00094 & 0.01991 & 0.9941 & 0.0009 & 0.01939 \\
\hline 3 & & 00377 & 00082 & & 1.00452 & 00087 & & 0.99854 & .00081 & \\
\hline 4 & a30 & 39885 & 0.00086 & & 1.00084 & 00083 & 0.0187 & & 0.00091 & 0.01845 \\
\hline 5 & & 00143 & 0.00086 & 0.01757 & 0.9992 & 0.00088 & 0.0177 & 0.99529 & 0.00088 & 0.01733 \\
\hline 6 & & & & & 39 & & & 0.99687 & & \\
\hline 7 & & 1.0029 & 0.00079 & & 1.00277 & 0.00092 & 607 & 1.00017 & 0.00069 & 0.01602 \\
\hline 8 & & 00185 & 0.00084 & 0.0 & 1.00081 & 0.0008 & & 0.99742 & 0.0008 & 0.0164 \\
\hline 9 & & & & & & & & 0.99972 & 573 & \\
\hline 10 & & & 0.0 & & 0.95 & & 0.0159 & 0.9957 & 0.00084 & 554 \\
\hline 11 & & 79 & & & & & 0.0 & 0.99795 & 0.00078 & 0.01461 \\
\hline 12 & & 0246 & 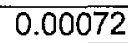 & & & 667 & & 0.99904 & 0.00064 & 1428 \\
\hline 13 & & 32 & 0.0 & 0.0 & 0.99855 & 0.00058 & 0.0 & 0.99532 & 0.00056 & 0.02492 \\
\hline 14 & & & 0.0 & & 0.9 & & & 0.991 & & 0.02802 \\
\hline 15 & & & 0.0 & & 1.0 & & 0.0 & 0.99624 & 0.00058 & 0.02615 \\
\hline 16 & & 01069 & 0.00 & & 1.01182 & 0.00101 & 0.05186 & 1.00714 & 0.00092 & 0.0514 \\
\hline 17 & & & & & & & & 0.99274 & 67 & \\
\hline 18 & & & & & & 0.0 & & 0.99335 & 066 & 0.0165 \\
\hline 19 & & 00141 & 0.0 & 0.0 & 1.00 & 0.0 & 0.8 & 0.99701 & 0.00065 & 0.0161 \\
\hline 20 & & & & & 0.99536 & & & 0.98964 & 063 & 0.0161 \\
\hline 21 & & & & & 0.99897 & & & 0.99468 & 0.0 & 0.0128 \\
\hline 22 & & 99935 & 0.00053 & & 0.99924 & & & 0.99507 & 0.00053 & 0.0126 \\
\hline 23 & & 99917 & 0.0 & 0.0126 & 0.99716 & 0.0 & 0.0127 & 0.99397 & 0.00051 & 0.0124 \\
\hline 24 & & 00116 & & & 1.00 & 0.0 & & 0.99637 & 0.00045 & 0.0113 \\
\hline 25 & & 0.99779 & 0.00048 & 0.0114 & 0.99732 & 0.00025 & 0.0114 & 0.99603 & 0.00041 & 0.0112 \\
\hline
\end{tabular}

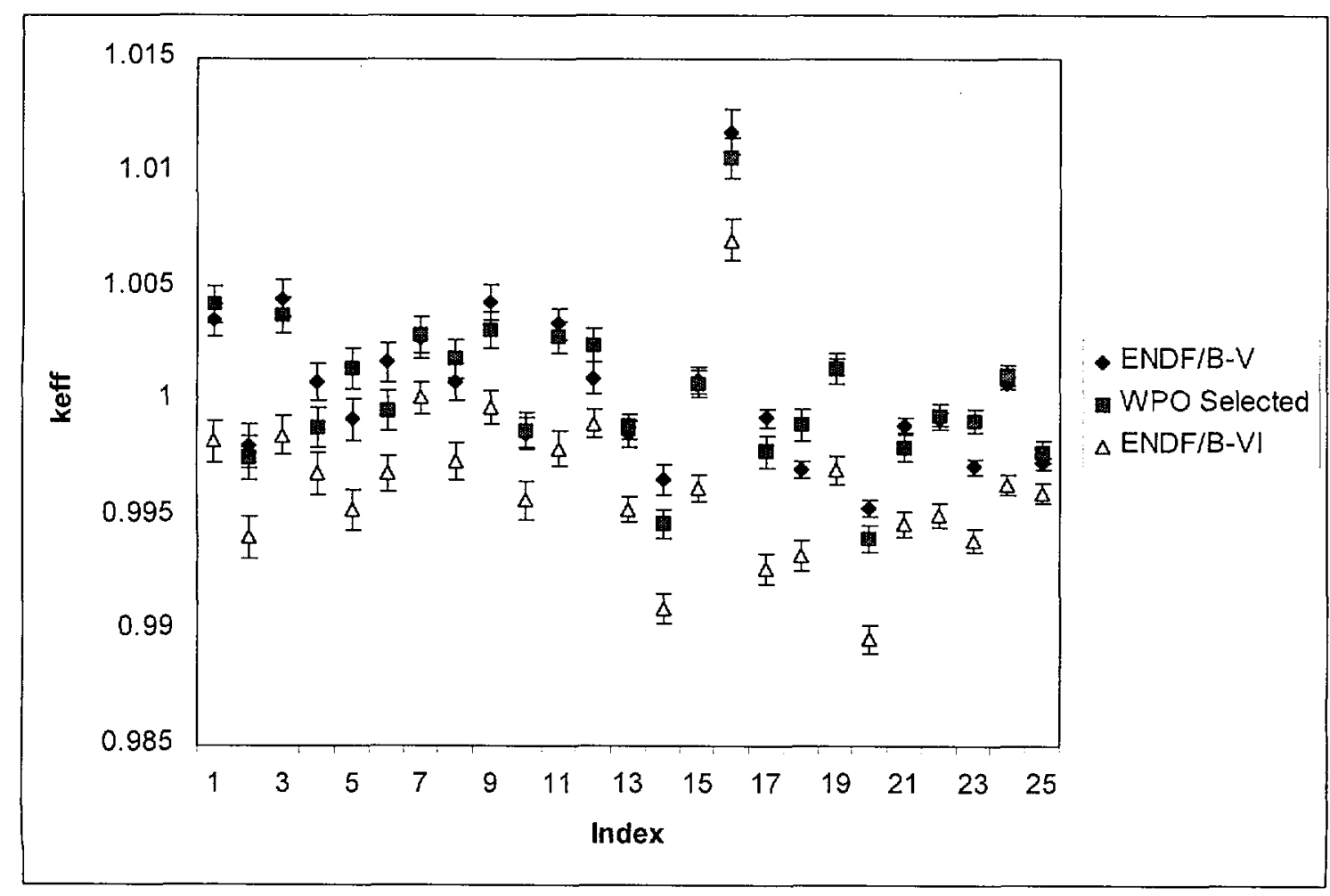

Figure 4.2-9. Homogenous Critical Experiments Using Low Enriched Uranium Nitrate Solutions (Thermal) 
Table 4.2-10. Homogenous Critical Experiments Using Low Enriched Uranium Solutions (Intermediate)

\begin{tabular}{|c|c|c|c|c|c|c|c|c|c|c|}
\hline \multirow{2}{*}{$\#$} & \multirow{2}{*}{ Case } & \multicolumn{3}{|c|}{ WPO Selected } & \multicolumn{3}{c|}{ ENDF/B-V } & \multicolumn{3}{c|}{ ENDF/B-VI } \\
\cline { 3 - 11 } & & $\mathbf{k}_{\infty}$ & $\sigma$ & AENCF & $\mathbf{k}_{\infty}$ & $\sigma$ & AENCF & $\mathbf{k}_{\infty}$ & $\sigma$ & AENCF \\
\hline 1 & sphu9a & 0.99004 & 0.00249 & 0.2541 & 0.99004 & 0.00249 & 0.2541 & 0.98665 & 0.00293 & 0.2562 \\
\hline 2 & sphu9b & 0.99269 & 0.00249 & 0.2163 & 0.99269 & 0.00249 & 0.2163 & 0.98518 & 0.00271 & 0.2155 \\
\hline 3 & sphu9c & 0.97871 & 0.00256 & 0.1883 & 0.97871 & 0.00256 & 0.1883 & 0.97958 & 0.0019 & 0.1839 \\
\hline 4 & sphu9d & 0.97914 & 0.00242 & 0.1737 & 0.97914 & 0.00242 & 0.1737 & 0.97132 & 0.00233 & 0.1740 \\
\hline 5 & sphu9e & 0.96607 & 0.00163 & 0.1591 & 0.96607 & 0.00163 & 0.1591 & 0.96429 & 0.00221 & 0.1660 \\
\hline 6 & sphu9f & 1.00952 & 0.00261 & 0.2511 & 1.00952 & 0.00261 & 0.2511 & 1.00009 & 0.00306 & 0.2543 \\
\hline 7 & sphu9g & 1.0136 & 0.00246 & 0.1839 & 1.0136 & 0.00246 & 0.1839 & 1.00763 & 0.00235 & 0.1906 \\
\hline 8 & sphu9h & 0.99713 & 0.00198 & 0.1651 & 0.99713 & 0.00198 & 0.1651 & 0.99364 & 0.00224 & 0.1642 \\
\hline 9 & sphu9i & 1.03372 & 0.00274 & 0.2495 & 1.03372 & 0.00274 & 0.2495 & 1.03156 & 0.00233 & 0.2499 \\
\hline 10 & sphu9j & 1.04207 & 0.00224 & 0.1783 & 1.04207 & 0.00224 & 0.1783 & 1.03178 & 0.0024 & 0.1760 \\
\hline 11 & sphu9k & 1.02951 & 0.00216 & 0.1661 & 1.02951 & 0.00216 & 0.1661 & 1.02122 & 0.00206 & 0.1670 \\
\hline 12 & sphu91 & 1.02281 & 0.0021 & 0.1549 & 1.02281 & 0.0021 & 0.1549 & 1.0191 & 0.00237 & 0.1545 \\
\hline
\end{tabular}

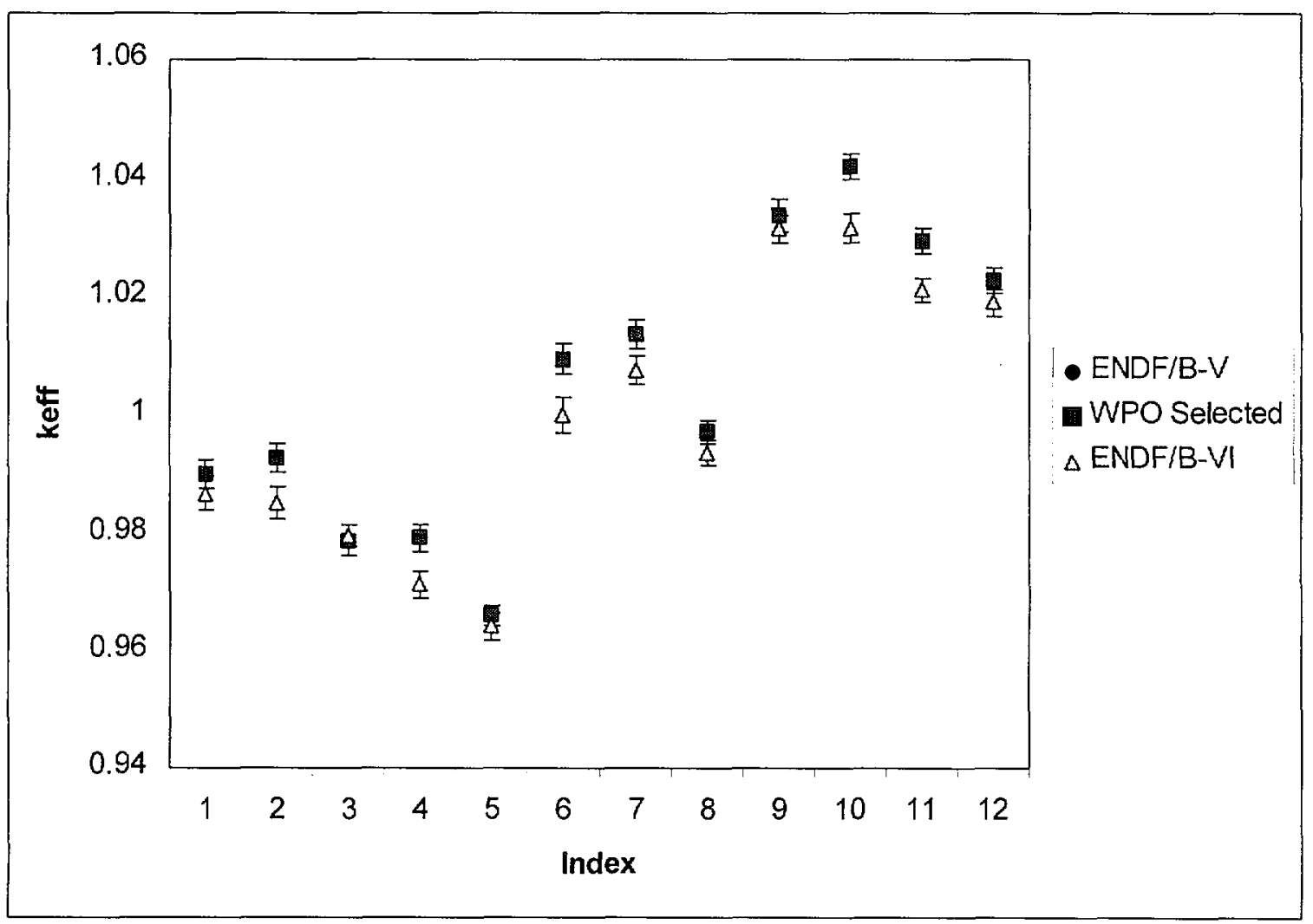

Figure 4.2-10. Homogenous Critical Experiments Using Low Enriched Uranium Solutions (Intermediate) 
Table 4.2-11. Homogenous Critical Experiments Using Uranium-233 Fuel (Thermal)

\begin{tabular}{|c|c|c|c|c|c|c|c|c|c|c|}
\hline \multirow{2}{*}{$\#$} & \multirow{2}{*}{ Case } & \multicolumn{3}{|c|}{ WPO Selected } & \multicolumn{3}{c|}{ ENDF/B-V } & \multicolumn{3}{c|}{ ENDF/B-VI } \\
\cline { 3 - 11 } & & $\mathbf{k}_{\infty}$ & $\sigma$ & AENCF & $\mathbf{k}_{\infty}$ & $\sigma$ & AENCF & $\mathbf{k}_{\infty}$ & $\sigma$ & AENCF \\
\hline 1 & $\mathrm{u} 233 \mathrm{~s} 1$ & 1.00153 & 0.00037 & 0.03738 & 1.00179 & 0.00039 & 0.00371 & 0.99824 & 0.00038 & 0.00367 \\
\hline 2 & $\mathrm{u} 233 \mathrm{~s} 2$ & 1.00029 & 0.00038 & 0.00390 & 1.00069 & 0.00038 & 0.00398 & 0.99773 & 0.00038 & 0.00404 \\
\hline 3 & $\mathrm{u} 233 \mathrm{~s} 3$ & 1.00045 & 0.00040 & 0.00402 & 1.00007 & 0.00039 & 0.00416 & 0.9969 & 0.00038 & 0.00413 \\
\hline 4 & $\mathrm{u} 233 \mathrm{~s} 4$ & 0.99951 & 0.00040 & 0.00432 & 0.99987 & 0.00039 & 0.00422 & 0.99667 & 0.0004 & 0.00423 \\
\hline 5 & $\mathrm{u} 23355$ & 0.99856 & 0.00039 & 0.00435 & 0.99998 & 0.00041 & 0.00440 & 0.99524 & 0.00041 & 0.00437 \\
\hline 6 & $\mathrm{u} 233 \mathrm{~s} 6$ & 0.99826 & 0.00027 & 0.00301 & 0.99911 & 0.00025 & 0.00309 & 0.99534 & 0.00026 & 0.00311 \\
\hline
\end{tabular}

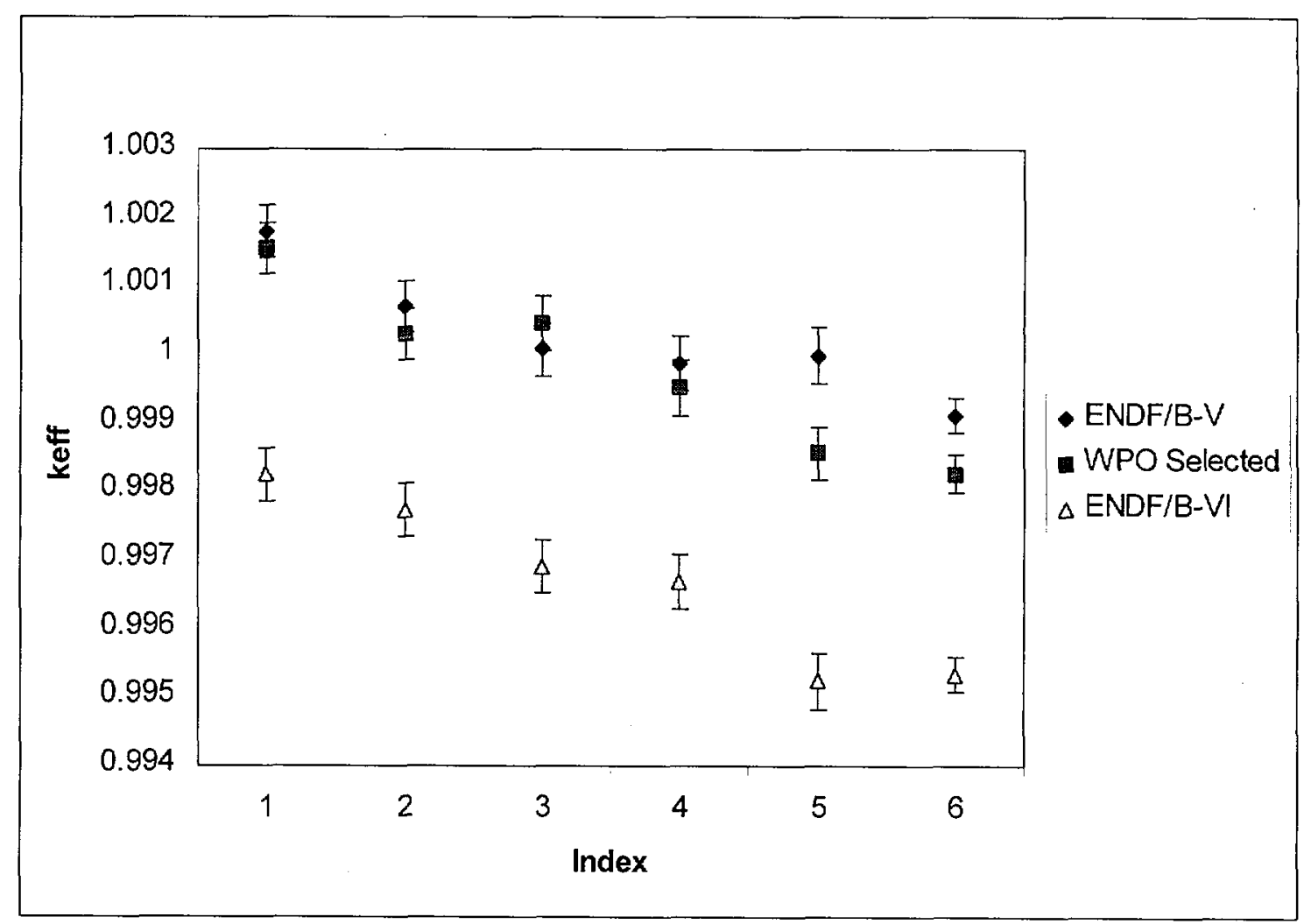

Figure 4.2-11. Homogenous Critical Experiments Using Uranium-233 Fuel (Thermal) 
Table 4.2-12. Homogenous Critical Experiments Using Uranium-233 Fuel (Fast)

\begin{tabular}{|c|c|c|c|c|c|c|c|c|c|c|}
\hline \multirow{2}{*}{$\#$} & \multirow{2}{*}{ Case } & \multicolumn{3}{|c|}{ WPO Selected } & \multicolumn{3}{c|}{ ENDF/B-V } & \multicolumn{3}{c|}{ ENDF/B-VI } \\
\cline { 3 - 10 } & & $\mathbf{k}_{\infty}$ & $\sigma$ & AENCF & $\mathbf{k}_{\infty}$ & $\sigma$ & AENCF & $\mathbf{k}_{\infty}$ & $\sigma$ & AENCF \\
\hline 1 & $\mathrm{u} 2331 \mathrm{a}$ & 0.99297 & 0.00038 & 1.77385 & 0.99297 & 0.00038 & 1.77385 & 0.99354 & 0.00038 & 1.77170 \\
\hline 2 & $\mathrm{u} 2332 \mathrm{a}$ & 0.99547 & 0.00038 & 1.73702 & 0.99547 & 0.00038 & 1.73702 & 0.99609 & 0.0004 & 1.72533 \\
\hline 3 & $\mathrm{u} 2332 \mathrm{~b}$ & 0.99807 & 0.00039 & 1.70789 & 0.99807 & 0.00039 & 1.70789 & 0.99764 & 0.00039 & 1.68809 \\
\hline 4 & $\mathrm{u} 2333 \mathrm{a}$ & 0.99583 & 0.00041 & 1.74832 & 0.99583 & 0.00041 & 1.74832 & 0.99645 & 0.0004 & 1.74824 \\
\hline 5 & $\mathrm{u} 2333 \mathrm{~b}$ & 0.99771 & 0.00041 & 1.76231 & 0.99771 & 0.00041 & 1.76231 & 0.99738 & 0.00042 & 1.76086 \\
\hline 6 & $\mathrm{u} 2334 \mathrm{a} 1$ & 1.00380 & 0.00041 & 1.61187 & 1.00356 & 0.00041 & 1.61336 & 1.00278 & 0.00043 & 1.61505 \\
\hline 7 & $\mathrm{u} 2334 \mathrm{~b} 1$ & 1.00705 & 0.00042 & 1.51777 & 1.00637 & 0.00043 & 1.51775 & 1.00564 & 0.00044 & 1.52050 \\
\hline 8 & $\mathrm{u} 2335 \mathrm{a}$ & 0.99351 & 0.00043 & 1.61950 & 0.99351 & 0.00043 & 1.61950 & 0.99452 & 0.00042 & 1.61670 \\
\hline 9 & $\mathrm{u} 2335 \mathrm{~b}$ & 0.99681 & 0.00045 & 1.51871 & 0.99681 & 0.00045 & 1.51871 & 0.99707 & 0.00045 & 1.51252 \\
\hline 10 & $\mathrm{u} 2336 \mathrm{a}$ & 1.00057 & 0.00045 & 1.77403 & 1.00057 & 0.00045 & 1.77403 & 1.00122 & 0.00047 & 1.77535 \\
\hline
\end{tabular}

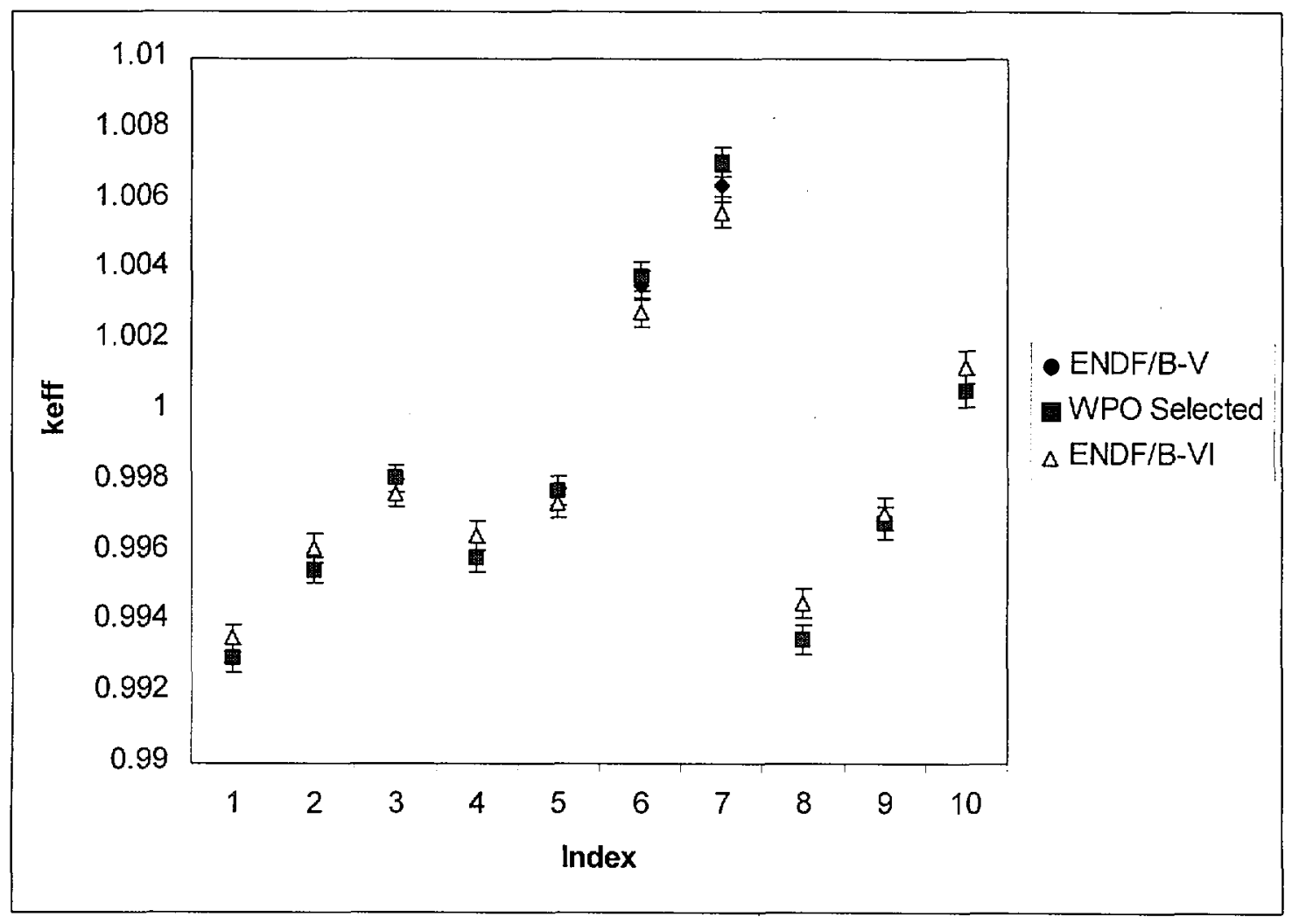

Figure 4.2-12. Homogenous Critical Experiments Using Uranium-233 Fuel (Fast) 


\section{CONCLUSIONS}

The data reported herein not identified with TBVs are acceptable for quality affecting activities and for use in analyses affecting procurement, construction, or fabrication. TBV data specified in Section 4 will require the release of TBVs-1357 through 1371 prior to its use in quality affecting activities and for use in analyses affecting procurement, construction, or fabrication. Table 5-1 provides a summary listing of the average calculated values of $\mathrm{k}_{\mathrm{eff}}$ for the LCEs with each library set. The values listed in Table 5-1 are based on unaccepted data, if the data from Table 5-1 are used as input into documents directly relied upon for radiological safety or waste isolation issues, then they are required to be identified and tracked as TBV in accordance with appropriate procedures.

Table 5-1. Average Values for $k_{\text {eff }}$ from LCE Results

\begin{tabular}{|c|c|c|c|c|}
\hline \multirow{2}{*}{ Type of System } & \multirow{2}{*}{$\begin{array}{l}\text { Number } \\
\text { of Cases }\end{array}$} & \multicolumn{3}{|c|}{ Average $k_{\text {eff }} /$ Standard Deviation } \\
\hline & & WPO Selected & ENDF/B-V & ENDF/B-VI \\
\hline \multicolumn{5}{|l|}{ Lattices } \\
\hline Mixed oxide & 18 & $1.0007 / 0.0044$ & $1.0002 / 0.0049$ & $0.9944 / 0.0038$ \\
\hline HEU & 77 & $1.0004 / 0.0076$ & $0.9995 / 0.0076$ & $0.9990 / 0.0071$ \\
\hline IEU & 2 & $1.0111 / 0.0029$ & $1.0083 / 0.0013$ & $1.0097 / 0.0032$ \\
\hline LEU & 65 & $0.9984 / 0.0043$ & $0.9979 / 0.0039$ & $0.9947 / 0.0045$ \\
\hline \multicolumn{5}{|l|}{ Homogeneous Systems } \\
\hline Mixed $\mathrm{Pu}$ and natural $\mathrm{U}$ nitrate & 34 & $1.0043 / 0.0053$ & $1.0045 / 0.0056$ & $0.9970 / 0.0055$ \\
\hline Pu nitrate & 73 & $1.0117 / 0.0053$ & $1.0117 / 0.0051$ & $1.0036 / 0.0056$ \\
\hline Pu metal fast & 12 & $0.9976 / 0.0027$ & $0 . 9 9 9 4 \longdiv { 0 . 0 0 2 9 }$ & $0.9990 / 0.0026$ \\
\hline HEU nitrate & 105 & $1.0055 / 0.0075$ & $1.0054 / 0.0073$ & $1.0020 / 0.0082$ \\
\hline HEU metal fast & 15 & $0.9971 / 0.0038$ & $0.9985 / 0.0057$ & $0.9967 / 0.0040$ \\
\hline IEU & 33 & $0.9965 / 0.0085$ & $0.9962 / 0.0087$ & $1.0036 / 0.0122$ \\
\hline IEU metal fast & 10 & $1.0041 / 0.0036$ & $1.0042 / 0.0045$ & $0.9991 / 0.0041$ \\
\hline LEU nitrate & 25 & $1.0004 / 0.0034$ & $1.0005 / 0.0034$ & $0.9963 / 0.0034$ \\
\hline LEU & 12 & $1.0046 / 0.0243$ & $1.0046 / 0.0243$ & $0.9993 / 0.0230$ \\
\hline${ }^{233} \mathrm{U}$ & 16 & $0.9988 / 0.0036$ & $0.9989 / 0.0035$ & $0.9977 / 0.0031$ \\
\hline
\end{tabular}

Based upon examinations of the average $k_{\text {eff }}$ values presented in Table $5-1$ it can be seen that the ENDF/B-V and WPO Selected library sets produce $\mathrm{k}_{\text {eff }}$ values that are closer to unity than the ENDF/B-VI library values for the lattice LCEs. For the homogenous systems, most of the ENDF/B-VI library results were closer to unity than the ENDF/B-V and WPO Selected library sets. 


\section{REFERENCES}

Baldwin, M.N.; Hoovler, G.S.; Eng, R.L.; and Welfare, F.G. 1979. Critical Experiments Supporting Close Proximity Water Storage of Power Reactor Fuel. BAW-1484-7. Lynchburg, Virginia: Babcock \& Wilcox (B\&W). TIC: 245055

Bierman, S.R. 1990. Criticality Experiments with Neutron Flux Traps Containing Voids. PNL7167. Richland, Washington: PNL. TIC: 205600

Bierman, S.R.; Clayton, E.D; and Durst, B.M. 1977. Critical Separation Between Subcritical Clusters of $2.35 \mathrm{Wt} \%{ }^{235} \mathrm{U}$ Enriched $\mathrm{UO}_{2}$ Rods in Water with Fixed Neutron Poisons. PNL2438. Richland, Washington: PNL. TIC: 223644

Bierman, S.R.; Durst, B.M.; and Clayton, E.D. 1981. Criticality Experiments with Subcritical Clusters of $2.35 \mathrm{Wt} \%$ and $4.31 \mathrm{Wt} \%{ }^{235} \mathrm{U}$ Enriched $\mathrm{UO}_{2}$ Rods in Water with Uranium or Lead Reflecting Walls. PNL-3926. Richland, Washington: PNL. TIC: 232754

Bierman, S.R. and Clayton, E.D. 1981. Criticality Experiments with Subcritical Clusters of 2.35 Wt\% and 4.31 Wt\% ${ }^{235} U$ Enriched $\mathrm{UO}_{2}$ Rods in Water with Steel Reflecting Walls. PNL-3602. Richland, Washington: PNL. TIC: 232871

Bierman, S.R.; Durst, B.M.; Clayton, E.D.; Scherpelz, R.I.; Kerr, H.T. 1979. "Critical Experiments with Fast Test Reactor Fuel Pins in Water." Nuclear Technology, 44, 141-151. American Nuclear Society (ANS). TIC: 239579

Bierman, S.R.; Murphy, E.S.; Clayton, E.D.; and Keay, R.T. 1984. Criticality Experiments with Low Enriched $\mathrm{UO}_{2}$ Fuel Rods in Water Containing Dissolved Gadolinium. PNL-4976.

Richland, Washington: PNL. TIC: 222973

Briesmeister, Judith F., ed. 1997. MCNP-A General Monte Carlo N-Particle Transport Code. User Manual, Report Number: LA-12625-M, Version 4B. Los Alamos, New Mexico: Los Alamos National Laboratory. TIC: 241044

Brown, C.L.; Lloyd, R.C.; Bierman, S.R.; Clayton, E.D. 1965. Exponential Experiments and Neutron Multiplication Measurements with 1.25 wt\% Enriched N-Reactor Fuel Elements in Light Water. BNWL-52. Richland, Washington: PNL. TIC: 241005

DeHart, M.D. and Bowman, S.M. 1995. Analysis of Fresh Fuel Critical Experiments Appropriate for Burnup Credit Validation. ORNL/TM-12959. Oak Ridge, Tennessee: Oak Ridge National Laboratory (ORNL). TIC: 240899

Durst, B.M.; Bierman, S.R.; and Clayton, E.D. 1982. Critical Experiments with $4.31 \mathrm{Wt} \%{ }^{235} \mathrm{U}$ Enriched $\mathrm{UO}_{2}$ Rods in Highly Borated Water Lattices. PNL-4267. Richland, Washington: PNL. TIC: 232755 
Mele, I.; Ravnik, M.; Trkov, A. 1994. "TRIGA Mark II Benchmark Experiment, Part I: SteadyState Operation." Nuclear Technology, 105, 37-51. American Nuclear Society. TIC: 240865

Miyoshi, Y.; Umano, T.; Tonoike, K.; Izawa, N.; Sugikawa, S.; and Okazaki, S. 1997. "Critical Experiments on 10\% Enriched Uranyl Nitrate Solution using a 60-cm Diameter Cylindrical Core." Nuclear Technology, 118, 69-82. Hinsdale, Illinois: American Nuclear Society (ANS). TIC: 244153

Newman, L.W. 1984. Urania-Gadolinia: Nuclear Model Development and Critical Experiment Benchmark. BAW-1810. Lynchburg, Virginia: B\&W. TIC: 233536

Organization for Economic Cooperation and Development-Nuclear Energy Agency (OECDNEA) 1998. International Handbook of Evaluated Criticality Safety Benchmark Experiments. NEA/NSC/DOC(95)03, September 1998 Edition. Paris, France: Nuclear Energy Agency. TIC: 243013

Radulescu, G. and Abdurrahman, N.M. 1997. "MCNP Criticality Benchmark Calculations of the Saxton Plutonium Program Experiments." Transactions of the American Nuclear Society, 76, 231-232. ISSN: 0003-018X. La Grange Park, Illinois: ANS. TIC: 242666

Taylor, E.G. 1965. Saxton Plutonium Program Critical Experiments for the Saxton Partial Plutonium Core. EURAEC1493, WCAP-3385-54. Pittsburg, Pennsylvania: Westinghouse Electric Corporation. TIC: 223286

Wittekind, W.D. 1992. K Basin Criticality Evaluation for Irradiated Fuel Canisters in Sludge. WHC-SD-NR-CSER-001 Rev. 0. Richland, Washington: Westinghouse Hanford Company. TIC: 240971

Department of Energy (DOE) Office of Civilian Radioactive Waste Management (OCRWM) 1998. Quality Assurance Requirements and Description. DOE/RW-0333P, REV 8. Washington, D.C.: DOE OCRWM. ACC: MOL.19980601.0022

DOE 1999. DOE Letter "Accepted Data Call", from R. E. Spence to J. L. Younker, July 27, 1999. North Las Vegas, Nevada: DOE OCRWM Yucca Mountain Site Characterization Office. ACC: MOL.19990811.0170

Civilian Radioactive Waste Management System (CRWMS) Management \& Operating Contractor (M\&O) 1998a . Disposal Criticality Analysis Methodology Topical Report. B00000000-01717-5705-00095 REV 00. Las Vegas, Nevada: CRWMS M\&O. ACC: MOL.19980918.0005

CRWMS M\&O 1998b. Software Qualification Report for MCNP Version 4B2, A General Monte Carlo N-Particle Transport Code. 30033-2003 REV 01; CSCI: 30033 V4B2LV. Las Vegas, Nevada: CRWMS M\&O. ACC: MOL.19980622.0637

CRWMS M\&O 1998c. Selection of MCNP Cross Section Libraries. B00000000-01717-570500099 REV 00. Las Vegas, Nevada: CRWMS M\&O. ACC: MOL.19980722.0042 
CRWMS M\&O 1999a. Classification of the Preliminary MGDS Repository Design. B0000000001717-0200-00134 REV 01. Las Vegas, Nevada: CRWMS M\&O. ACC: MOL.19981103.0546

CRWMS M\&O 1999b. Laboratory Critical Experiment Reactivity Calculations. B0000000001717-0210-00018 REV 01. Las Vegas, Nevada: CRWMS M\&O. ACC: MOL.19990526.0294

CRWMS M\&O 1999c. LCE for Research Reactor Benchmark Calculations. B0000000001717-0210-00034 REV 00. Las Vegas, Nevada: CRWMS M\&O. ACC: MOL.19990329.0394

CRWMS M\&O 1999d. LCEs for Naval Reactor Benchmark Calculations. B00000000-017170210-00087 REV 00. Las Vegas, Nevada: CRWMS M\&O. ACC: MOL.19990819.0239

CRWMS M\&O 1999e. QAP-2-0 Activity Evaluation. Neutronics Methodology-SR, 1101 2380 M1. Las Vegas, Nevada: CRMWS M\&O. ACC: MOL.19990318.0037 